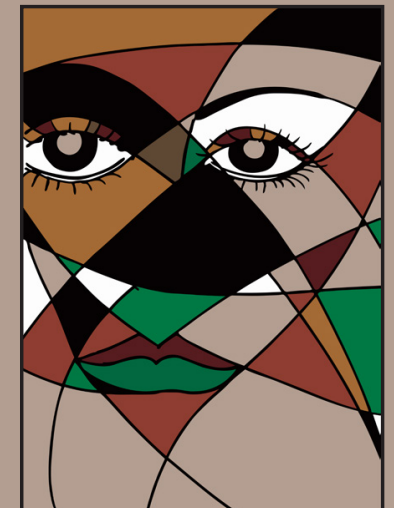

Cover design by Ashiwel Okang as part of a visual campaign by White Code Centre to stop all forms of violence against women

Adebayo Okeowo is the founder of White Code Centre, a platform that makes use of audio-visuals to educate on human rights. He is a multiple award winning visual campaigner and is also known for his photos and videos which bring attention to issues of inequality and injustice.

Adebayo is a Research Fellow with the Center for Human Rights Science at Carnegie Mellon University, Pittsburgh USA. He is also the Advocacy Coordinator at the Centre for Human Rights, University of Pretoria, South Africa. countability. He is a strong advocate on the power of visuals in creating change.

Pretoria University Law Press - PULP

www.pulp.up.ac.za

ISSN: $1998-0280$

PRETORIA STUHPENT LAW REVIEW $2017 \cdot 11$ 


\title{
PRETORIA STUDENT LAW REVIEW (2017) 11
}

\author{
Pretoria Tydskrif vir Regstudente \\ Kgatišobaka ya Baithuti ba Molao ya Pretoria
}

\author{
Editor in chief: \\ Sarah Burford \\ Editors: \\ Simon Botha \\ Privilege Chanana \\ Rutendo Chinomona \\ Roxanne Gilbert \\ Trisha Jivan \\ Lethabo Mailula \\ Agnes Matasane \\ Raeesah Thomas \\ Thomas White \\ Jurgen Zwecker
}




\title{
(2017) 11 Pretoria Student Law Review
}

\begin{abstract}
Published by:
Pretoria University Law Press (PULP)

The Pretoria University Law Press (PULP) is a publisher, based in Africa, launched and managed by the Centre for Human Rights and the Faculty of Law, University of Pretoria, South Africa. PULP endeavours to publish and make available innovative, high-quality scholarly texts on law in Africa. PULP also publishes a series of collections of legal documents related to public law in Africa, as well as text books from African countries other than South Africa.
\end{abstract}

For more information on PULP, see www.pulp.up.ac.za

Printed and bound by:

Minit Print, Hatfield, Pretoria

\section{Cover:}

Design by Ashiwel Okang as part of a visual campaign by White Code Centre to stop all forms of violence against women

For more information, visit: www.whitecodecentre.org

To submit articles, contact:

PULP

Faculty of Law

University of Pretoria

South Africa

0002

Tel: +27 124204948

Fax: +27 123625125

pulp@up.ac.za

www.pulp.up.ac.za

ISSN: 1998-0280

두 2017 


\section{TABLE OF CONTENTS}

Editors' note

Sarah Burford

From the Dean's desk

vi

Andre Boraine

Media freedom in Kenya in 2017: A reality or

a mirage?

Shirley Genga

Re-imagining a culture of justification through transformative constitutionalism and the philosophy of ubuntu

Ofentse Thato Kgabo

The effects of public participation on environmental impact assessment Amori Kock

A comparative analysis of the UNICITRAL Model Law on Cross-Border Insolvency and EU Insolvency Regulation 2017, against the background of various sources of cross-border insolvency law

Primrose E.R. Kurasha

Anti-doping: The credibility of the

Whereabouts rule

Primrose E.R. Kurasha

Tax morality: Examining the BEPS debate, work of the OECD and its impact on Africa

Daniel Godson Olika

Marikana, a past never truly escaped: A critique on the commodification of the legal system and the law as an instrument of justice in post-apartheid South Africa Vaughn Rajah 
Administrative law - a tool for social justice and transformative constitutionalism:

The implications of Melani $v$ City

of Johannesburg

Nelsie Siboza

Reflection and cogitation on the fallacy of postapartheid jurisprudence and the residue of apartheid jurisprudence: The Marikana massacre

Tshepo Twala 


\section{EDITORS' NOTE}

It is with great joy that I, along with the editorial committee, present to you, reader, the 2017 Pretoria Student Law Review. On this journal's 11 th edition, it has been an expansive year with a wider variety of topics being researched and produced by our authors. As law students, young scholars and future legal practitioners, we have a duty to utilise the unique position that we are in to challenge the status quo. Fittingly, the topics covered prove themselves to be contemporary and legally pertinent and encourage critical thinking of the law and its place in South African society.

This year has not only been a challenging one for students, staff and parents but also for the citizens of South Africa as a whole. It is thus with even greater pleasure that we offer our humble contribution to legal academia.

Every year of publication faces its own challenges, and this year was no different. However, it is through setbacks and ambitious deadlines that which makes a finalised product that much more deserved. This year's edition touches on a variety of themes which is certain to pique anyone's interest.

This year's edition of the PSLR would not have been possible without the dedication and hard work of a particularly motivated and dedicated team. To Simon Botha, Privilege Chanana, Rutendo Chinomona, Roxanne Gilbert, Lethabo Mailula, Agnes Matasane, Raeesah Thomas, Thomas White and Jurgen Zwecker for your long hours and persistence in the production of this year's edition. You all have contributed to the mechanism of this wonderful team and it has been a privilege to have worked with you. I would further like to thank the authors for their submissions and tireless efforts to produce quality articles.

My further thanks to Prof Andre Boraine and Lizette Hermann for their consistent guidance and leadership this year. This year's edition would not be the success it is without their encouragement and input this year. A further thank you to Prof Philip Stevens for his contributions and input.

I would also like to thank Adebayo Okeowo for his contribution for the cover for this year's edition.

I trust you, the reader, will find the included articles as insightful and though-provoking as the editorial team did.

\section{Sarah Burford}

Managing editor

2017 


\section{FROM THE DEAN'S DESK}

The Editorial Board of PSLR deserves hearty congratulations for the timely finalisation of the 2017 edition.

The PSLR provides our students with an excellent opportunity to develop their research and writing skills and to contribute to the academic discourse on legal and societal issues.

This edition covers various topical issues, namely: transformative constitutionalism and Ubuntu; jurisprudential reflections on Marikana; administrative law as a tool for social justice and transformative constitutionalism; public participation on environmental impact assessment; anti-doping measures in sports law; media freedom in Kenya and international instruments as sources of cross-border insolvency. The contributions all were subjected to an independent peer-review process and provide a broad range of topical discussions.

As always, I want to encourage our students to contribute to the $P S L R$. The experience gained by participating, either as an author or as serving on the editorial board, will stand you in good stead in any future career in law.

\section{Prof André Boraine}

Faculty of Law

University of Pretoria 


\section{NOTE ON CONTRIBUTIONS}

We invite all students to submit material for the eleventh edition of the Pretoria Student Law Review. We accept journal articles, case notes, commentary pieces, response articles or any other written material on legal topics. You may even consider converting your research memos or a dissertation chapter into an article.

Please visit our website at www.pslr.co.za for more information.

You may submit your contribution to:

pretoriastudentlawreview@gmail.com

Alternatively you may submit your contribution by hand at the office of the Dean of the Law Faculty:

Dean's Office

Faculty of Law

4th Floor

Law Building

University of Pretoria

Pretoria

0002 



\title{
MEDIA FREEDOM IN KENYA in 2017: A REALITY OR A MIRAGE?
}

\author{
by Shirley Genga*
}

\section{Introduction}

Freedom of expression is one of the most crucial elements of democracy. ${ }^{1}$ Freedom of expression protects and fosters a number of values, including the pursuit of truth, the functioning of democracy and individual self-fulfilment. ${ }^{2}$

The right to express oneself extends the free will to publish with no impediment whatsoever. ${ }^{3}$ Therefore, communication devoid of external restraints does not only confirm self-actualisation and selfidentity, but also upholds the validity of the natural right given to man to conceive and say what he perceives to be right. ${ }^{4}$ Notably, a necessary concomitant of freedom of expression is media freedom. ${ }^{5}$

Media freedom is the capacity of the media to act as a barometer to call government to account vis-à-vis the Constitution of Kenya, $2010^{6}$ especially the values, spirit and ethos enshrined therein. ${ }^{7}$ So much so that countries which are strong democracies always have strong and free media. ${ }^{8}$ A free and democratic society is not possible without an independent, free and responsible media and an active civil society. ${ }^{9}$

A free media is important in the development of democratic processes in contemporary societies. The core responsibilities of the

* $\quad$ LLB, LLM (University of Nairobi, Law School).

1 AM Busair, C Pride \& AK Corsy 'Free speech, press freedom, and democracy in Ghana' in LL Mukhongo \& JW Macharia (eds) Political influence of the media in developing countries (2016) 59.

2 Freedom of Expression Institute The media and the law: A handbook for community journalists (2007) 4.

3 Busair et al (n 1 above) 59-60.

4 Busair et al (n 1 above) 60.

5 SA Jazbhay 'Media, freedom, democracy and the rule of law' SANEF Seminar (19th October 2005) 1.

6 The Constitution of Kenya, 2010.

7 Jazbhay (n 5 above) 1.

8 AM Hanan, $N$ Saleem, A Ali, \& $S$ Mukhtar 'Role of media in strengthening democracy in Pakistan: Journalists' perception' (2016) 31 South Asian Studies 333.

9 Hanan et al (n 8 above) 333. 
media should be understood to involve their roles as watchdogs, agenda setters, and gatekeepers. ${ }^{10}$

As watchdogs, the media has a responsibility to help guard the public interest, ensuring the accountability of powerful decision makers by highlighting cases of malfeasance, misadministration, and corruption, thereby strengthening the transparency and effectiveness of governance. ${ }^{11}$

In fact, the media is often referred to as the fourth branch or fourth estate of government because of its watchdog role. ${ }^{12}$ The media's key role in democratic governance has been recognised since the late 17th century, ${ }^{13}$ and remains a fundamental principle of modern-day democratic theory and practice. ${ }^{14}$

As agenda setters, the news media has a responsibility to raise awareness of pervasive social problems, helping to turn public attention to matters of common interest, to inform governing officials about social needs and to inform the international community about development challenges. ${ }^{15}$ As gatekeepers, the news media has a responsibility to reflect and incorporate the plurality of viewpoints and political persuasions in reporting, to maximise the diversity of perspectives and arguments heard in rational public deliberations, and to enrich the public sphere. ${ }^{16}$ By training the citizens and informing them about what is happening, journalists play an active role in policy-making, and contribute directly or indirectly to political life. In order to have a mature democracy the electorate needs to be well informed. ${ }^{17}$ When citizens are not informed they will not be able to constructively participate and engage with the democratic process. ${ }^{18}$ In a healthy democracy, those who disseminate information must not be fettered in their role of holding government accountable. A free media will help in building the democracy of a country. Democracy exists on a foundation of self-governance and

10 BM Obiero 'Journalism in the struggle for democracy in Kenya: Analysis of the standard and nation news coverage on freedom of the media in the Kenyan Constitution (2010)' unpublished PHD thesis Instituto Politécnico de Lisboa Escola Superior de Comunicação Social (2016) 1.

11 Obiero (n 10 above) 1.

12 As above.

13 SS Coronel 'The role of the media in deepening democracy' http:// unpan1.un.org/intradoc/groups/public/documents/un/unpan010194.pdf (accessed July 2017).

14 Coalition for the International Criminal Court 'NGO media outreach: Using the media as an advocacy tool' September 2003 http://www.iccnow.org/documents/ NGO-media training.pdf (accessed July 2017) 3.

15 Obiero (n 10 above) 1.

16 As above.

17 As above.

18 As above. 
free, responsible mass media are essential to both democracy and self-governance. ${ }^{19}$

In Kenya the role played by the media is not only highly regarded, but according to an opinion poll carried out by the Infotrak, a research consulting firm, the media is the most trusted institution in Kenya. ${ }^{20}$

A survey conducted in 2015 found that 83 percent of Kenyans had faith in the media and were satisfied with the watchdog role played by journalists. ${ }^{21}$ In 2016, another survey confirmed further that the media enjoys the level of highest trust by Kenyans. ${ }^{22}$ Yet, as scholars, we must ask the pertinent question as to whether the media deserves the high levels of trust the Kenyan public has bestowed upon it. To those to whom much is given, much is expected. Is the media really free? If so, is it playing the watchdog role that is expected of it, particularly at a time when the nation is going through a momentous period of transition with the implementation of the new Constitution? These are some of the questions this paper will attempt to answer. ${ }^{23}$

Furthermore, it is worth noting that although Kenya has improved remarkably in media freedom and is considered to have a freer media compared to other developing countries. ${ }^{24}$ The 2017 World Press Freedom Index published by Reporters Without Borders (RWB) ranks Kenya in 95th position. ${ }^{25}$ This ranking is below Malawi which is ranked in 70th position, Botswana in 48th position and South Africa in 31st position. ${ }^{26}$ Additionally, Kenya's RWB 2014 Index was placed in 90th position globally, which represents an 18 place drop from its 2013 position which illustrates a consistent improvement between 2009, when it scored 60 and in 2012, when it scored 52. ${ }^{27}$

It is evident, from the above, that the Kenyan media has been slipping in world rankings over the last few years, something is clearly not right when it comes to media freedom in Kenya. Further, according to the Freedom House Report, the Kenyan media is in a very unique position of being 'partly' free. ${ }^{28}$ This conclusion by the

19 A Ali 'Media ownership and control versus press freedom in a democratic Africa' (2015) Journal of Mass Communication Journalism 239.

20 Dr Mutunga 'Media's role in free and fair elections is critical' April 162016 http: / /www.nation.co.ke/oped/opinion/medias-role-in-free-and-fair-elections-iscritical/440808-3161330-an9oyu/index.html (accessed 1 July 2017).

21 Obiero (n 10 above) 23.

22 As above.

23 Mutunga (n 20 above).

24 JC Ghai 'What explains ranking of Kenya's freedom of media' 6 May 2017 http: / / www. thestar.co.ke/news/2017/05/06/what-explains-ranking-of-kenyas-freedomof-media_c1554230 (accessed 10 July 2017).

25 As above.

26 As above.

27 O Nyanjom, 'The impact of Kenya's legal and institutional frameworks on media freedom' 2014 https://www.article19.org/data/files/medialibrary/37750/Kenya research_report_A5_ALL_v2.pdf (accessed 2 July 2017). 
Freedom House Report results from the fact that Kenya currently finds itself in a very interesting position where media freedom exists boldly on paper, but the reality on the ground is something else. The current Constitution of Kenya which came into force on 27 August 2010, has not only been hailed as reformist, ${ }^{29}$ but it has a new and progressive Bill of Rights requiring extensive reforms to both the media and information management frameworks. ${ }^{30}$ However, the government seems to have another agenda. As will be observed below, the government has introduced several laws that, on the outside appear to be progressive and in line with the new Constitution, but upon closer inspection clearly has an agenda that undermines media freedom in Kenya. ${ }^{31}$ In the sections which follow, this paper will analyse the legal framework and social factors relevant to media freedom in Kenya.

\section{An overview of media freedom in Kenya}

\subsection{International law}

Kenya is bound to a series of international and regional legal instruments regarding media freedom. ${ }^{32}$ Firstly, Article 19 of the 1948 Universal Declaration of Human Rights (UDHR) which Kenya is a signatory to, states: ${ }^{33}$

Everyone has the right to freedom of opinion and expression; this right includes freedom to hold opinions without interference and to seek, receive and impart information and ideas through any media and regardless of frontiers.

Secondly, Kenya is a party to the International Covenant on Civil and Political Rights (ICCPR), under which Article 19 imposes legal obligations on states to protect freedom of expression and information. ${ }^{34}$ Article 19 provides that 'everyone shall have the right to hold opinions without interference, 35 and 'everyone shall have the right to freedom of expression; this right shall include freedom to seek, receive and impart information and ideas of all kinds, regardless of frontiers, either orally, in writing or in print, in the form of art, or through any other media of his choice. ${ }^{, 36}$

29 C Glinz 'Kenya's new Constitution: A transforming document or less than meets the eye?' (2011) 44(1) Verfassung und Recht in Übersee/Law and Politics in Africa, Asia and Latin America 60-80.

30 Bill of Rights in Chapter 4 of the Constitution of Kenya, 2010.

31 Nyanjom (n 27 above) 6.

32 Nyanjom (n 27 above) 9.

33 Art 19 of the UN General Assembly Universal Declaration of Human Rights, 10 December 1948.

34 Art 19 of the UN General Assembly International Covenant on Civil and Political Rights (ICCPR) 16 December 1966 UN Treaty Series.

35 Art 19(1) of the ICCPR.

36 Art $19(2)$ of the ICCPR. 
Nevertheless, the ICCPR permits governments to impose certain restrictions or limitations on freedom of expression if such restriction is provided for by law and if it is necessary for either the respect of the rights or reputations of others or for the protection of national security or of public order or of public health or morals. ${ }^{37}$

Thirdly, Kenya is also a party to the African Charter on Human and Peoples' Rights (ACHPR), ${ }^{38}$ which in Article 9 states that 'every individual shall have the right to receive information, 39 and that 'every individual shall have the right to express and disseminate his opinions within law.'40 Additionally, the ACHPR Commission's 2002 Declaration of Principles on Freedom of Expression in Africa sets out regional norms guaranteeing free expression. ${ }^{41}$ The African Commission has held that governments should not enact provisions that limit freedom of expression 'in a manner that override constitutional provisions or undermine fundamental rights guaranteed by the [Charter] and other international human rights documents. ${ }^{42}$

\subsection{National law}

\subsubsection{The Constitution}

Media Freedom in Kenya is guaranteed in Articles 33, 34, and 35 of the Constitution of Kenya. ${ }^{43}$ Article 33 provides for the right to freedom of expression, and Article 35 provides for the right to access to information, both key rights which are important elements of media freedom as you cannot have media freedom without the other two. ${ }^{44}$ Article 34 provides for media freedom in Kenya specifically, stating: ${ }^{45}$

(1) Freedom and independence of electronic, print and all other types of media is guaranteed, but does not extend to any expression specified in Article 33(2).

(2) The State shall not -

(a) exercise control over or interfere with any person engaged in broadcasting, the production or circulation of any publication or the dissemination of information by any medium; or

(b) penalise any person for any opinion or view or the content of any broadcast, publication or dissemination.

37 Art $19(3)$ of the ICCPR.

38 O Namwaya 'Not worth the risk: Threats to free expression ahead of Kenya's 2017 Elections' 30 May 2017 https://www.hrw.org/report/2017/05/30/not-worth-risk/ threats-free-expression-ahead-kenyas-2017-elections (accessed 8 July 2017) 49.

39 Art 9(1) of the Organisation for African Unity (OAU) African Charter on Human and Peoples' Rights (Banjul Charter) 27 June 1981.

40 Art 9(2) of the Banjul Charter.

41 African Charter on Human and Peoples' Rights Commission (ACHPR) Declaration of Principles on Freedom of Expression in Africa 22 October 2002.

42 Namwaya (n 38 above) 50.

43 Arts 33, 34 \& 35 of the Constitution of Kenya, 2010.

44 Arts 33 \& 35 of the Constitution of Kenya, 2010.

45 Art 34 of the Constitution of Kenya, 2010. 
(3) Broadcasting and other electronic media have freedom of establishment, subject only to licensing procedures that -

(a) are necessary to regulate the airwaves and other forms of signal distribution; and

(b) are independent of control by government, political interests or commercial interests.

(4) All State-owned media shall -

(a) be free to determine independently the editorial content of their broadcasts or other communications;

(b) be impartial; and

(c) afford fair opportunity for the presentation of divergent views and dissenting opinions.

(5) Parliament shall enact legislation that provides for the establishment of a body, which shall -

(a) be independent of control by government, political interests or commercial interests;

(b) reflect the interests of all sections of the society; and

(c) set media standards and regulate and monitor compliance with those standards.

Most importantly, the Fifth Schedule of the Constitution of Kenya stipulates that laws pertaining to media freedom should be passed within three years, i.e. August 2013. This was extended to December 2013, when the Media Council Act (MCA) ${ }^{46}$ and the Kenya Information and Communications Amendment Act (KICA) ${ }^{47}$ were passed by the National Assembly and assented to by President Uhuru Kenyatta. ${ }^{48}$

\subsubsection{MEDIA COUNCIL ACT (MCA)}

The body responsible for self-regulating the media and the conduct and discipline of journalists, is the Media Council of Kenya (MCK) which was first established by the 2007 Media Act. ${ }^{49}$

The function of the Council under the 2007 Media Act included a wide variety of functions including mediating or arbitrating disputes between the government and the media, the public and the media and intra-media, promoting and protecting freedom and independence of the media and promoting high professional standards among journalists. ${ }^{50}$

Furthermore, and of great importance, is the fact that the Media Act states that the Council shall operate without any government, political, commercial or other bias or interference. ${ }^{51}$ The Media Council is to be wholly independent and separate from the

46 Media Council Act No 46 of 2013 (MCA).

47 Kenya Information and Communications Amendment Act No 41A of 2013 (KICA).

48 Nyanjom (n 27 above) 9.

49 Sec 3 of the Media Act No 3 of 2007.

50 As above.

51 Sec 5 of the Media Act. 
government, ${ }_{52}$ political parties, organisations and commercial

However, before the Media Act, the MCK was a self-regulatory body for media stakeholders. It was only after the conclusion of agreements between the Kenyan government and the media that it was converted into a statutory body, in $2007 .{ }^{53}$ Council membership is drawn from media stakeholders in Kenya including the Media Owners Association, Kenya Union of Journalists, Kenya Correspondents Association, Kenya Editors Guild, Public Relations Society of Kenya, Kenya News Agency, Private and Public Universities, the Kenya Institute of Mass Communication and the Law Society of Kenya. ${ }^{54}$ Even though MCK led to some independence, the government's influence did not cease. It was still viewed as a quasigovernmental organisation because it depended on public funding and the government maintained control over it by appointing representatives to the $M C K{ }^{55}$

In 2013, parliament passed a new law in light of the provision in Article 34 (5) of the Constitution. ${ }^{56}$ This was achieved through the MCA which repealed the Media Act of 2007 . This new law reestablished the MCK. ${ }^{57}$ This time around although the functions of the MCK are more elaborate, the government still maintains control. ${ }^{58}$

The Cabinet Secretary has the power to appoint or reject the names provided by the selection panel, which is mandated to come up with a list of nominees for the eight member council. ${ }^{59}$ It is, thus, not farfetched to say that the buck ends with the government and this gravely endangers media freedom in Kenya.

Additionally, Section 27 of the MCA establishes a Complaints Commission which is independent from the MCK. ${ }^{60}$ The Complaints Commission's main function is to enforce the media standards set the by the MCK, and to arbitrate in disputes between: 1) public and the Media, 2) government and media, and 3) within the media (Intramedia). ${ }^{61}$ The Complaints Commission consists of seven members. ${ }^{62}$

Obiero (n 10 above) 47.

As above.

Sec 6 of Media Act Cap 411 B of 2007.

Obiero (n 10 above) 47 - 48.

Art 34(5) of the Constitution of Kenya, 2010 provides: 'parliament shall enact legislation that provides for the establishment of a body, which shall be independent of control by government, political interests or commercial interests; reflect the interests of all sections of the society; and set media standards and regulate and monitor compliance with those standards.'

Sec 5 of the MCA.

SR Kipngetich 'Freedom of the media in Kenya: An estranged concept?' Unpublished LLB Degree Dissertation Strathmore University 2016.

Secs 7(3), (10) \& (11) of the MCA.

Sec 27 of the MCA.

Sec 28(1)(b) of the MCA.

Secs 28(1)(a) \& (b) of the MCA. 
Interestingly, members of the Commission who are appointed can also be rejected by the Cabinet Secretary which clearly illustrates government involvement. ${ }^{63}$ It is evident that the government is still trying to control this regulatory body through recruitment of the Chairperson and the other members of the Complaints Commission, and still fighting for power to check the conduct of journalists. Furthermore, Section 38(1)f, 48 and 49 of the MCA gives both the Complaints Commission and Media Council wide reaching powers to not only impose jail terms, but also place heavy fines on journalists and media houses for various offences provided in the MCA. ${ }^{64}$

\subsubsection{Kenya Information and Communications Amendment Act (KICA)}

Parliament enacted KICA to address the regulation challenges posed by the need to give effect to Article 34 of the Constitution of Kenya. KICA amended the Kenya Communication and Information Act 2009 to align with the Constitutional thresholds on the independence of the media as set out in Article 34 of the Constitution. ${ }^{65}$ KIKA created the Communications Authority of Kenya (CAK) ${ }^{66}$ to replace the Communications Commission of Kenya. ${ }^{67}$ Its main functions range from licensing and regulating postal, to ensuring that the broadcasters adhere strictly to the subscribed or authorities subscribing code. ${ }^{68}$

Here, although the selection of a list of potential candidates is carried out by individuals from different sectors such as the Law Society of Kenya, to the Institute of Engineers of Kenya, ${ }^{69}$ the President and the Cabinet Secretary have the final authority under KICA to appoint the chairman and the members of the CAK. ${ }^{70}$ This is a fact that could explain why only those who are closely aligned to the government have in the past been granted both television and print licenses to operate in Kenya. ${ }^{71}$

Furthermore, a controversial section of the law is the creation of the Communications and Media Appeals Tribunal which has the power to impose heavy penalties under Section $102 .{ }^{72}$ Here again, the members of the tribunal are appointed by the Cabinet Secretary, thus

63 Secs $27(3),(4)$ \& (5) of the MCA.

64 Secs $38(1)(f), 48$ \& 49 of the MCA.

65 This itself had been an amendment to the Kenya Information and Communication Act 2 of 1998.

66 Sec 3 of KICA.

67 Kipngetich (n 58 above) 27.

68 As above.

$69 \mathrm{Sec} 6 \mathrm{~B}(2)(1)$ of KICA.

70 Sec $6 B(2)$ (9) of KICA.

71 Obiero (n 10 above) 24.

72 Obiero (n 10 above) 25. 
interfering with the independence of the tribunal which is feted with lethal power that can interfere with media freedom in Kenya. ${ }^{73}$ The mandate of this tribunal is to determine disputes against journalists or media houses and in so doing, to impose hefty fines on media houses and journalists, recommend de-registration of journalists and make any order on freedom of expression. Further, the tribunal can impose a fine of not more than 20 million Kenyan Shillings (USD $\$ 193,799$ ) on any respondent media enterprise and a fine of not more than five hundred thousand shillings on any journalist adjudged to have violated KICA. ${ }^{74}$ It can thus be argued that this one section can be used by the government to silence the media and infringe on the right to media freedom, especially seeing as the tribunal may not be independent from the government because the Cabinet Secretary has the final word on who is appointed.

Besides the MCA and KICA above which were borne from the Kenyan government reviewing specific media laws as required by the Fifth Schedule in the Constitution. ${ }^{75}$ The government seemingly overlooked the need to review other existing laws which contravene the imperatives of the Constitution and of the regional and international frameworks relating to media freedom and which Kenya is obligated to uphold. ${ }^{76}$

An example is the Books and Newspapers Act CAP 111 Revised Edition 2012 (2003). ${ }^{77}$ This Act establishes the Office of the Registrar of Books and Newspapers in the Attorney-General's Office. ${ }^{78}$ Under $\mathrm{KICA}$, new publications must seek registration from the Office of the Registrar of Books and Newspapers, deposit a cash bond of 1 million Kenyan Shillings (USD $\$ 10,000$ ) and two copies of the new publication before they are allowed to publish. ${ }^{79}$ Furthermore, Section 11 of KICA requires payment of a bond of USD $\$ 12,000$ with sureties as security towards any monetary penalty or damages that may be imposed, before authority is granted to print a newspaper. ${ }^{80} \mathrm{~A}$ second conviction for not paying a bond can result in a permanent ban on publishing a newspaper. ${ }^{8}$

KICA also provides excessive fines and imprisonment for contravention of its provision, ${ }^{82}$ as well as extensive discretion to police officers to seize any book or newspaper which is actually or

73 Sec 102(4) of KICA.

$74 \mathrm{Sec} 102 \mathrm{E}(\mathrm{f})$ Kenya Information and Communications (Amendment) Act $41 \mathrm{~A}$ of 2013.

75 Nyanjom (n 27 above) 9

76 As above.

77 Books and Newspapers Act CAP 111 Revised Edition 2012 [2003].

$78 \mathrm{Sec} 3$ of the Books and Newspaper Act.

79 Nyanjom (n 27 above) 9.

80 Sec 11(1) of the Books and Newspaper Act.

81 As above.

82 Sec 9 of the Books and Newspaper Act 
reasonably suspected to have been printed or published in contravention of the law, no matter where it is found.

Thus, as it stands, the laws that regulate media freedom in Kenya give the state a measure of control over the governing bodies they institute. The laws compromise the independence of frameworks for appointments and removal from office, and provide no safeguards for state funding while creating avenues for controlling the media bodies they establish. ${ }^{84}$

\section{Kenyan case law on media freedom}

\subsection{Coalition for Reform and Democracy (CORD) \& Another $v$ Republic of Kenya \& ten Others [2015] eKLR}

On 11 December 2014, the Parliamentary Committee on National Security and Administration sent the Security Laws (Amendment) Bill 19 of 2014 (SLAA) to parliament. ${ }^{85}$ The bill was passed against backdrop of the increased attacks targeting Kenyan civilians as a result of Kenya's invasion of Somalia in the context of military operations against Al-Shabaab in October 2011, and under the auspices of the African Union initiative of a free Somalia. ${ }^{86}$

On 18 December 2014, during a dramatic and chaotic session of parliament in which legislators exchanged blows in the parliamentary sitting while discussing the bill, parliament passed the bill. ${ }^{87}$ The following day, 19 December, President Uhuru Kenyatta signed the bill into law. ${ }^{88}$ The bill contained a wide array of amendments to 22 laws. ${ }^{89}$ However, the hastily passed security bill infringed on many basic rights and freedoms protected in Constitution as well as under international human rights law. ${ }^{90}$

83 Sec 14 of the Books and Newspaper Act.

84 Nyanjom (n 27 above) 5.

85 Security Laws (Amendment Act) 19 of 2014 (SLAA).

86 Kenya Law Reform Commission 'Security law Amendment Act Ruling' http:// www.klrc.go.ke/index.php/media-center/523-security-law-amendment-actruling (accessed 24 July 2016).

87 Kipngetich (n 58 above) 2.

88 As above.

89 The Acts which have been amended by the SLAA include: Rent Restriction Act (CAP 296), Kenya Airport Authority Act (CAP 395), Traffic Act (CAP 403), Investment Promotion Act (CAP 485), Labour Institutions Act (2012), Public Order Act (CAP 56), Extradition (continuous and foreign countries) Act (CAP 76), Penal Code (CAP 63), Criminal Procedure Code (CAP 75), National Transport Safety Authority Act (2012), Refugee Act (2006), National Intelligence Service Act (2012), Kenya Citizenship and Immigration Act (2011), National Police Service Act (2011) and Civil Aviation Act (2013), Public Benefits Organizations Act(2013), Prevention of Terrorism Act (2012), Sexual Offenses Act (2006), Registration of Persons Act (CAP 107), Evidence Act (CAP 80), Prisons Act (CAP 90), Firearms Act (Cap 114), and Radiation protection Act (Cap 243).

90 Kipngetich (n 58 above) 2. 
As a result, what followed were three consolidated petitions challenging the constitutionality of the SLAA. ${ }^{91}$ The High Court of Kenya considered the constitutionality of the provisions of the SLAA vis-a-vis the Bill of Rights. ${ }^{92}$ The court considered the question whether SLAA was unconstitutional as it violated: (1) the right to freedom of expression and the right to freedom of the media guaranteed under Articles 33 and 34; (2) the right to privacy under Article 31 ; (3) the rights of an arrested person under Article 49 and the right to fair trial under Article 50; (4) entitlement to citizenship and registration of persons under Article 12 and (5) the right to freedom of movement under Article 39 and the rights of refugees under Articles 2(5) and 2(6) of the Constitution and International Conventions. ${ }^{93}$

The controversial sections included Sections 12, 16, 26, 29, 48, 56,58 , and 64 . On the question whether the impugned provisions of the SLAA were unconstitutional for violating the Bill of Rights, the court found that eight provisions in the SLAA were unconstitutional. ${ }^{94}$ For the purposes of this paper, the inclusion of Section 12 of the SLAA which amended Section 66A of the Penal Code and Section 64 that introduces Section 30F of The Prevention of Terrorism Act are particularly important as the two touch on media freedom. ${ }^{95}$

Section 12 of SLAA creates the offence of publishing or causing to be published or distributing obscene, gory or offensive material which is likely to cause fear and alarm to the general public or disturb public peace. The offence created was a felony and if committed, the penalty is a fine not exceeding 5 million Kenyan Shillings (USD $\$ 48,450)$ or imprisonment for a term not exceeding three years or both. ${ }^{96}$

Section 64 which introduces Section 30F of the Prevention of Terrorism Act 30 of 2012, ${ }^{97}$ provided that a person who publishes or broadcasts any information which undermines investigations or security operations by the National Police Service or the Kenya Defence Forces commits an offence and is liable, upon conviction, to a fine not exceeding five million Kenyan shillings (USD \$48,450) or imprisonment for a term not exceeding three years, or both. ${ }^{98}$

The court declared Section 12 of the SLAA and Section 66A of the Penal Code unconstitutional for violating the freedom of expression

91 Kenya Law Reform Commission (n 86 above).

92 Coalition for Reform and Democracy (CORD) \& two Others $v$ Republic of Kenya \& ten others [2015] eKLR

93 Coalition for Reform and Democracy (n 92 above) para 463(c).

94 As above.

95 As above.

96 Sec $12(1)$ of the SLAA.

97 Prevention of Terrorism Act 30 of 2012

98 Kipngetich (n 58 above) 3. 
and the media guaranteed under Articles 33 and 34 of the Constitution. ${ }^{99}$

\subsection{Jacqueline Okuta \& Another $v$ Attorney General \& two Others [2017] eKLR}

The 2017 case of Jacqueline Okuta v Attorney General ${ }^{100}$ brought into focus the constitutionality of the offence of criminal defamation created under the provisions of Section 194 of the Penal Code CAP 63 Revised Edition 2014 (2012), Laws of Kenya. ${ }^{101}$

Section 194 of the Penal Code provides; ${ }^{102}$

Any person who, by print, writing, painting or effigy, or by any means otherwise than solely by gestures, spoken words or other sounds, unlawfully publishes any defamatory matter concerning another person, with intent to defame that other person, is guilty of the misdemeanour termed libel.

Article 19, an international organisation advocating for the right to freedom of expression, alongside Jaqueline Okuta and Jackson Nery, petitioned the High Court in Nairobi to declare that Section 194 was disproportionate and that it amounted to an unjustifiable limitation of freedom of expression. ${ }^{103}$ Okuta and Njeru had been charged under Section 194 of the Penal Code for publishing posts about a prominent Kenyan lawyer on a consumer protection Facebook page called 'Buyer Beware'. ${ }^{104}$ Thus, Okuta and Njeru sought a declaration that Section 194 of the Penal Code was unconstitutional and invalid; and a declaration that any continued enforcement of Section 194 against them to be held as being unconstitutional. ${ }^{105}$ That the Section unjustly violated the freedom of expression by imposing sanctions on the civil wrong of defamation which was inconsistent with the constitution, and thus was void to the extent of the inconsistency. ${ }^{106}$

The case thus raised two fundamental questions: whether or not criminal defamation is a ground on which a constitutional limitation on the rights of freedom of the expression, can be legally imposed and whether defamation law infringes the right of freedom of expression guaranteed under the constitution or whether it is one of the

99 Coalition for Reform and Democracy (n 92 above) para 463(c)(i).

100 Jacqueline Okuta \& Another v Attorney General \& two Others [2015] eKLR.

101 Penal Code CAP 63 Revised Edition 2014 (2012).

$102 \mathrm{Sec} 194$ of the Penal Code CAP 63.

103 Kenya Union of Journalist 'Reprieve for journalists as court strikes out criminal libel law' 7 February 2017 http://www.kenyaunionofjournalists.org/reprievejournalists-court-strikes-criminal-libel-law/(accessed 19 July 2017).

104 Kenya Union of Journalists (n 103 above).

105 Okuta (n 100 above) para 2.

106 Okuta (n 100 above) para 3. 
reasonable and justifiable limitations justifiable in an open democratic society? ${ }^{107}$

It was held that the petitioners had successfully demonstrated that the offence of criminal defamation was not reasonably justifiable in a democratic society, hence criminal sanctions on speech ought to be reserved for the most serious cases particularised under Article $33(2)(a)-(d)$ of the Constitution which are aimed at protecting public interest. ${ }^{108}$ Furthermore, it was held that Section 194 of the Penal Code, CAP 63, was unconstitutional and invalid to the extent that it covered offences other than those contemplated under Article $33(2)(a)$ to (d) of the Constitution and that continued enforcement of Section 194 was unconstitutional and a violation of the petitioners' fundamental right to the freedom of expression guaranteed under Article 33(1)(a) to (c) of the Constitution. ${ }^{109}$

Therefore, the prospect of criminal proceedings and a jail term of up to two years for defamation was excessive and unjustifiable in an open and democratic society, and the law created a disproportionate limit on freedom of expression. ${ }^{110}$ This was a major win for media freedom in Kenya. ${ }^{111}$ The judge reasoned that Section 194 was unnecessary as there is already an appropriate and satisfactory alternative remedy for defamation. ${ }^{112}$ The case is very important to journalists and Kenyans who have found themselves on the receiving end of this law due to utterances and comments about government officials and other powerful and influential members of Kenyan society. 113

\subsection{Robert Alai $v$ The Hon Attorney General \& Another [2017] eKLR}

In Robert Alai $v$ The Hon Attorney General \& Another the constitutionality of Section 132 of the Penal Code, CAP 63 Laws of Kenya was challenged. ${ }^{114}$

\section{Section 132 provides: ${ }^{115}$}

Any person who, without lawful excuse, the burden of proof whereof shall be upon him, utters, prints, publishes any words or does any act or thing, calculated to bring into contempt, or to excite defiance of or

107 Okuta (n 100 above) para 1.

108 Okuta (n 100 above) para 43 (ii)

109 As above.

110 Article 19 'Kenya declares criminal defamation unconstitutional' 16 February 2017 https://www.ifex.org/kenya/2017/02/16/criminal_defamation (accessed 12 July 2017).

111 Article 19 (n 110 above).

112 Okuta (n 100 above) para 39.

113 Article 19 (n 110 above).

114 Robert Alai V The Hon Attorney General \& Another [2017] eKLR.

115 Sec 132 of the Penal Code CAP 63. 
disobedience to, the lawful authority of a public officer, is guilty of offence and is liable to imprisonment for a term not exceeding three years.

On 17 December 2014,

Robert Alai, the petitioner [was] arraigned before the Chief Magistrate's Court at Kiambu, [and was] charged with the offence of undermining the authority of a Public Officer Contrary to Section 132 of the Penal Code. Particulars of the offence stated that; while using the open source website Twitter, the petitioner posted the words 'Insulting Raila (opposition Leader) is what Uhuru (the current president of Kenya) can do. He hasn't realised the value of the Presidency. Adolescent President. This seat needs Maturity' which publication was calculated to bring into contempt the lawful authority of the President of the Republic of Kenya. ${ }^{116}$

The petitioner believed that the charge was a violation of his constitutional rights and filed the petition against the Attorney General and the Director of Public Prosecution, ${ }^{117}$ and sought a declaration that Section 132 of the Penal Code was unconstitutional and invalid, and that the continued enforcement of the section against him was unconstitutional. ${ }^{118}$ 'On 17th May, 2016, Article 19 was enjoined in these proceedings as an interested party, whose participation was limited to filing and highlighting of submissions.'119

In this case, the High Court declared Section 132 was unconstitutional and that the continued enforcement of Section 132 of the Penal Code against the petitioner was unconstitutional and a violation of his fundamental right to freedom of expression. ${ }^{120}$

\subsection{Nation Media Group Limited \& six Others v Attorney General \& nine others [2016] eKLR}

The above three cases were major wins for media freedom in Kenya, however the biggest loss was the 2016 case where the constitutionality of the Kenya Information and Communication (Amendment) Act (KICA) and the Media Council Act (MCA), as discussed above, was challenged. ${ }^{121}$ The two media laws were passed in December 2013, and immediately after received a significant amount of backlash from the media fraternity and human rights

116 Alai (n 114 above) para 1.

117 As above.

118 As above.

119 Alai (n 114 above) para 3.

120 Alai (n 114 above) para 62(1).

121 Nation Media Group Limited \& six Others $v$ Attorney General \& nine Others [2016] eKLR http://kenyalaw.org/caselaw/cases/view/122358 (accessed 24 August 2017). 
activists. ${ }^{122}$ This led to a January 2014 constitutional challenge by a coalition of media stakeholders that saw the Kenyan High Court issue an injunction against the full operation of the laws, with a hearing date set for 16 October 2014. ${ }^{123}$

The case, Nation Media Group Limited \& six Others $v$ Attorney General \& nine Others, challenged the constitutionality of Sections $38(1)(f)$ and $(h)$ of the MCA and Sections 102E(1)(f) and $(h)$ of the KICA on the basis that the two provisions contravened Articles 29 and 34 of the Constitution. ${ }^{124}$

A key contention in the KICA was the creation of the Multi Media and Appeals Tribunal, which would be top heavy with government appointees, and which have the authority to grant hefty fines of 500,000 Kenya Shillings (USD \$4844) to any journalist and 20 million Kenya Shillings (USD $\$ 193,799$ ) against any media outlet deemed to be in violation of that Act. ${ }^{125}$

The court found that both sections are constitutional. ${ }^{126}$ Consequently, the Complaints Commission created by the MCA within the Media Council of Kenya, which also has the authority to impose extreme sanctions against journalists was validated by the ruling. Thus Section 38(1) (f) of the MCA and Sections $102 \mathrm{E}(1)$ (f) and (h) of the KICA, which both include penalties for journalists, will severely constrain media freedom in Kenya and make it difficult for the media to play a watchdog role aimed at holding leaders and public institutions accountable. ${ }^{127}$ Also the ruling means journalists can be fined up to 500, 000 Kenya Shillings (USD \$4844) and media companies up to 20 million Kenya Shillings (USD \$193,799) if a new governmentregulated board finds them in breach of a government-dictated code of conduct. ${ }^{128}$ This will make journalists and media houses shy away from critical reporting and might kill investigative journalism for fear of heavy fines that are handed over by the MCA and the Communications and Media Appeals Tribunal, two bodies which are both under the control of government as illustrated above. ${ }^{129}$

122 M Murimi 'Blow to media as court rules Media Council Act constitutional' 27 May 2016 https://citizentv.co.ke/news/blow-to-media-as-court-rules-media-councilact-constitutional-128116 (accessed 10 July 2017).

123 Nyanjom (n 27 above) 10.

124 Nation Media Group Limited (n 121 above) para 17.

125 Kenya Correspondents Association 'High Court gives new date for hearing of case on controversial media laws' 7 August 2014 https://www.facebook.com/ KenyaCorrespondentsAssociation/posts/578377745622229 (accessed 9 July 2017).

126 Nation Media Group Limited (n 121 above) para 239(4).

127 Kenya Correspondents Association (n 125 above).

128 Murimi (n 122 above).

129 As above. 
Ironically although the judges found all the controversial sections listed above as constitutional, the judges found two other sections of the laws unconstitutional. ${ }^{130}$ The judges declared Section 3(2) of the MCA unconstitutional, to the extent that it requires that those to sit in the tribunal probing complaints against journalists must reflect interests of all sections of society. ${ }^{131}$ The judges said this provision limits the right to freedom of expression. ${ }^{132}$ Additionally, they declared Section $6(2)$ (c) of the MCA unconstitutional for being vague in its description as to what constitutes matters of national security. ${ }^{133}$ Although the issue of national security is of importance, the ruling was a major blow to media freedom in Kenya. ${ }^{134}$

\section{Extra-legal factors hampering media freedom in Kenya}

The government has not only adopted legislative means to interfere with media freedom in Kenya as is illustrated above, it has also adopted non-legislative methods of control in order to muzzle the media. ${ }^{135}$ Consequently, 'what you get is not always all there is to know ... Doublespeak is the name of the game!'136

\subsection{Media ownership}

The media is a very powerful tool especially in Kenya where it is rated as one of the most trusted institutions. ${ }^{137}$ As a result it remains the main source of information, and its role as a forum for public discussion and debate has always been recognised by politicians and Kenyan citizens. ${ }^{138}$ Essentially, whoever controls the media has the power because they control the narrative that is sold to the people. This is why politicians like former President Daniel Moi, current president Uhuru Kenyatta, politician Kenneth Matiba and many others, tried by all means to have some influence on the media companies, through ownership of the media groups or by funding. ${ }^{139}$

It is worth noting, is that although Kenya's Information and Communications Act empowers the Communications Authority to

130 Nation Media Group Limited (n 121 above) para 239(3)i \& 239(3)ii.

131 Nation Media Group Limited (n 121 above) para 239(3)i.

$132 \mathrm{~J}$ Kadida 'Blow to media as court declares "draconian laws" constitutional' 27 May 2016 http://www.the-star.co.ke/news/2016/05/27/blow-to-media-ascourt-declares-draconian-laws-constitutional_c1359056 (accessed 4 July 2017).

133 Nation Media Group Limited (n 94 above) para 239(3)ii.

134 Kadida (n 132 above).

135 Nyanjom (n 27 above) 15.

136 Nyanjom (n 27 above) 6.

137 Mutunga (n 20 above).

138 Obiero (n 10 above) 23.

139 As above. 
either issue or deny frequency licenses to both individual and institutional applicants, it fails to provide clear safeguards against political favouritism in the allocation of frequencies. ${ }^{140}$

Furthermore, the government has always maintained tight control over the allocation of radio and television frequency licenses and as a result, the broadcasting sector in Kenya has largely been dominated by individuals close to government. ${ }^{141}$ For example, state-owned Kenya Broadcasting Corporation (KBC) - both radio and television was the sole broadcaster until 1989 when then - President Daniel Moi and his political allies established the first private television station, Kenya Television Network (KTN). ${ }^{142}$ This was at a time when the government denied frequency licenses to other applicants for private television and radio stations. 143

During former President Mwai Kibaki term, Ali Chirau Mwakwere, whose family operates Kaya FM at the coast, and Koigi Ameer, who owns Sauti Yes Mwananchi Radio and TV Ltd in the Rift Valley, acquired frequency licenses when they both served as ministers in his government between 2003 and 2007. Samuel Poghisio, whose wife owns Elgonet Communication Technologies Ltd, which operates a radio station in the Rift Valley, acquired frequency licences while he served as Information and Communications Minister under President Kibaki between 2007 and 2013. ${ }^{144}$

Currently in Kenya five big media groups own and operate the nation's 22 television stations. The groups are: (1) KTN, owned by the family of former president Moi; (2) NTV, which is part of the Nation Media Group (NMG) of which the Aga Khan, the global spiritual leader of Shia Ismaili Muslims, is the largest individual shareholder; (3) the government-owned Kenya Broadcasting Corporation (KBC) (which also by 2012 had 85 of the 300 radio frequencies operational or on air); (4) K24, owned by the family of President Uhuru Kenyatta; and (5) Citizen TV owned by Royal Media Services of Samuel K. Macharia, a businessman and politician. ${ }^{145}$ Additionally, all the five major television operators mentioned above also operate radio stations with considerable geographic reach, which means that, unlike all the other media houses, each of the five have countrywide coverage. ${ }^{146}$

When it comes to print, the media companies which dominate in TV and radio also make an appearance here. Kenya has for decades been dominated by the Daily Nation and its weekend editions, all owned by NMG of the Aga Khan and the Standard newspapers that is

140 Namwaya (n 38 above) 15.

141 Namwaya (n 38 above) 16.

142 Namwaya (n 38 above) 15.

143 As above.

144 Namwaya (n 38 above) 16.

145 As above.

146 Namwaya (n 38 above) 16-17. 
predominantly owned by the family of former President Moi, whose family has publicly supported President Kenyatta. The other two daily newspapers, The Star, is owned by Radio Africa Group, closely associated with Kiprono Kitony, a relative of former President Moi, and The People, owned by the Kenyatta family. ${ }^{147}$

As a result of the control that the government has over Kenyan media, there was a blanket media 'blackout' on the coverage of the opposition Coalition for the Restoration of Democracy party's Saba Saba rally on 7 July 2014 arose from a Communications Authority (CA) threat to 'take the necessary regulatory action, including the withdrawal of frequencies from offending stations.'148

Media ownership has led some to question the authenticity of media houses and their reporting. ${ }^{149}$ This is because whoever owns the media house has to some extent, discretionary powers over what is to be reported to the masses. This creates a problem as information maybe be presented in such a way as favouring one party rather than an objective approach to news coverage. ${ }^{150}$

\subsection{Advertising}

Another non legislative method employed by the government to muzzle the Kenyan media is through advertising. Interestingly enough National governments remains the single largest source of revenue for news organisations in Africa. In Rwanda, for example, a staggering 85 to 90 percent of advertising revenue comes from the public sector. ${ }^{151}$

In Kenya, it is estimated that 30 percent of newspaper revenue comes from government advertising. ${ }^{152}$ An example of just how much power the Kenyan government has over media revenue is illustrated by a 2013 incident where the government spent 40 million Kenyan Shillings (USD 387,578 ) in two weeks just to publish congratulatory messages for the new President Uhuru Kenyatta. ${ }^{153}$

With 8 August 2017 elections fast approaching, the Kenyan government decided to stop advertising in local commercial media. ${ }^{154}$

147 Namwaya (n 38 above) 17.

148 Nyanjom (n 27 above) 6.

149 Namwaya (n 38 above) 17.

150 Kipngetich (n 52 above) 40.

$151 \mathrm{G}$ Ogola 'How African governments use advertising as a weapon against media freedom' 23 April 2017 https://www.standardmedia.co.ke/business/article/ 2001237400/how-african-governments-use-advertising-as-a-weapon-againstmedia-freedom (accessed 10 July 2017).

152 Ogola (n 151 above)

153 As above.

154 Namwaya (n 38 above) 40 - 41. 
On 8 February 2017, Kenyan authorities banned government ministries, departments, and agencies from placing state advertisements in private media. ${ }^{155}$ President Kenyatta's Chief of Staff and Head of the Civil Service, Joseph Kinyua, directed state accounting officers responsible for placing government advertisements, to advertise only in a new government publication, My.Gov, which was initially created in 2015 as an online portal. ${ }^{156}$

Currently the government publication is now being published as paid inserts in the four newspapers, The Daily Nation, The Standard, The Star newspaper and People Daily, the latter owned by the Kenyatta family.

A coincidence? It's difficult not to characterise the withdrawal of state advertising from commercial media as punitive. ${ }^{158}$ The revenue stream provided by government is very important and without it, newspapers are likely to close shop like in Serbia, Hungary, Namibia, Lesotho and Swaziland. ${ }^{159}$

Nevertheless, the government argued that the move was part of an initiative to curb runaway spending by lowering the advert spend in Kenya's mainstream media and directing all the money to the new title. 160

A similar move was made in South Africa last year when the government's communications arm announced that it would scale down government advertising in local commercial media. ${ }^{161}$ Instead, advertisements would be carried in the government newspaper Vuk'uzenzele. The decision withdrew an estimated USD \$30 million from the country's commercial newspaper industry. ${ }^{162}$ Like Kenyan, the South African government also claimed that the move was made to reduce government spending. But critics have argued that the decision was made to punish a media outlet that's been particularly critical of President Jacob Zuma's presidency. ${ }^{163}$

When the government withdraws government advertising from commercial media, it can be interpreted as a way to undermine the freedom of expression. Starving news media of revenue is a means of indirect state control. ${ }^{164}$

155 As above.

156 Nyanjom (n 27 above).

157 Ogola (n 151 above).

158 Namwaya (n 38 above) 41.

159 Ogola (n 151 above).

160 As above.

161 As above.

162 As above.

163 As above.

164 As above. 


\subsection{Threats and attacks against journalists}

There have also been an increase in threats and attacks on journalists who are critical of the government. ${ }^{165}$ Organisations have documented 17 separate incidents in Kenya, in which 23 journalists and bloggers were physically assaulted between 2013 and 2017 by government officials or individuals believed to be aligned to government officials. ${ }^{166}$ Of these, at least two died under circumstances that may have been related to their work. ${ }^{167}$ Furthermore, 16 incidents have been documented of direct death threats against journalists and bloggers across the country in the same period. ${ }^{168}$ Police has also arbitrarily arrested, detained, and later released at least 14 journalists and bloggers. ${ }^{169}$ Despite receiving formal complaints from journalists, the police have rarely investigated the attacks or threats. ${ }^{170}$ There is no evidence that any state actor has in the past five years been held accountable for threatening, intimidating, or physically attacking a journalist or blogger in Kenya. ${ }^{171}$

Kenyan authorities have often invoked alleged national security concerns as a basis to obstruct free expression and access to information. While national security can be a basis for limiting free expression under internationally accepted principles, governments must use the least restrictive means possible in prohibiting such speech and the national security interests should be legitimate. ${ }^{172}$

\section{Media freedom and the Kenyan General Election (2017)}

Media freedom recently came into sharp focus during the campaign trail and Kenyan General Election held on 8 August 2017 election. ${ }^{73}$ Kenyan citizens on various platforms accused local media and journalists of bias in their role of informing the public, with some critics claiming that local media had failed in carrying out its major functions in playing the watchdog role during the 2017 Kenyan elections. ${ }^{174}$ Even before the Election Day, the Kenya Television

165 Namwaya (n 38 above) 27.

166 As above.

167 Namwaya (n 38 above) 2.

168 Namwaya (n 38 above) 3.

169 As above.

170 As above.

171 As above.

172 As above.

173 T Makokha 'Kenyans accuse local media of biased reporting' 12 August 2017 https://www.standardmedia.co.ke/article/2001251105/kenyans-accuse-localmedia-of-biased-reporting (accessed 24 August 2017).

174 As above. 
Network (KTN), one of the leading traditional media houses in Kenya, was accused of under-representing the policy of opposition in Kenya and openly supporting the Jubilee government ahead of the 2017 general election in August. ${ }^{175}$ The broadcaster came under fire from social media users who suggested that a series of distorted news reports it ran discriminated against the opposition party, National Super Alliance (NASA) and that the reports designed to deliberately condition the mind of voters and ultimately shape their opinions on key campaign issues and the respective candidates. ${ }^{176}$ This further lead to some Kenyans on Twitter (popularly known as \#KOT) running a hashtag labelled '\#PartisanPressKE' which trended on Twitter on 19 June. ${ }^{177}$ On 13 August 2017, NASA told its supporters to boycott the Nation Media Group newspapers and television, alleging bias. ${ }^{178}$

On 12 August 2017, despite concerns about the authenticity of the results by the opposition, the Independent Electoral and Boundaries Commission declared President Uhuru Kenyatta the winner of the presidential race. ${ }^{179}$ This led to a weekend of protests and riots, particularly in the opposition strongholds. ${ }^{180}$ Interesting enough, media reports on the protest were scant, in fact one would not be faulted for claiming the local media gave the whole incident a blackout for almost two days. ${ }^{181}$ However, as the weekend wore on, it became clear that all was not well in Kenya. The opposition coalition, in a press statement on Saturday, claimed that 100 people had been killed by police officers in the post-election violence, while the Kenya National Commission on Human Rights placed the number at $24 .{ }^{182}$ This confusion was fuelled by the fact that mainstream media chose not to cover the incident. There were even complaints that local journalists were not reporting what innocent Kenyans were going through at the hands of the police, and were instead airing children's shows on TV. ${ }^{183}$

175 'Media terrorism exposed: Public outraged by KTN's open hostility against Raila Odinga and NASA' 21 June 2017 https://www.kenya-today.com/news/mediaterrorism-exposed-ktn-tv-accused-structural-bias-raila-odinga-nasa (accessed 24 August 2017).

176 As above.

177 As above.

178 K Houreld \& E Cropley 'Kenya opposition leader defies pressure to concede defeat' 13 August 2017 https://www.reuters.com/article/us-kenya-electionidUSKCN1ATOBY(accessed 23 July 2017).

179 N Sambuli 'How Kenya became the latest victim of "fake news"' 17 August 2017 http://www.aljazeera.com/indepth/opinion/2017/08/kenya-latest-victim-fakenews-170816121455181.html17 (accessed 25 August 2017).

180 As above.

181 As above.

182 As above.

183 C Muganda, 'Media accused of not playing watchdog role' 20 August 2017 https: // wWw.standardmedia.co.ke/article/2001251955/media-accused-of-not-playingwatchdog-rolehttps: //www.standardmedia.co.ke/article/2001251955/mediaaccused-of-not-playing-watchdog-role_(accessed 25 August 2017). 
As all this played out, many Kenyans, who were not satisfied with the mainstream media's limited coverage of the situation, were glued to social media channels for updates. ${ }^{184}$ Mainstream media eventually began to cover the stories, but only after international media had beat them to the task. ${ }^{185}$ When the local mainstream media eventually began coverage of police brutality on those who were protesting the Kenyan elections, reports of complaints of harassment against journalists by police began powering in. ${ }^{186}$ For example, on 12 August 2017, KTN journalist Duncan Khaemba was arrested whilst reporting on violent post-election protests in Nairobi's Kibera slum. ${ }^{187}$ Additionally, Matina Stevis, Africa correspondent for The Wall Street Journal, told the Committee to Protect Journalists (CPJ) that a police officer hit her over the head with a wooden stick on 12 August $2017 .{ }^{188}$ In the western city of Kisumu, an opposition stronghold, police officers blocked journalists from approaching demonstrators. ${ }^{189}$ Nation Media photographer, Dennis Onsongo, stated someone stole his lens as he moved through a crowd to the aftermath of a child's death in post-election protests in the Mathare area of Nairobi. ${ }^{190}$

\section{Conclusion}

The challenges facing the media, as detailed above, are not unique to Kenya. Around the world, concerns have been raised about the impact of concentration and commercialisation of the quality of the media, and the consequences of this on its ability and willingness to hold power to account. ${ }^{191}$ The Kenyan regulatory environment is still hostile to media freedom. Furthermore, while the Constitution of Kenya is very firm on protecting media freedom, various intervening factors have so far acted to undermine the extent of the realisation of this freedom. It is thus possible to make a few general observations about media freedom in Kenya.

Firstly, from the above there seems to be a lack of strong political will to fully implement the Constitution or to amend parts of it as necessary. There have been various instances of violations of the Constitution in general and of media freedom specifically, including the half-hearted attempt to review media laws in Kenya as provided

184 As above.

185 As above.

186 Committee to Protect Journalist, 'Kenyan journalists harassed, detained reporting on election violence' 17 August 2017 https://cpj.org/2017/08/kenyanjournalists-harassed-detained-reporting-on-.php (accessed 25 August 2017).

187 As above.

188 As above.

189 As above.

190 As above.

191 Ali (n 19 above). 
in 5th Schedule of the Constitution and the failings evident in the adaptation of the KICA and the MCA. ${ }^{192}$

While there are those who may argue that media freedom is not absolute, a true fact protected by the Constitution, nevertheless if the government wants to limit media freedom in Kenya for whatever reason, then it should do it through legal channels in order to avoid constitutional challenges. The Constitution provides for the limitation of rights and fundamental freedom. A right or fundamental freedom in the Bill of Rights, in this case media freedom shall not be limited except by law, and only to the extent that the limitation is reasonable and justifiable in an open and democratic society based on human dignity, equality and freedom, taking into account all relevant factors. Additionally, a limitation is only valid if one of the following conditions are met: (1) the legislation specifically expresses the intention to limit that right or fundamental freedom, and the nature and extent of the limitation; (2) the provision is clear and specific about the right or freedom to be limited and (3) the nature and extent of the limitation; and shall not limit the right or fundamental freedom so far as to derogate from its core or essential content. ${ }^{193}$

As it stands the Kenyan government seems to be engaged in a cat and mouse game where it gives with one hand and takes with the other. The government has been claiming to uphold the Constitution with one hand and with the other using both legislative and nonlegislative means to muzzle the Kenyan media. ${ }^{194}$ It is evident that Kenya still has a long way to go when it comes to media freedom.

192 Nyanjom (n 27 above) 29.

$193 \mathrm{Sec} 14$ of the Constitution of Kenya, 2010.

194 G Gathigi 'How the media covered Kenya's General Election' 10 August 2012 https: / theconversation.com/how-the-media-covered-kenyas-general-election82324 (accessed 24 August 2017). 


\title{
RE-IMAGINING A CULTURE OF JUSTIFICATION THROUGH TRANSFORMATIVE CONSTITUTIONALISM AND THE PHILOSOPHY OF UBUNTU
}

\author{
by Ofentse T Kgabo*
}

\section{Introduction}

Twenty years after the adoption of the Constitution, ${ }^{1}$ it is fitting to reflect on the development of our constitutional democracy. In light of purposive interpretation of statutes, ${ }^{2}$ one is required to question the intention of the drafters of the Constitution, to consider the context which necessitated its promulgation and to contemplate whether effect has been given to the content of the rights and freedoms contained therein. ${ }^{3}$ Ever-increasing inequalities in our society have prompted a return to the promise of 'transformative constitutionalism'. ${ }^{4}$ Klare defines transformative constitutionalism as a 'long-term project of constitutional enactment, interpretation, and enforcement' committed to transforming political and social institutions 'in a democratic, participatory, and egalitarian direction.' 5 The main problem which will be evaluated in this article is identified by Klare as the 'formalistic legal culture' which persists in all spheres of our socio-political and economic life. Several questions are asked; the first being whether transformative constitutionalism is able to overcome this pervading formalistic legal culture inculcated in our judicial system to advance social transformation and drive the progressive realisation of socioeconomic rights.

In so doing, a further question addresses whether the doctrine of separation of powers has been eroded by the flurry of political matters and executive functions which have increasingly come under question before our courts. Courts are sometimes required to remove the veil to derive new patterns of legal thought in order to strengthen constitutional dialogue between state institutions. However, it can be

Final year LLB, University of Pretoria.

Constitution of the Republic of South Africa, 1996.

19952 SACR 1 (CC) para 9; 19951 SACR 568 (CC).

3 The Bill of Rights safeguards the individual rights and freedoms of all people who reside within the territory of the Republic. However, these rights and freedoms are not absolute and are subject to limitation in terms of section 36 (often referred to as the 'limitation clause').

4 K Klare 'Legal culture and transformative constitutionalism' (1998) 14 South African Journal on Human Rights 146.

$5 \quad$ Klare (n 4 above) 150. 
argued that many of the matters which come before our courts are burdensome and may be negotiated better through the effective and purposive implementation of policy objectives.

A third question deals with the legacy of colonialism and apartheid, which will be addressing the marginalisation of indigenous law as a result of legal formalism which continues to suppress African values in favour of long-standing common law principles. It seems clear that at the heart of these problems is the formal legal culture which continues to pervade our courtrooms and chambers. In keeping with the transformative aspirations of our Constitution, this article seeks to illustrate the need for a distinctly African jurisprudence (specifically Ubuntu) which takes cognisance of the need for transformative policies to be implemented to bring about the restoration of the dignity of our indigenous black people. ${ }^{6}$

\subsection{From authoritarianism to a culture of justification}

As engaged legal scholars, we ought to ask such questions as 'what is (the) law?' and even more so, 'what ought (the) law to be?' Boyd White contends that the law is an 'inherently unstable structure of thought and expression, built upon a distinct set of dynamic and dialogic tensions. ${ }^{7}$ These tensions present themselves in the form of contestation between the realisation of liberty on the one hand, and the exercise of legal constraint on the other. ${ }^{8}$ Boyd White views the law as a mechanism for the reinvention of old ideals and their realignment with the lived experiences of modern society. He further suggests that law has the ability to appease its own conscience by acknowledging historical customs, while addressing the demands of social justice and transformation. The law carries immense gravitas to drive national and political imperatives thus it is futile to attempt to espouse a distinction between the realm of politics and that of law. In order to make significant strides in the achievement of transformation, the courts and the judges who preside over them ought to persist in their engagement of the merits of law when formulating legal judgments. In a constitutional democracy, judicial adjudication can no longer be considered a mere mechanical function as this is inconsistent with the language of generous and purposive interpretation. ${ }^{9}$ Harkening back to the words of Mureinik, ${ }^{10}$ it is imperative that all exercises of public power be justified in order to

6 The terms 'black' and 'African' are used interchangeably throughout this paper to denote people of African descent.

7 J Boyd White 'Justice in tension: An expression of law and the legal mind' (2012) 9 No Foundations 1.

$8 \quad$ Klare (n 4 above) 149.

9 Zuma (n 2 above) para 14.

10 E Mureinik 'A bridge to where? Introducing the interim Bill of Rights' (1994) 10 South African Journal on Human Rights 33. 
satisfy the founding constitutional values of accountability, responsiveness and transparency as expressed in section 1 (d) of the Constitution. This notion is well-articulated in the advent of transformative constitutionalism. This article will examine the existing legal culture and legal traditions in South Africa and postulate whether transformative constitutionalism goes far enough to facilitate large-scale social and political transformation.

Subsequent to the promulgation of the Constitution, commentary and critique which included the conception of transformative constitutionalism followed almost immediately. Prior to this, the nature and character of the South African Constitution was widely under dispute. Based on a reading of the preamble, it is unambiguous that the Constitution represents a conscientious pursuit of restoration and social justice which is buttressed on the recognition of fundamental human rights and equality before the law; a commitment to the rule of law as the basis for a democratic and open society; a commitment to the improvement of the basic living conditions of all citizens and most importantly, the democratisation of our country and reconciliation of all its people. This undertaking is fraught with diverging conflicts between the changes and advancements which are necessary to achieve transformation and the certainty of legal discourse in adjudication. ${ }^{11}$ The Postamble to the interim Constitution ${ }^{12}$ makes reference to 'a historic bridge between the past of a deeply divided society [...] and a future founded on the recognition of human rights. 13 The late Etienne Mureinik builds on this analogy of a 'historic bridge' to assert that what the bridge represents is a break away from a history of authoritarianism under the apartheid regime, to a 'culture of justification [...] in which every exercise of power is expected to be justified.' 14 This transition into a new democratic order recalls a past steeped in coercion. At the same time, it also articulates the promise of a future where 'the leadership given by government rests on the cogency of the case offered in defence of its decisions, [and] not the fear inspired by the force at its command.' 15

Klare's advancement of transformative constitutionalism as a substantive theory of constitutional enactment centres itself around the enforcement and interpretation of law to transform the historical link between 'political and social institutions, and [ensuing] power relationships in a democratic, participatory and egalitarian direction." 16 This entails an undertaking to induce 'large-scale social

11 AJ van der Walt 'Legal history, legal culture and transformation in a Constitutional democracy' (2006) 12 Fundamina 4.

12 Constitution of the Republic of South Africa Act 200 of 1993.

13 Mureinik (n 10 above) 31.

14 Mureinik (n 10 above) 32.

15 As above.

16 Klare (n 4 above) 150. 
change through nonviolent political processes grounded in law.' ${ }^{17}$ In a context where legal positivism has had devastating consequences for the lives and social welfare of indigenous black people, the language of law is a powerful source of intervention to drive an overarching enterprise dedicated to the advancement of human dignity, equality and freedom. After four hundred years of British colonial rule, the National Party government systematically passed laws which fashioned a blueprint for the sophisticated architecture of institutionalised racism. The system of parliamentary sovereignty which existed at the time in question did not represent the will of the people, but was nonetheless used to enact laws that would prescribe the conditions in which indigenous African people led their daily lives. It is this prostitution of law which ultimately leads to the perversion of state for political ends. It is due in part to these very injustices that we now live in a democratic society built on the principles of Constitutional supremacy contained in the founding provisions. ${ }^{18}$

\subsection{Transformative constitutionalism as ideology}

The late Chief Justice Langa was of the opinion that the objective of transformation (and by extension, a transformative Constitution) is the realisation of 'a truly equal society.' 19 Even after the achievement of equal access to resources and basic services, transformation remains a 'permanent ideal' through which we ought to view the world. ${ }^{20}$ This ideal or perspective, he contends, "creates a space in which dialogue and contestation are truly possible [...] and in which change is unpredictable but the idea of change is constant. 21 There is something beautiful about this particular expression of transformative constitutionalism, as it reinforces the ultimate vision of a Constitution that is 'transformative, rather than [...] transitional. ${ }^{22}$ In re-imagining what a truly equal society might look like, it is fundamental to conceive the changes which must be made. It is also crucial to acknowledge (albeit hesitantly so) that equality is an ideal which we might possibly never achieve.

Albertyn and Goldblatt have noted that although there has been widespread consensus on the challenge of transformation underlying the Constitution, ${ }^{23}$ several readings of the Constitution are

17 As above.

18 Sec 2 of the Constitution, 1996.

19 P Langa 'Transformative constitutionalism' (2006) 3 Stellenbosch Law Review 354

20 As above.

21 Langa (n 19 above) 354

22 As above.

23 C Albertyn \& B Goldblatt 'Facing the challenge of transformation: Difficulties in the development of an indigenous jurisprudence of equality' (1998) 14 South African Journal on Human Rights 249. 
plausible. ${ }^{24}$ However, the key focus and mandate of our Constitution is the restoration of our society through the 'redistribution of power and resources along egalitarian lines. 25 Due to the many complexities at play, the redistribution of resources is an arduous task. The segregation along race, gender and class lines in South Africa is systemic throughout social and political institutions. ${ }^{26}$ An insidious relationship is evident from the manner in which law and politics relate to one another. Unjust political determinations can easily find legitimacy through law. Thus, as a necessary precaution, one should always be circumspect of the responsibility placed on those who develop the laws of South Africa.

\subsection{Obfuscation of substantive reasoning in a formal legal culture}

The Constitution functions as a time capsule by preserving memory through the overarching emphasis on dignity and equality. An insightful discussion on the distinguishing factors of the South African Constitution would be incomplete without mention of its archival role. ${ }^{27}$ When one begins to view the Constitution through an archival lens, one becomes more responsive in deducing the cautionary tales contained therein. The wording of the Constitution is heavily loaded in places, requiring one to tease out the intention of those who drafted it. The framing of founding provisions is unrepentant in its recollection of the past. ${ }^{28}$ This nuanced recollection fossilises South Africa's ghastly history but is not intended to confine one to that particular moment in history. ${ }^{29}$ The past presents itself as a sharp mirror, scrutinising past moral failings and magnifying the call for the achievement of substantive equality. ${ }^{30}$ In this way, the Constitution leverages South Africa's collective memory to cultivate fertile ground for participatory and responsive democracy. ${ }^{31}$

Scrutiny of the legal culture which permeates the corridors of courtrooms suggests that the transformation of our laws (or at the very least, law-making processes) has not significantly translated into the reconstitution of judicial method or adjudication. Klare makes the descriptive point that even on the back of a Constitution which

I will discuss this in greater detail at a later stage. This discussion takes place in reference to Klare's assessment that a 'postliberal' reading of the Constitution is the most plausible, if not the only plausible one.

25 Albertyn \& Goldblatt (n 22 above) 249.

26 As above.

27 D Cornell \& K Van Marle ‘Exploring Ubuntu: Tentative reflections' (2005) 5 African Human Rights Journal 198.

28 The Preamble to the Constitution 'recognise[s] the injustices of our past; [and] honour[s] those who suffered for justice and freedom in our land ...'

29 Klare (n 4 above) 155.

30 Sec 9 of the Constitution, 1996.

31 Klare (n 4 above) 155. 
actively mandates social transformation; the role of participants in a pervading legal culture is what ultimately determines the rules of engagement. ${ }^{32}$ In this sense, legal actors are complicit in the survival of the formal legal culture within which they find themselves constrained. Klare further suggests that the character of our legal culture and education need to be transformed in order to bring them in line with the values espoused in the Constitution. ${ }^{33}$ Though this disconnect seems obvious to Klare, Froneman J offers a diverging view which I believe is closer to the truth. ${ }^{34}$ Froneman $\mathrm{J}$ differs with the idea that legal actors actively observe the manifestation of formal reasoning in their work and proposes a self-awareness of the means through which conservatism in legal culture shapes professional sensibilities. ${ }^{35}$ Once all practitioners in the legal profession have taken it upon themselves to understand the reasons for which formal reasoning is employed, then it would simply be dishonest to continue to take refuge in a position of ignorance.

On one level, Klare is correct in asserting that legal practitioners who find themselves in a specified legal culture are trained in a particular manner to identify what constitutes a persuasive argument or method of adjudication and what does not. ${ }^{36}$ On another level, legal education cannot take credit entirely for orienting perceptions on solving legal problems. If one relies on 'cultural coding' to determine the manner in which legal problems and questions are framed, ${ }^{37}$ then this hinders the substantive development of law. Uneasiness abounds from certain corners within the legal profession when one invokes the necessity of a substantive formulation of law because a value-based approach is implied. Klare rightly points out that the supposed neutrality of formal law is a fiction because consequentially, a judge's personal beliefs and convictions can never fully be filtered out of the interpretive process. ${ }^{38}$ The narrative of an individual's daily life is centralised to his or her own experiences, therefore the point of view taken by a judge in their exercise of adjudication is uniquely their own. This unique perception or viewpoint, however, should not preclude judges from appreciating constructs of reason outside of their own. The contention here is that what distinguishes the work of judges is the skill they have acquired in striking a balance between applying existing formal rules and employing their imagination to innovate novel solutions to indistinct Stellenbosch Law Review 3

Froneman (n 33 above) 5.

Klare (n 4 above) 167.

Klare (n 4 above) 168. Klare (n 4 above) 163. 
questions of law. Therefore the trade of a judge involves a weighing up between purposive imagination and legal constraint. ${ }^{39}$

The common fear when it comes to a substantive vision of law is the space judges are given to impress their personal values and convictions in the exercise of their work. On the contrary, when one strips down the content of a formal rule, it is unavoidable to conceive the circumstances which existed or the intended outcome which warranted the formulation of that rule in the first place. ${ }^{40}$ At an initial level, justification for formal rules takes place in the lawmaking process. The framing of a particular formal rule cannot and does not take place within a vacuum because the "justification for the rule and what its likely consequences may be' motivates the formulation thereof. ${ }^{41}$ Thus the formulation of a formal rule simply "incorporate[s] those substantive reasons in its content. ${ }^{42}$ Froneman $\mathrm{J}$ cautions against this conceptualisation of law because when one devises formal rules which are substantively above reproach, law is given a life of its own and individuals are absolved of the decisions they implicitly make. ${ }^{43}$

To drive home this argument, advocacy for a substantive vision of law does not imply that 'anything goes' or that substantive reasoning allows us to imbue whatever textual meaning we so wish. ${ }^{44}$ Conversely, the point at which the legal materials before us become constrained in their meaning and our own legal interpretation proceeds, cannot be objectively determined. ${ }^{45}$ Law must be certain and determinable to some extent, but must also remain malleable enough to foster an environment in which to achieve its purpose. On the notion of legal subsidiarity (which is interpreted for present purposes to construe the hierarchy of sources of law), Klare accepts the proposition tendered by Van der Walt. ${ }^{46}$ The challenge from Van der Walt, lies in becoming "comfortable with gaps [in our law] rather than seeking refuge in supposedly stable and all-inclusive rules[...] because gaps open space for conversation, diversity, dissent, contestation, and judgment. ${ }^{47}$

39 Klare (n 4 above) 160.

40 Froneman (n 33 above) 6.

41 As above.

42 As above.

43 As above.

44 Klare (n 4 above) 160.

45 As above.

46 K Klare 'Legal subsidiarity \& constitutional rights: A reply to AJ van der Walt' (2008) 1 Constitutional Court Review 129.

47 Klare (n 4 above) 130. 


\section{Judicial reasoning and the exercise of public power}

All exercises of public power must comprise the rational exercise of that power. Insofar as the judicial authority of the Republic is vested in the courts, ${ }^{48}$ it is within their functional area of competence to institute judicial review proceedings of policy or conduct which is not in line with the spirit, purport and objects of the Constitution. I will address the role of courts (and especially that of the apex court, the Constitutional Court) to drive the transformative design ${ }^{49}$ of the Constitution. In line with this approach, arguments for a closer 'constitutional dialogue, 50 follow in fostering a culture of justification.

At this point in this discussion, it is important to note the operation of the doctrine of separation of powers, ${ }^{51}$ which must be inferred from the structure of the provisions in our Constitution. ${ }^{52}$ In addition to those provisions which establish the authority vested in various state organs, section $41(1)(e)$ explicitly provides that 'all organs of state within each sphere' must respect the constitutional status, powers and functions of government. Further, organs of state may 'not assume any power or function except those conferred on them in terms of the Constitution'. ${ }^{53}$ These provisions establish and give content to the doctrine of separation of powers. ${ }^{54} \mathrm{An}$ acknowledgement of the operation of the separation of powers is crucial to this discussion as this principle informs one aspect of the rational exercise of public power and necessitates the inclusion of checks and balances. In $S \vee$ Dodo, ${ }^{55}$ the Court emphasised that the principle of separation of powers as envisioned in our Constitution: ${ }^{56}$

... embodies a system of checks and balances designed to prevent an overconcentration of power in any one arm of government; it anticipates the necessary or unavoidable intrusion of one branch on the terrain of another; this engenders interaction, but does so in a way which avoids diffusing power so completely that government is unable to take timely measures in the public interest.

48 Sec 165(1) of the Constitution, 1996.

49 D Moseneke 'The fourth Bram Fischer memorial lecture: transformative adjudication' (2006) 18 South African Journal on Human Rights 309.

50 S Ngcobo 'South Africa's transformative Constitution: Towards an appropriate doctrine of separation of powers' (2011) 1 Stellenbosch Law Review 3739.

$51 \mathrm{~K}$ McLean Constitutional deference, courts and socio-economic rights in South Africa (2009) 105.

52 This separation of power is evidenced by the differentiation between the powers vested in the executive, the legislature and the judiciary (established in secs $85(1), 43$ and 165(1) of the Constitution respectively).

53 Secs 41(1)(f) \& (g) of the Constitution, 1996.

54 Ngcobo (n 49 above) 106.

5520013 SA 382 (CC).

56 Dodo (n 54 above) para 16.1. 
Ngcobo CJ refers to an 'appropriate doctrine of separation of powers' which acknowledges the operation of a symbiotic relationship between the role of the Constitutional Court and the other branches of government. ${ }^{57}$ In fact, a constitutional obligation is placed on the Court to decide matters where a branch of government has exceeded the bounds of the exercise of authority vested therein by the Constitution. ${ }^{58}$ Increasingly, the executive (and by extension the governing party, the African National Congress) has expressed concern over 'judicial overreach' in matters which are patently of a political nature. ${ }^{59}$ In his critique of Klare, Roux suggests that the 'politically engaged and politically transparent method of constitutional interpretation' 60 that accompanies the ideological project of transformative constitutionalism, is the only feature which distinguishes it from traditional interpretive methods otherwise employed by so-called 'liberal legalists. ${ }^{.61}$

Transformative constitutionalism departs from this school of thought by offering a post-liberal interpretation of the Constitution (post-liberal insofar as it proposes a 'politically loaded' method of transformative adjudication). ${ }^{62}$ The question which must be asked here is whether a transformative approach to adjudication does not inherently require a politicised discourse, especially in the realm of socio-economic rights, for example. In his analysis, Klare has found that 'the Constitution suggests not only the desirability, but the legal necessity, of a transformative conception of adjudicative process and method. ${ }^{\prime 63}$ Although the purging of legal reasoning and legal culture entrenched by apartheid policies is required, it is inadequate to pass new legislation to supplant apartheid-era laws without a material shift towards transformative adjudicative methods. Substantive legal reasoning, as a function of transformative constitutionalism, obliges judicial officers to openly engage in an evaluation of 'policy objectives or policy considerations' which inform the outcomes of their decisions. ${ }^{64}$ Legal outcomes should always find their basis in the purpose of prevailing principles and not in the mechanical operation of existing legal knowledge. Common law, indigenous law and case law should be relied on as interpretive guides. Over and above that,

57 Ngcobo (n 49 above) 40.

58 As above.

59 Ngcobo (n 49 above) 208.

60 T Roux 'Transformative constitutionalism and the best interpretation of the South African Constitution: Distinction without a difference?' (2009) 2 Stellenbosch Law Review 258266.

61 Ngcobo (n 59 above) 265.

62 Roux proposes that the insistence on a list of essential features which Klare identifies as characterising a postliberal Constitution is 'uncontroversial'. He contends that what should be understood from this label is an acknowledgment of a reading which is 'mandated by the text of the Constitution' itself.

63 Klare (n 4 above) 156.

64 G Quinot 'Substantive reasoning in administrative-law adjudication' (2010) 3 Constitutional Court Review 113. 
all relevant factors (especially extra-legal factors) ought to be considered in the framing of legal problems and must direct the rational means through which a solution may be reached.

The Constitutional Court should take a leading role in advancing widespread transformation. Of course, there are other mechanisms in place to deal with violations of fundamental rights. Chapter 9 of the Constitution establishes several institutions which exist in support of constitutional democracy. ${ }^{65}$ These institutions are required to respond to allegations of unfair discrimination, and to give an account of the pace and scale at which various state policies are being implemented. Pointedly, section 184 of the Constitution places an obligation on the South African Human Rights Commission (SAHRC) to ensure that measures taken by government to advance the realisation of socio-economic rights are evaluated on an annual basis. This leads to an argument for 'constitutional dialogue' between organs of state, which are jointly bound to 'respect, protect, promote and fulfil the rights in the Bill of Rights.' 66

\subsection{Constitutional dialogue between state institutions}

Langa CJ bemoaned the insurmountable task which has been placed at the feet of judges and legal practitioners. It is simply unrealistic for the burden of transformation to be solely placed in the hands of the judiciary. The executive branch creates policy, which ought to guide the process of large-scale social change. Efficient government processes are required to ensure the seamless implementation of transformative policies. However, we know that this is often not the case. In these instances, the legislature should be required to flex its own constitutional muscle by fulfilling its oversight role and demanding accountability for the popular mandate given to the executive. The legislature also has sole law-making powers and as such, should also play its role by debating and reflecting on mechanisms which can strengthen our constitutional democracy.

The Constitutional Court struck a balance in dealing with the procurement of a service provider for the disbursement of social assistance to grant recipients. ${ }^{67}$ This matter is significant for several reasons. Section 27 of the Constitution explicitly provides for the need to address the plight of previously disadvantaged groups and mandates the provision of access to basic services such as healthcare, food, water and pertinently, social assistance to those people who are unable to support themselves. Furthermore, the Social Assistance Act

65 S Liebenberg Socio-economic rights: Adjudication under a transformative Constitution (2010) 37.

66 Secs 7(2) and 8(1) of the Constitution.

67 [2017] ZACC 8 ['Black Sash']; 20141 SA 604 (CC) ['Allpay 1']; 20144 SA 179 (CC) ['AllPay 2']. 
establishes the circumstances under which social assistance may be given to groups who are eligible as contemplated in the provisions of this Act. ${ }^{68}$ Currently, many people in South Africa continue to suffer from rampant poverty as a result of various social ills including living in conditions of squalor, the widening income inequality gap and the stark increase in unemployment. Consequentially, millions of people now rely on the social grants which they receive from the South African Social Security Agency (SASSA). ${ }^{69}$

In Allpay 1, leave to appeal had been sought by AllPay Consolidated Investment Holdings (Pty) Ltd (Allpay) in relation to irregularities in the awarding of a tender for the provision of social grants to all nine provinces. ${ }^{70}$ Allpay had been unsuccessful in its bid for the tender and were seeking an order setting the contract aside. The Constitutional Court (the Court) dealt with a string of procedural issues relating to the process which was followed in bringing this review application, ${ }^{71}$ but for purposes of this discussion, focus will fall squarely on one central issue: the black economic empowerment (BEE) component (or lack thereof) of the winning bidder Cash Paymaster Services (Pty) Ltd (CPS).

CPS claimed, as a result of the requirements of the tender bid, that their BEE partners would manage $75 \%$ of the projects which would be embarked on in the contract. ${ }^{72}$ The Supreme Court of Appeal had maintained that the SASSA was not obliged to test the veracity of the claim made by CPS, which this Court found to be incorrect on the basis that BEE 'generally requires substantive participation in the management and running of any enterprise. ${ }^{, 73}$ The Court held that the legislative procurement framework specifically champions the need for economic redress for previously disadvantaged persons, ${ }^{74}$ and makes provision for state organs such as the SASSA to make determinations on a 'preferential procurement policy. ${ }^{75}$ The Broad-Based Black Economic Empowerment Act $^{76}$ centres itself on the empowerment of black people through the promotion of skills development and the endorsement of black management and control of companies that provide services to the state. ${ }^{77}$ As a result, the SASSA was under an obligation in terms of the Empowerment Act to 'ensure that the empowerment credentials of the prospective tenderers were investigated and confirmed before

68 Ch 2 of Act 13 of 2004.

69 In terms of section 2(2) of the Social Assistance Act 13 of 2004, SASSA is the body responsible for the provision of social assistance.

70 Allpay 1 (n 67 above) para 2.

71 Allpay 1 (n 67 above) para 15.

72 Allpay 1 (n 67 above) para 21.

73 Allpay 1 (n 67 above) para 22(e).

74 Allpay 1 (n 67 above) para 47.

75 Allpay 1 (n 67 above) para 48.

76 Act 53 of 2003 ('the Empowerment Act').

77 Allpay 1 (n 67 above) para 50. 
the award was finally made. That obligation became even more crucial when there were no other competitors left in the second stage. ${ }^{78}$ The Court held that the failure of the SASSA to investigate the empowerment credentials of CPS, despite the constitutional importance of substantive empowerment was fatally flawed. ${ }^{79}$ In light of the evidence led before the Court, the leave to appeal was upheld and the contract was set aside. However, in consideration of the devastating consequences that disruptions in the provision of grants would have, the Court opted to suspend the declaration of invalidity 'pending determination of a just and equitable remedy.' 80

In a separate matter (Allpay 2), the Court set out to deal with the appropriate remedy following the judgment on the merits. ${ }^{81}$ In considering whether a new tender process should be started, the Court was careful to contemplate whether initiating a fresh tender process would be more onerous on the public purse than upholding the existing (though constitutionally invalid) contract. ${ }^{82}$ The relevant factors to be considered which were advanced by the Centre for Child Law (Amicus Curiae) are persuasive for many reasons. Of paramount importance is protecting the: ${ }^{83}$

interest of beneficiaries in the uninterrupted payment of social grants, especially that of children; [the] cost to the public purse versus the proper use of public funds; and [the] need to promote respect for the rule of law, including both the value of deterrence and the maintenance of and respect for a fair and lawful procurement system.

After hearing submissions from the SASSA indicating that the agency intended to take over the provision of social grants by April 2017, ${ }^{84}$ and that in the meantime it would be too costly to undergo the process of awarding a new tender, the Court held that if a new tender is not awarded as stipulated in its order then the current contract would be allowed to run its course until 31 March 2017. The Court did not give this order lightly, taking cognisance of its obligation in terms of section 172(1)(a) to limit the extent of this inconsistency and treading carefully so as not to violate the separation of powers. ${ }^{85}$

The concluding matter is the ongoing failure by the SASSA to secure an internal grants distribution system, thereby placing the livelihoods of millions of people at risk. In the third related matter (Black Sash), ${ }^{86}$ the Court deals with the failure by the SASSA (and on a grander scale by the political office bearer responsible for 
oversight, the Minister of Social Development) to order a new tender process or to take over the grants payments system itself as directed in the remedial order (Allpay 2). ${ }^{87}$ This judgment is extremely important for purposes of this discussion because it demonstrates the gravitas of the constitutional powers vested in the Constitutional Court to make orders which bind other organs of state. As the guardian of the Constitution, ${ }^{88}$ the Court is sometimes required to broaden the boundaries of its discretionary powers (in close proximity to the violation of separation of powers) in order to uphold the spirit and purport of the Bill of Rights. In this case, the Constitutional Court is very careful to ensure that the right (as provided in section 27(1) of the Constitution) of millions of people to social assistance is not infringed. The Court makes the following decisive orders, amongst others: ${ }^{89}$

- 'It is declared that the SASSA and CPS are under a constitutional obligation to ensure payment of social grants to grant beneficiaries from 1 April 2017 until an entity other than CPS is able to do so and that a failure to do so will infringe upon grant beneficiaries' rights of access to social assistance under section 27(1)(c) of the Constitution.'

- 'The declaration of invalidity of the contract is further suspended for [a] 12-month period ...'

- 'The Minister is called upon to show cause on affidavit on or before Friday 31 March 2017 why -

- $\quad$ she should not be joined in her personal capacity; and

- $\quad$ she should not pay costs of the application from her own pocket.

The abovementioned orders are important to discuss for several reasons. The first reason is that CPS is placed under a constitutional obligation to ensure the continued payment of social grants until an entity other than CPS is able to perform its functions. The basis of this claim lies in the determination of the Court that CPS is an organ of state by way of the function it performs of ensuring the payment of social grants (a function which is public in nature). ${ }^{90}$ The Court is empowered to make this order to facilitate the continued and uninterrupted payment of social grants to grant recipients. Secondly, a further extension of the earlier invalidated contract is contentious. Madlanga $J$ proposes that as a necessary consequence, the constitutional obligation placed on CPS to ensure continued payments to grant recipients nullifies the earlier declaration of invalidity. ${ }^{91}$ As such, arising out of this order is a valid and binding contract between

87 Black Sash (n 67 above) para 3.

88 H Klug 'Finding the Constitutional Court's place in South Africa's democracy: The interaction of principle and institutional pragmatism in the Court's decision making' (2010) 3 Constitutional Court Review 1.

89 Black Sash (n 67 above) para 76.

90 Allpay 2 (n 67 above) para 52.

91 Black Sash (n 67 above) paras 79 \& 80. 
the SASSA and CPS (until such a time that an entity other than CPS is able to take over the grants payment system). Thirdly, Froneman J holds that arising out of her powers to appoint the CEO of the SASSA as well as her accountability to Parliament, the Minister of Social Development is ultimately responsible for the payments crisis and must therefore show cause why she should not be held personally liable for costs. ${ }^{92}$ Such an order has never been made and suggests that the Court takes very seriously the role of the executive in fulfilling its duties, especially in matters affecting the most vulnerable population groups. Although not expressly stated by the Court, it is curious that the parliamentary committee responsible for Social Development failed in its oversight role over the department.

The abovementioned orders given by the Constitutional Court illustrate a self-awareness of the immense responsibility placed on the Court to ensure that over 15 million South Africans receive the necessary social assistance which they require. It is evident that the Court may be required to deliver judgments which strike a balance between 'principled argument and institutional pragmatism'. ${ }^{93}$ This measured approach should be celebrated because it creates space for reflection on the dynamic and engaged role which the Court plays in postcolonial South Africa. The tension which exists between 'the internal [traditional patterns of legal argumentation] and external [pragmatic and executive-minded] dimensions of the Court's role as guardian of the Constitution' permits the court to develop a jurisprudence of its own. The convergence of these opposing dimensions in turn allows the Court to engage in a highly politicised discourse without much legal restraint, in order to safeguard the rule of law. ${ }^{94}$ The existence of constitutional dialogue between state institutions is vital to ensuring that the Constitutional Court does not continue to bear sole responsibility for the development of substantive reasoning in rights discourse, as well as in the widespread transformation of our social and political institutions.

\section{The influence of Ubuntu on constitutionalism}

In its first ruling, the Constitutional Court was delegated the prerogative of deciding on the constitutionality of capital punishment as a valid sentencing option. ${ }^{95}$ However, this matter dealt with more than just a question of the interpretation of the right to life, protected under section 11 of the Constitution. This matter was of great importance in developing the 'value-based jurisprudence' which continues to inform legal reasoning and adjudicative methods 
used today. ${ }^{96}$ A key question is how to move towards an African jurisprudence that takes up a dignified identity and is given the necessary credence in law? The main problem which sits at the heart of the colonial project is the epistemicide that ensued. As a result, communal values were replaced by individual freedoms, morality was replaced by law and reconciliation was replaced by retribution. ${ }^{97}$ This began the impoverishment of moral and ethical considerations in law, and by operation throughout social, political and economic institutions.

In the early nineteenth-century, English law started making a transition to positivism which saw these ideals being transplanted to the South African legal system. ${ }^{98}$ This inadvertently had a devastating effect on indigenous African systems of law, which continue to enjoy subordinate status in modern South African law. Fast-forward to the present day and the intrinsic demand for justice (entailing the restoration of the dignity of the indigenous African people) has still not been addressed. ${ }^{99}$ Restitution and reparations ought to have followed immediately after the achievement of democracy, ${ }^{100}$ but this was not the case. In the process of securing political rights (such as the right of franchise and the right to freedom of association) ${ }^{101}$ for all people, especially for the indigenous African population, the state failed to prioritise important projects such as the acceleration of land reform, land tenure reform and the redistribution of land, ${ }^{102}$ as well as other mechanisms to address the class and racial divide which still persists. Adopting an Ubuntu understanding of law in existing social and economic institutions is essential in dealing with the prevailing effects of colonisation, apartheid and racism. ${ }^{103^{3}}$

\subsection{Ubuntu: Collective self-determination}

It can be no coincidence that in his description of a post-liberal reading, Klare refers to the Constitution as embracing 'a vision of collective self-determination. ${ }^{104}$ Not only is collective selfdetermination invoked as a vision to be aspired towards, but this right is further entrenched in section 235 of the Constitution. This vision of law aligns with and closely resembles the core belief at the heart of

96 Quinot (n 63 above) 111.

97 W Le Roux 'Natural law theories' in C Roederer and D Moellendorf (eds) Jurisprudence (2004) 40.

98 J Dugard 'The judicial process, positivism and civil liberty' (1971) 88 South African Law Journal 184.

99 MB Ramose 'An African perspective on justice and race' Polylog Themes/Focus https: / / them.polylog.org/3/frm-en.htm (accessed 15 March 2017).

100 Ramose (n 99 above) 2.

101 Secs 19(3)(a) and 18 of the Constitution, 1996.

102 Secs 25(5), (6) \& (7) of the Constitution, 1996.

103 Ramose (n 99 above) 4.

104 Klare (n 4 above) 153. 
the philosophy of Ubuntu. Klare further asserts that unlike other bills of rights which are rooted in classic liberal tradition, 'the South African Constitution embodies the idea that the power of the community can (and must) be deployed to achieve goals consistent with freedom, that collective power can be tapped to create social circumstances that will nurture and encourage people's capacity for self-determination. ${ }^{105}$ In his doctoral thesis, ${ }^{106}$ Prof Ndima takes a similar line in his characterisation of pre-colonial African tradition. The indigenous African traditions of the time evince the acceptance of a worldview informed by 'a shared communal life, a sense of common belonging, collective ownership of assets, and group solidarity - all of which combined to foster a distinctly African concept of justice, law and human rights. ${ }^{107}$ In this characterisation, Ndima advances the idea that these values held so much significance within this social system, that tenets of indigenous religion and culture seemed to form the source of acceptable human conduct. ${ }^{108}$

Ubuntu is a very specific philosophical concept which is encompassed by the word 'Botho' in my own native tongue of Setswana. However, I will lean on the isizulu expression of the word as it is more descriptive in its formulation and etymological origins. Ubuntu comprises two words, the prefix ' $u b u$ ' and the root ' $n t u$ '. ${ }^{109}$ These two words are inseparable as they jointly designate a oneness as well as an indivisible wholeness. ${ }^{110}$ Ubuntu law as we know it responds to the lived experiences of indigenous African people and necessarily never reaches finality until harmony has been realised. ${ }^{111}$ In keeping with African beliefs, justice is deemed to be immutable irrespective of changing circumstances and as such, cannot be undone by prescription or the passage of time. ${ }^{112}$ Conversely, in pursuit of restoration and transformation, Ubuntu should function as a barometer by which the validity of law and justice must be measured. ${ }^{113}$ More than just an African philosophical ideal, it embodies values which ascribe ethical considerations for the fulfilment of common societal goals.

105 As above.

106 DD Ndima 'Re-imagining and re-interpreting African jurisprudence under the South African Constitution,' unpublished PhD thesis, University of South Africa, 2013.

107 Ndima (n 106 above) 2.

108 As above.

109 Ramose (n 99 above) 2.

110 As above.

111 Ramose (n 99 above) 3.

112 As above.

113 Ramose (n 99 above) 1. 


\subsection{The pursuit for restorative justice}

When the negotiated settlement was reached in the events leading up to the attainment of constitutional democracy, two conditions were being sought: decolonisation as well as democratisation. ${ }^{114}$ Decolonisation had to do with reclaiming the title to land and dominion over that land, ${ }^{115}$ which under normal circumstances would require colonisers to renounce their claim to territory. The inclusion of a property clause in the Constitution (which calls for the expropriation of land subject to the provision of just and equitable compensation $)^{116}$ protected the ownership rights of existing property owners and in so doing compromised the ability of the state to reclaim the title to land. Democratisation on the other hand, was concerned with bestowing entitlements to the once-excluded indigenous African people which they previously did not enjoy. So whilst the advent of a new Constitution might have brought democracy, the question of title to land still remains to this day. Throughout the liberation struggle, the language used by political activists at the time pivoted on the fight for freedom and not on the pursuit of democracy. Previously disadvantaged groups understood the objective to be socio-economic and political emancipation. It is difficult to argue that this has been achieved when black people remain the face of poverty. A contradiction existed between the compromises reached between political representatives and the justice sought by ordinary citizens. ${ }^{117}$ In recent times, there has been public outcry about the framing of language used at the time and how this distorted the meaning of what ordinary people understood to be the common objective. The Sotho proverb molato ga o bole is relevant here as it holds the belief that justice does not and cannot prescribe through the mere passage of time. As a result, the restoration of title to territory is an immutable consequence which must still be attended to even as things stand right now. In light of this deliberate oversight, ${ }^{118}$ democratisation in this context has had little success to restore sovereignty unencumbered to the precise quantum by which it was taken at conquest.

Sibanda conceives constitutionalism and the intention thereof to limit the powers of the state to the confines of a written text. ${ }^{119}$ In his engagement with this discourse, Sibanda concedes that there

114 Ramose (n 99 above) 5.

115 Ramose (n 99 above) 7.

116 Secs 25(1), (2) \& (3) of the Constitution, 1996.

117 Ramose (n 99 above) 7.

118 On the face of it, 'deliberate oversight' could present as a paradox but it is my belief that the parties present at the negotiations of the early 1990s were aware of this need to restore title to territory but acknowledged (consciously or otherwise) that this would be highly contentious among existing property owners and could potentially impede the negotiations for a democratic settlement. 
seems to be very little evidence of scholarly interrogation into the correspondence between constitutionalism and the national project to eradicate poverty. ${ }^{120}$ In excavating the role of constitutionalism to bring about the eradication of poverty, regard must be given to the question whether constitutionalism should even pivot on social transformation. ${ }^{121}$ Sibanda proposes two approaches which are useful in the conception of liberalism, an 'orthodox or liberal democratic approach' and a 'transformative approach. ${ }^{122}$ Proponents of the first approach might accord credence to a peaceful transition of power which derives legitimacy from the existence of 'regular free and fair elections', a 'representative democracy' and an 'independent judiciary' with constitutional powers of review and the upholding of the rule of law. ${ }^{123}$ Proponents of the second approach recognise that even with the 'inclusion of socio-economic rights in the Bill of Rights' and a focus on the improvement of the lives of all South Africans, most black South Africans remain subject to rampant poverty. ${ }^{124}$ Worse still, the effects of apartheid such as income inequality and spatial geography only serve to deepen existing levels of poverty.

\subsection{The 'land question'}

Sibanda is partially correct in his view which recognises that transformative constitutionalism might not be capable (in and of itself) of driving social transformation with any more expediency to cultivate true political and economic agency. ${ }^{125}$ Several limitations are inherently present in the preservation of a liberal democratic tradition which does not cogently translate to the eradication of poverty. ${ }^{126}$ The provision of basic resources such as water, food, housing and education ought to be integral to the project of restorative justice. Although these interventions have already been implemented by the state, significantly more people are dependent on the state for social assistance today than at any other time since the adoption of the Constitution. More is required in the form of political will (or possibly something else) to put into motion an aggressive socialist programme which aims not only to provide basic resources to previously disadvantaged groups, but also imparts vital skills to curtail prolonged dependence on the state.

119 S Sibanda 'Not purpose-made! Transformative constitutionalism, postindependence constitutionalism and the struggle to eradicate poverty' (2011) 22 Stellenbosch Law Review 482.

120 As above.

121 Sibanda (n 121 above) 483.

122 Sibanda (n 121 above) 484.

123 As above.

124 Sibanda (n 121 above) 485.

125 Sibanda (n 121 above) 486.

126 Sibanda (n 121 above) 498. 
In reflection, the enactment of the Promotion of National Unity and Reconciliation $\mathrm{Act}^{127}$ was a clear foray into unearthing the unspeakable wrongs of the past with a focus on restorative justice. However, the framing and wording of this Act (which established the Truth and Reconciliation Commission) places a heavy emphasis on the granting of amnesty to those persons who tender truthfulness for rights violations committed during apartheid. Under the prescripts of indigenous African law, justice and restoration are incompatible with amnesty because the perpetrator loses nothing of their own. The descriptive point here is that even this measly attempt towards restorative justice is of itself a flawed process because perpetrators of racially motivated crimes lose nothing. Evidently, the state does not fully grasp the tenets of restorative justice. To even attempt to address the land question seems unfathomable in this context

The point of departure would be to establish an African conception of property or property rights. The key characteristic of indigenous African law (as derived from the philosophy of Ubuntu) is communal life. Property rights function in much the same way. Individuals only lay exclusive claim to personal use items such as clothes, letters and other items which are not of direct interest to the other members of the group. ${ }^{128}$ However, 'communal ownership [is] applied in respect of major assets such as land, livestock, [and] farming implements ...,129 Items are expressed 'using inclusive language, ${ }^{130}$ therefore, even on a literary level there seems to be a disjuncture between the Roman-Dutch common law and indigenous African law. This perhaps informs the phenomenon of matyotyombe (in isiXhosa) or baipei (in the Sotho languages). The phenomenon of matyotyombe is a manifestation of the failure of political leadership to deliver the unencumbered tenure of land. ${ }^{131}$ Matyotyombe are squatters who are forced to occupy conditions of filth, extreme poverty and human degradation. ${ }^{132}$ Matyotyombe penetrate and affix themselves on vacant land, be it private property or not. ${ }^{133}$ The reason for this might be more obvious when adopting baipei. The Sotho term is more descriptive because it denotes a people who have affixed themselves to a particular place and are not confined to demarcated space. ${ }^{134}$ This unearths the assertion by baipei of their perceived right to the occupation of any vacant land. To prevent a crisis, the state must expedite land reform and scrutinise the current land reform programme. Ndima asserts that African law ought to be

127 Act 34 of 1995.

128 Ndima (n 106 above) 81.

129 As above.

130 Ndima (n 106 above) 82.

131 Ramose (n 99 above) 8.

132 As above.

133 As above.

134 As above. 
implemented 'within its own life-world' and that when 'Western normative standards' are construed upon it, ${ }^{135}$ immense distortion takes place. Unfortunately, the flexibility for which African jurisprudence is known has been lost to the rigidity imbued upon it 'by changing the system's texture and complexion to suit Western standards of justice and morality. ${ }^{136}$ As such, it would be futile to advocate for the recognition of constitutional status equal to that of the Roman-Dutch common law.

\section{Conclusion}

In reflection, transformative constitutionalism is a system of constitutional enactment which is revered for its key feature of transformation, and which places the achievement of equality in social and political institutions at the fore. In re-imagining what a truly equal society could look like, transformative constitutionalism is instructive to foster a culture of reconciliation and substantive reasoning, and to root out a culture of authoritarianism. So where will the South African be in the future? Klare cautions against a tendency of participants in a specified legal culture to 'reach consensus' on a 'narrow range of outcomes' which are constrained in the text of the legal materials before them. ${ }^{137}$ Judges and legal actors should reflect more deliberately on what constitutes persuasive legal argument and should actively pursue their 'interpretive creativity' to promote the 'democratic and egalitarian values enshrined in the Constitution.'138

On the question of a formal versus a substantive vision of law, one can hardly exist to the exclusion of the other. However, insistence on a formal vision of law merely conceals one's 'substantive reasoning and choices. ${ }^{139}$ This circular logic generates a warped sense of reality in which the authority for the existence of a legal rule is derived from the substance of the rule itself. ${ }^{140}$ Klare emphasises that 'no neutral decision procedures exist capable of [...] definitively establishing' what constitutes an objective interpretation of a particular text. ${ }^{141}$ As a result, judges imbue legal materials with 'value-laden meanings' informed by their own political and moral convictions. ${ }^{142}$ By his own account, Klare concedes that a 'progressive legal culture' alone is insufficient to assure the success of the transformative enactment of our Constitution. ${ }^{143}$ In my opinion, employing a politically engaged

135 Ndima (n 106 above) 121.

136 Ndima (n 106 above) 120.

137 Klare (n 4 above) 160.

138 Klare (n 4 above) 171.

139 Froneman (n 33 above) 5.

140 Froneman (n 33 above) 7.

141 Klare (n 4 above) 160.

142 Klare (n 4 above) 163.

143 Klare (n 4 above) 170. 
method of adjudication yields honesty about one's policy choices and promotes transparency. In this regard, it is helpful to leverage interaction with other branches to facilitate dialogue between the judiciary, the legislature and the executive which must collectively uphold the Constitution.

Ndima bemoans the perversion of the 'conception of law that presents Western jurisprudence as synonymous with law.' ${ }^{144}$ Law is not self-generating. In this sense, judges and legal practitioners are therefore complicit in applying Eurocentric legal sensibilities to African legal problems. ${ }^{145}$ What is evident is the need to find the place of Ubuntu in our constitutional discourse once again. If not in the form of justiciable principles, then at least as an interpretive tool to advance 'ethically sound interpretations of difficult [constitutional] clauses' which cannot be solved by 'traditional liberal jurisprudence." 146 Finally, the 'collective unity, group solidarity and conformity' of Ubuntu can be harnessed to 'promote new patriotism' integral to a renewed transformative jurisprudence. ${ }^{147}$

144 Ndima (n 106 above) 103.

145 Ndima (n 106 above) 103.

146 Cornell \& Van Marle (n 29 above) 220.

147 Y Mokgoro 'uBuntu and the Law in South Africa' in Cornell D and Mavangua N (eds) Ubuntu and the law: African ideals and post-apartheid jurisprudence (2012) 318. 


\section{THE EFFECTS OF PUBLIC PARTICIPATION ON ENVIRONMENTAL IMPACT ASSESSMENT}

by Amori Kock*

\section{Introduction}

Every physical development in South Africa requires that significant consideration of any environmental impact must be given long before the development can commence. ${ }^{1}$ Environmental management, and environmental impact assessment (EIA) as one of its tools, is the regulation of any effect that people's actions, products or services may have on the environment. Environmental legislation is encompassed within the National Environmental Management Act 107 of 1998 (NEMA). Environmental law, however, is not a solitary area of law but must be read, and applied, through supreme legislation such as the Constitution ${ }^{2}$ and general legislation like the Promotion of Administrative Justice Act 3 of 2000 or the Spatial Planning and Land Use Management Act 16 of 2013. South Africa, therefore, lacks a single, comprehensive legislative framework for the compliance of environmental management resulting in great uncertainty in spite of various legislative works pertaining to the same issue. Public participation is considered a valuable component of the EIA process and should be encouraged through comprehensive community consultation. However, there seems to be a difference in view between development corporations and interested and affected parties on the value and degree of such participation. ${ }^{3}$

In accordance with section 24 of the Constitution, everyone has the right to an environment which is not harmful to one's health and for it to be protected for present and future generations. Section 32 of NEMA, in line with section 38 of the Constitution, allows for persons to act on behalf of the environment without those representative's rights necessarily being affected. ${ }^{4}$ The natural question arising from this is who can be included in the term 'people'. The Constitution clearly calls for any person who has an interest in the situation, or

* BCom Law (University of Pretoria), Final year LLB Student, University of Pretoria.

$1 \quad$ M Kidd Environmental Law (2011) 1.

2 The Constitution of the Republic of South Africa, 1996 (the Constitution).

3 C O'Faircheallaigh 'Public participation and environmental impact assessment: Purposes, implications, and lessons for public policy making' (2010) 30.1 Environmental Impact Assessment Review 19.

4 W du Plessis \& AA du Plessis 'Striking the sustainability balance in South Africa' in $M$ Faure \& W du Plessis (eds) The balancing of interests in environmental law in Africa (2011) 413. 
anyone bringing the application on behalf of someone who cannot bring such an application, before a competent court or tribunal. ${ }^{5}$ Furthermore, section 34 gives everyone the right of access to the courts in a fair and open trial. However, at present no specialised environmental courts are available to hear such an application pertaining to an environmental matter

Public participation is not only encouraged but also expected in every EIA in terms of NEMA and the Environmental Impact Assessment Regulations. Section 4 of the PAJA, ${ }^{6}$ specifically requires that if any administrative action could affect the legitimate expectations of any person (whether it be materially and/or adversely), such action must be constituted as procedurally fair. Therefore, every person that may possibly be affected by the construction of an environmentally detrimental project, must be notified and be given the opportunity to state their own case. ${ }^{7}$

With this research, I aim to address the practical aspect of legal compliance most major industry companies struggle to obtain. In South Africa, there seems to be an issue relating to legal compliance of environmental authorisations given by the Department of Environmental Affairs and Tourism (DEAT). Companies, specifically those companies which have a significant impact on the nonrenewable resources, are burdened with legal requirements that cannot be met, whether it be unreasonable or practically impossible to obtain. With every project undertaken by these companies an Environmental Management Plan (EMP) must be issued (by the company itself) outlining the expectations and limitations of the proposed project through an Environmental Impact Assessment (EIA) that clearly summarises the intended development and its impact ${ }^{8}$ Should the EMP be accepted by the Regional Manager, a Scoping Report will be provided, by the applicant, clearly outlining the legal requirements and limitations placed on the proposed project. These conditions are mostly vague, as to what is expected or uncertain of how it should be achieved

Companies and individuals, therefore, cannot approach a court (or tribunal) on issues relating to the interpretation of vague requirements as set out in an EMP. The Macsand case clearly highlighted the fact that the interpreter of legislation must consider

5 Sec 38 of the Constitution.

6 The Promotion of Administrative Justice Act 3 of 2000 (PAJA).

7 Sec 4 of PAJA (n 7 above).

8 T Humby 'The Environmental Management Programme: Legislative design, administrative practice and environmental activism' (2013) 130 South African Law Journal 6061. 
legislation as a whole. ${ }^{9}$ Furthermore, the legislation only invites the general public to raise concerns for upcoming events which can possibly jeopardise the environment. However, very few guidelines exist on how to achieve community involvement as factors such as uneducated people or mala fide intentions can adversely affect those companies aiming for a better developed community.

Ultimately this research aims to provide a link or alternative method to bridge the gap between the conflict of interest that arise between the industry's sometimes capital-driven goals and the public's more future orientated disposition.

\section{Contextualisation}

\subsection{Introduction}

Environmental law is based on two very distinct principles: the 'polluter pays'-principle and the precautionary principle. ${ }^{11}$ Both these principles relate to the manner in which environmental management and permitting are undertaken and implemented and should, therefore, be used as the building blocks to discuss any legal environmental issue.

The polluter pays principle was first coined in 1974 and means that the person who is responsible for the polluting, should also be responsible for the cost and prevention of said pollution. ${ }^{12}$ It is an economic principle as it imposes a cost on pollution for the polluter rather than being passed on to the consumer and reflecting in the price of the product. ${ }^{13}$ This principle gave way to a dual aspect view - a preventative and compensatory approach to environmental law. Regrettably, the South African legislation does not comprehensively cover this dual-approach, regardless of its recognition in the international sphere. At the other end of the spectrum, we find the precautionary principle entailing preventative measures against any action that may cause harm to the environment. ${ }^{14}$ The latter encompasses the idea that it will be better to avoid harm than try and remedy it later, resulting in a single approach view. The South African

9 C Botha \& B Bekink 'Macsand v City of Cape Town, Minister for Water Affairs and Environment, MEC for Local Government, Environmental Affairs and Development Planning, Western Cape Province, Minister for Rural Development and Land Reform and Minister for Mineral Resources 20124181 (CC)' 2015 De Jure 456.

10 A du Plessis 'Public participation, good environmental governance and fulfilment of environmental rights' (2008) 2 Potchefstroomse Elektroniese Regsblad 17.

11 Kidd (n 1 above) 7.

12 Kidd (n 1 above) 8.

13 ML Larsson 'The law of environmental damage: Liability and reparation' (1999) 90.

14 Kidd (n 1 above) 9. 
legislature prefers the precautionary principle as evident in section 2(4)(a)(vii) of NEMA. It is, therefore, safe to argue that South African environmental impact legislation is primarily based on the precautionary principle.

Other environmental principles include the responsibility to remediate any past harm to the environment or mitigate any unavoidable harm or viewing the environment from a public trust doctrine. Even though these views have substance, little to no weight has been attached to them in South Africa. ${ }^{15}$ However, in practice it is difficult to denote a singular approach to reduce or halt harmful operations, resulting in the selection and combination of various methods to reduce environmental damage. ${ }^{16}$

\subsection{History of environmental permitting and authorisations in South Africa}

The first EIA, as we know it today, was recognised by the USA in 1970 in its National Environmental Policy Act as a procedure to identify and investigate environmental consequences resulting from development. ${ }^{17}$ South Africa, as previously stated, only implemented similar provisions much later on, after realising its success and necessity in the international sphere. Broadly put there were 3 legislative mechanisms used to enact environmental legislation: the Constitution, NEMA and lastly issue specific legislation such as EIA Regulations. 18

During the environmental law revolution of the 1970's the EIA was debated as a necessary and appropriate tool to achieve environmental conservation. In 1972 the Committee on Environmental Conservation was appointed to advise the cabinet on environmental conservation matters and their corresponding impacts, but these procedures were never implemented. ${ }^{19}$ During this stage, public participation was strictly limited to the distribution of information to a limited number of interest groups and conservation lobby organisations. ${ }^{20}$ South Africa first considered the EIA process in 1977. Practical guidelines that would assist professional planners in effectively taking environmental consequences into consideration were published in

15 Kidd (n 1 above) 11.

16 Larsson (n 14 above) 89.

17 M Sowman, RF Fuggle \& $G$ Preston 'A review of the evolution of environmental evaluation procedures in South Africa' (1995) 15.1 Environmental Impact Assessment Review 46.

18 RF Fuggle \& MA Rabie 'Environmental Management: An Introduction' in HA Strydom \& ND Kings (eds) Environmental Management in South Africa (2011) 193.

19 Sowman et al (n 17 above) 49.

$20 \mathrm{~N}$ Rossouw \& K Wiseman 'Learning from the implementation of environmental public policy instruments after the first ten years of democracy in South Africa' (2004) 22.2 Impact Assessment and Project Appraisal 133. 
1980 but lacked in many areas and were never adopted. A Commission of Inquiry was appointed by the President in 1981 to consider the need for environmental legislation - the Commission's report proposed a bill to promote environmental conservation essentially providing the basis for the Environment Conservation Act 79 of 1989 (hereafter ECA). ${ }^{21}$

With the process of democratisation looming, environmental policy procedure had to also undergo serious changes. ${ }^{22}$ Although the ECA was South Africa's first piece of environmental legislation to coordinate and regulate matters that may be harmful to the environment, it did not contain any EIA elements or procedures. ${ }^{23}$ The international community started to exercise influence over South Africa to introduce EIA as a regulating mechanism for projects likely to have a substantial influence on the environment. In accordance with the ECA, a committee was established in the Council for the Environment namely the Committee for EIA. This committee was tasked to initiate research, workshops and gather all the necessary documentation on different EIA models available to South Africa. ${ }^{24}$ The Committee showed unanimous support for an ElA process in South Africa and developed and published an environmental management process they had coined Integrated Environmental Management (IEM) in 1989. The committee reasoned that the term EIA was too constrictive and narrow to encompass all the elements of the planning and reactive stages and that the process had to be flexible, generally applicable, widely accepted and practical. ${ }^{25}$ The IEM process applied to both the private and public-sector projects and developments and subject to approval by governmental authority. Chapter 5 of NEMA elaborates on the IEM process with section 23(2) providing the purpose of IEM. ${ }^{26}$ The difference between the terms IEM and EIA lies in the fact that IEM can be considered as a complete philosophy of the balance between the environment and development whereas EIA is merely a tool to accomplish the IEM philosophy. ${ }^{27}$ For purposes of this research, we will discuss the EIA specifically as a way to obtain IEM.

EIA, as we implement it today, was first published in terms of the 1989 ECA but has since gone through three very extensive revisions in 2006, 2010 and very recently in 2017 under NEMA. NEMA grew out of an environmental policy development process known as the Consultative National Environmental Policy Process that actively incorporates public participation and commenced on 29 January

Sowman et al (n 18 above) 49.

Rossouw et al (n 21 above) 133

Sowman et al (n 18 above) 49.

Sowman et al (n 18 above) 50

Sowman et al (n 18 above) 51

Fuggle \& Rabie (n 19 above) 204.

Enviropaedia 'Integrated Environmental Management' http://www.enviropaedia. com/topic/default.php?topic_id=141 (accessed 27 March 2013). 
1999. ${ }^{28}$ NEMA has been amended seven times since its commencement, two of which specifically concern the EIA framework. Both of these amendments were undertaken to broaden EIA principles and simplify the EIA process.

\subsection{Specific matters relating to the EIA process}

According to section 23(1) of NEMA, IEM systems identify and evaluate the actual and potential impacts that activities pose on the environment to assess the risks, consequences, and alternatives. It aims to mitigate these negative impacts and maximise any potential benefits. ${ }^{29}$ As a way to obtain and sustain integrated environmental governance, NEMA has implemented a legislative framework for the EIA process in section 24. This provision was later amended to extend certain matters in the 2006 EIA Regulations publication. ${ }^{30}$

The process of IEM, and more specifically EIA, can be broadly described in three stages. The first stage refers to the development and initial assessment of the proposed development. ${ }^{31}$ It is during this stage that all interested or affected parties (whether it be public or private) must be notified of the proposal together with the consideration of any and all mitigation measures. The proposal must set out the possibility of any significant impact that the project may pose to the environment. Should the authorities feel that the proposal is too vague and/or uncertain, it can be sent back to the developers for further investigation. ${ }^{32}$ The developer should also include a scoping report which will indicate the procedures and requirements for the impact assessment as well as other reasonable alternatives. The second stage deals with the authorities' decision to approve the proposal should it comply with the planning requirements. This stage created a special role for local government within environmental management requiring environmental sustainability issues to be integrated into municipal planning. ${ }^{33}$ Should the authorities, consisting of the municipal planners of the DEAT, approve the proposal, an environmental checklist must be compiled that indicates any conditions or constraints on the proposed development. The checklist will comprise of the identified environmental factors that may possibly be affected. ${ }^{34}$ The third and final stage of the IEM process concerns the implementation of the proposed development subject to the conditions of the environmental contract. Periodic

Kidd (n 1 above) 36.

Fuggle \& Rabie (n 19 above) 204.

As above.

Sowman et al (n 18 above) 55.

Sowman et al (n 18 above) 56 \& 59.

Rossouw et al (n 21 above) 137.

Sowman et al (n 18 above) 61. 
audits of the effects must be undertaken by the authorities to determine the compliance with the conditions of approval. ${ }^{35}$

The EIA process in South Africa is based on the sustainable development principle. This principle was confirmed in the $B P$ Southern Africa (Pty) Ltd $\vee$ MEC for Agriculture, Conservation and Land Affairs case, where J Claasen stated that sustainable development is the fundamental building block of environmental legal norms and that it should be regarded with the same seriousness as any pure economic principle. ${ }^{36}$ The principle is also encompassed in section 2(b)(iii) of our Constitution, making it a fundamental human right under Chapter 2 of the Bill of Rights. When any statutory provision is under scrutiny, by any organ of state which may exercise said function, the sustainability principle will be crucial with regard to economic and social development. ${ }^{37}$

\subsection{Conclusion}

Even though the EIA process, under the umbrella term IEM, has changed over the years, the fundamental principle of sustainable development that requires accountability, forms the basis of environmental legal compliance bringing us back to base with the "polluter-pays" and precautionary principles.

From the brief discussion on NEMA, and its provisions relating specifically to EIA, it is clear that NEMA is addressing the weaknesses of the past. It establishes a strategic approach to environmental governance and co-ordinates the functions of government and other key players. Furthermore, NEMA is systematically moving away from the classic command and control system on an ad-hoc basis. ${ }^{38}$ Although there are a lot more mechanisms to control enforcement and compliance than before, the South African legislative framework is still lacking in certain areas with the most prominent one being the effective application thereof. ${ }^{39}$ The current EIA practice in South Africa does not need any exhaustive legislative adjustments but must rather be better aligned under NEMA through a three level approach. The first approach is the improvement of current control mechanisms, the second approach calls for minor adjustments and the third for a complete replacement. ${ }^{40}$ This would result in only certain provisions being completely repealed with the focus on mildly adjusting the majority of provisions for a better holistic approach. The need for any

Sowman et al (n 18 above) 62.

(2004) ZAGPHC (18) 144.

Kidd ( 1 above) $36 \& 39$.

Fuggle \& Rabie (n 19 above) 221.

A Morrison-Saunders \& $F$ Retief 'Walking the sustainability assessment talk Progressing the practice of environmental impact assessment (EIA)' (2012) 36 Environmental Impact Assessment Review 12.

40 Morrison-Saunders et al (n 40 above) 12. 
further alignment must be viewed with a democratic approach - for the people and by the people. This is incorporated in the idea of public participation.

Public participation is a big role player in the EIA process. O'Faircheallaigh defines public participation as any form of interaction between a branch of government, corporate actors and the public. ${ }^{41}$ It is therefore an empowering mechanism for individual communities to allow communal aspirations or priorities to be taken into account in major decisions. ${ }^{42}$ Public participation in EIA assists in redistributing power from sole-government control to the general public. Participation in environmental decision making proves to be an effective tool to environmental legal compliance and effective solutions to environmental challenges. ${ }^{43}$ Public participation will be the deciding and key factors when the legislature considers any further amendments or addendums to our current EIA process and environmental legislative framework and therefore must be discussed in greater detail.

\section{Public participation}

\subsection{Introduction}

Any administrative action that is undertaken, must be lawful, reasonable and procedurally fair in terms of section 33 of the Constitution. Furthermore, should anyone's rights be adversely affected by said administrative action, those affected must receive written reasons for proposed action. ${ }^{44}$ This right has been enacted and broadened, by the legislature, with PAJA to provide for the review of administrative action by a court or independent and impartial forum. ${ }^{45}$ This entire process, wherein the potentially affected can convene with the prospective project team, takes shape in the form of public participation. The weight of public participation has been extended to be included within the scope of NEMA as it can be used as a tool to prevent environmental injustice. ${ }^{46}$ Since the effectiveness of environmental law depends, mostly, on administrative action which is lawful, reasonable and procedurally fair, it is of cardinal importance to examine and fully comprehend this right.

During the apartheid years in South Africa, policy formulation, together with any administrative action, was highly centralised,

41 O'Faircheallaigh (n 3 above) 20.

42 O'Faircheallaigh (n 3 above) 20.

43 Du Plessis (n 11 above) 10.

44 Kidd ( 1 above) 27.

45 Kidd (n 1 above) 27.

46 Secs 2(4)(b) - (o) of PAJA (n 7 above). 
secretive and dominated by the state and legislature. The entire apartheid era was designed to exclude the majority of people from public participation and therefore also keeping them from participating in decisions ultimately affecting their lives. ${ }^{47}$ It was this dark phase in our history that necessitated the need for the development of administrative, legal and social structures, including improved access to state-controlled information and the provision of reasons for any decision taken. Under our new democratic regime, it is deemed unethical and undemocratic to not involve the public and those who may experience the relevant environmental and social impacts. ${ }^{48}$ This fundamental shift, with particular reference to public participation in the EIA process, hopes to achieve a more equitable distribution of political power and by doing so, improving the quality of the decision-making process. ${ }^{49}$

According to Wilkinson, there are three general functional categories of public participation: education or informative, review or reaction and interactive or dialogue. ${ }^{50}$ Each one the abovementioned functions can be viewed as an integral part of the decision-making process and therefore cannot be applied in a singular manner. ${ }^{51}$ All three of the functions must be applied flexibly in terms of the degree of participation involved and in terms of the situation at hand. ${ }^{52}$ However, even though South Africa has an extensive environmental legislative framework in place for public participation, there has been little to no provision made for the socio-economic challenges we face on an everyday basis. ${ }^{53}$ The environmental law incorporates certain general and specific principles of administrative law as environmental issues are addressed in the principles of administrative law. Administrative law should therefore also be discussed in the light of the socio-economic challenges we face with regards to environmental and social responsibility.

\subsection{Administrative action}

Section 33 of the Constitution, together with Chapter 10 of the Bill of Rights, provides the basis for the protection and promotion of administrative action, including the field of environmental law. This section calls for administrative action which is lawful, reasonable and procedurally fair and for the provision of sound reasons for any administrative action taken. The realisation of the right to just

51 P Wilkinson 'Public participation in environmental management: A case study' Natural Resources Journal 16 (1976) 117.

52 Wilkinson (n 52 above) 119.

53 A du Plessis (n 11 above) 20. 
administrative action is based on the contingency of two other rights: the right to information and the right to access of courts, tribunals or forum. ${ }^{54}$ Lastly, the Constitution also specifically realises the right to an environment which is not harmful to one's health or well-being while protecting the environment for the benefit of present and future generations. ${ }^{55}$ The bare fact that the legislature does not only encompass environmental rights multiple times in the Bill of Rights, the most protected piece of legislative work in South Africa, but also goes further to specifically include the application thereof under administrative action, emphasises the fact that environmental conservation and preservation is deemed to be a fundamentally important aspect in South Africa. Therefore, the application of section 24 is strengthened by section 33, guaranteeing that all environmental decisions must be undertaken in a lawful, reasonable and procedurally fair manner. However, these fundamental rights might be deemed worthless if there is no guarantee of formal participation by the right holders in the implementation. ${ }^{56}$

The ambit of administrative power is determined by either the empowering statute or provision. The PAJA is empowered under section 33 of the Constitution and applies to all actions of administrators and particularly that of an environmental administrator. The Act lays down certain general requirements as well as certain specific requirements such as procedural fairness and the providing of reasons for any decision that may adversely affect another's rights. ${ }^{57}$ In the environmental sphere, it can be concluded that any action by an environmental administrator to implement or execute policy, will be regarded as administrative action even if just a simple decision is taken. ${ }^{58}$ PAJA clearly outlined the requirements for lawful administrative action, procedural fairness, and reasonableness in section 6. All three of the abovementioned requirements are of vital importance, but for the purposes of this research, focus shall be directed upon procedural fairness to fully comprehend the notion of public participation.

PAJA distinguishes between administrative action that affects any one singular person (section 3 ) and administrative action that affects the public (section 4). In the rare instance that an environmental decision only adversely affects one individual, the injured party must be able to prove that his or her right or a legitimate expectation was materially and adversely affected. ${ }^{59}$ The second and generally more occurring scenario if that of administrative action that has a general 
impact on the public, this usually occurs with the enactment of proposed environmental legislation or action. ${ }^{60}$ Should a section 4 scenario be present, an administrator must hold a public inquiry following a notice-and-comment procedure or a combination of the above. ${ }^{61}$ This public inquiry encompasses the idea of public participation. Public participation is therefore, a crucial element in the fulfilment of environmental rights and essentially guaranteeing fundamental rights and good environmental governance.

\subsection{Public participation - the what, why and when}

Broadly put, public participation can be reduced to the communication of concerns on public issues by those concerned and/ or affected. However, if properly defined it can be viewed as the real involvement of all social actors in social and political decision-making processes that will potentially affect the communities in which they live and work. 62

Public participation is the involvement of individuals, who will be either positively or negatively affected by a proposed project, programme, plan or policy where they can significantly influence the decision-making process. ${ }^{63}$ Public participation has been used as a term for citizen power - a process that empowers the formerly marginalised groups by redistributing executive power. It is also a form of participatory democracy based on the constitutional values of equality, dignity, and freedom. Public participation can be found at different levels of society and in many forms. Public participation can be applied in a formal manner with public inquiries, commissions, and notices or can be effected in a more informal manner involving protest marches, media campaigns, and petitions. ${ }^{64}$ It is this process that ensures that big corporations have a vast collection of information at their disposal that they would not usually have encountered, as well as providing the decision makers with the information on actual costs and benefits the proposed project will yield. Public participation can assist with problem solving by suggesting ideas, concepts, solutions and resources and the calculation of the political consequences. ${ }^{65}$ However, developers do not usually favour public participation, regardless of the many advantages, as it may risk the completion of a high-profile project as

60 Kidd (n 1 above) 231.

61 Sec 4 of PAJA (n 7 above).

62 A du Plessis (n 11 above) 4.

63 A Glucker, PPJ Driessen, A Kolhoff \& Runhaar H.A.C et al 'Public participation in environmental impact assessment: why, who and how?' Environmental Impact Assessment Review 43 (2013) 105 (Glucker et al).

64 Glucker et al (n 64 above) 105.

65 O'Faircheallaigh (n 3 above) 21. 
well as being costly and time consuming. ${ }^{66}$ Public participation has been used as a systemic attempt to delay and block development and in extreme cases even completely stop the projects. ${ }^{67}$

Public participation has been linked to various statutory frameworks in South Africa including (but not restricted to) the PAJA, NEMA and the Promotion of Access to Information Act 2 of 2002 (PAIA). ${ }^{68}$ All of the abovementioned legislative frameworks aim to improve the quality and extent of the information that should be made available to those who want to exercise protection over their fundamental rights. ${ }^{69}$ However, there is still disagreement among scholars, legal practitioners of big corporations and the legislature on the extent of information supplied to 'the public' and the weight that these opinions must carry. The wider the spectrum of people and groups that are allowed to participate will not only bear a paramount risk to the developer but will eventually frustrate the participants resulting in a decrease in willingness to participate in the EIA process. $^{70}$

\subsection{Public participation in the EIA process}

Public participation, for the extent of this article, is a framework of regulatory requirements that a development company must comply with in order to obtain a permit for a proposed project in the energy, mining or natural resource sector. ${ }^{71}$ The requirements must be imposed by general legislation or more specific environmental protection legislation to allow the public to make written or oral submissions to the regulatory body. In South Africa, EIA is the framework for this process that must be taken into account when the regulatory body either makes the decision or a recommendation to the Minister of Environmental Affairs. ${ }^{72}$

Most scholars agree that public participation holds the key to effective environmental assessment, by improving the quality of the decisions taken, but disagree on the meaning and extent of the process. ${ }^{73}$ Furthermore, academics also seem to be divided on the objective that public participation pursues behind the backdrop of the EIA process.

67 Glasson et al (n 67 above) 154.

68 Act 2 of 2000.

69 Sec 32 of the Constitution (n 2 above).

70 Glucker et al (n 64 above) 109.

71 B Barton 'Underlying concepts and theoretical issues in public participation in resources development' (2002) Human rights in natural resource development: Public participation in the sustainable development of mining and energy resources 78 .

72 Barton (n 72 above) 78.

73 Glucker et al (n 64 above) 104. 
Public participation in the EIA framework and its importance have been formally recognised by both legislation and international law. During the 1992 Rio Conference on Environment and Development, the United Nations acknowledged that environmental issues are best handled when all concerned citizens, on every level, are actively involved in any process affecting the natural environment. The 1998 Convention on Access to Information, Public Participation in Decision Making and Access to Justice in Environmental Matters, was the first framework to set out the minimum requirement for public participation, resulting in the signatory states adopting measures to implement public participation. South Africa adopted NEMA together with the 2014 Environmental Impact Assessment Regulations framework to address the matter of the EIA and specifically its relationship with the public participation process in Chapter $6 .^{74}$

In terms of the EIA Regulations of 2017, the developer must submit the basic assessment report, including the preliminary EIA, to all the registered, interested and affected parties at least 30 days prior to the initiation of the proposed project. ${ }^{75}$ Furthermore, the developer must provide access to all information that reasonably or may possibly influence the decision to the competent authority and relevant, registered and affected parties. ${ }^{76}$ The statute clearly set out the process that must be followed, by the developer, in section 41 of the EIA Regulations including the placing of a public notice and giving written notice to the jurisdictional municipality and those who will, possibly, be affected the most. ${ }^{77}$ The legislature went further to include alternative methods of public participation to include the disadvantaged or illiterate.

It seems as if the legislature has, extensively, tried to accommodate everyone who might want to participate in this process either for protection of a personal right or as a locus standi party in terms of section 38 of the Constitution in pursuance of the objectives of public participation. The objects of public participation have derived from both normative and substantive ideas and principles, including the development of citizenship skills and social learning to the enhancement of the quality of decisions made. ${ }^{78}$ However, the real value of public participation should be explored: government uses public participation as a valuable role in filling information gaps to render information contestable while the industry suffers under the heavy legal constraints; the developer gains valuable information but

74 Amendment to the Environmental Impact Assessment Regulations 326 of 2017 published under Government Notice No. 982, Gazette No 3822 (EIA Regulations 2017).

75 Sec 40(1) of ElA Regulations 2017 (n 75 above).

76 Sec 40(2) of EIA Regulations 2017 (n 75 above).

77 Sec 41 of EIA Regulations 2017 (n 75 above).

78 Glucker et al (n 64 above) 107. 
the public is burdened by an intimidating and time consuming process. $^{79}$

Participation definitely yields an educative function by enabling citizens to develop a comprehensive understanding of the government system and providing insights into the interests of fellow citizens. ${ }^{80}$ This is a very important quality as it empowers community members to exercise control over their own environment and future development at every stage possible. However, in practice, the powerless are the least likely to participate in the EIA process due to its daunting and intimidating nature. ${ }^{81}$

\subsection{Conclusion}

From the above stated arguments, it is clear that South Africa already has a clear statutory framework in place to regulate EIA processes and procedures in various statutes and regulations. However, it seems that the current situation leans more towards the effective and real value that these processes could yield to both the regulator and the regulated. Most researchers agree that public participation enhances the decision-making process by identifying, anticipating, recognising and avoiding of potential impacts ${ }^{82}$ and risks that would otherwise not have been identified. ${ }^{83}$

Regard must also be given to the substantive value the public's involvement must carry; many scholars believe that the general public is not qualified enough to provide a meaningful contribution to the planning stage of a complex development. In the Netherlands, the developer must provide a non-technical summary to the public and other decisions makers during the public participation process. South Africa, however, still seems to be lacking this statutory provision in the various and comprehensive EIA Regulations. ${ }^{84}$ It seems as if public participation will remain a weak and, sometimes, neglected aspect of the EIA process until both the developer and the legislature see that the benefit of public participation can exceed the cost thereof. ${ }^{85}$ Public participation will only become an invaluable commodity to the community if it seeks to conform to the public's needs and realistic abilities. Even though legislation like the PAJA, PAIA and EIA Regulations aim to involve an affected community, the involvement will only yield the results and outcomes they are reasonably capable

79 O'Faircheallaigh (n 3 above) 25.

80 O'Faircheallaigh (n 3 above) 22.

81 O'Faircheallaigh (n 3 above) 23.

82 EIA Regulations 2017 (n 75 above).

83 DF Luca \& $\mathrm{K}$ Wallace-Jones 'The effectiveness of provisions and quality of practices concerning public participation in EIA in Italy' (2000) 20.4 Environmental Impact Assessment Review 5. 
of. This will remain a problem in South Africa until such a time that socio-economic problems are sufficiently addressed and the real consequences of public participation are effectively considered whether it be through the process of EIA or a more socially orientated approach.

\section{$4 \quad$ Recommendations}

\subsection{Introduction}

The EIA system has been implemented in South Africa during the last two decades and has gone through many phases and changes even though one communal goal has remained: sustainability. The EIA process is not a scientific method where scientific facts and knowledge must be applied to solve a problem, but it is a platform where people with different interests can come together and approach a situation in an evaluative manner. ${ }^{86}$ The EIA process is in its very nature dependent on political will and change and is therefore deeply dependent on the conscious involvement of effective public participation to achieve fair and sustainable development. ${ }^{87}$

Public participation is, however, to a large extent, considered to be an advantage rather than a deterrent. It is a mechanism to ensure that all relevant issues, those reasonably foreseeable by the developer and even those whose likeliness was not anticipated, are duly considered before the development may commence. ${ }^{88}$ It can also be viewed as a method to acquire more innovative, viable and publicly accepted ideas and solutions. Alternative methods and solutions that were identified are also easier to incorporate during this phase of development and usually at a fraction of the cost. ${ }^{89}$ It seems as though the effectiveness of EIA and public participation, as with beauty, lies within the eyes of the beholder.

\subsection{Effectiveness of current system}

The EIA process gives effect to rights contained in the Constitution, NEMA, PAJA, and PAIA. Each of these rights is accompanied by factors that can be considered positive or detrimental depending on the view taken. The EIA process and NEMA has an effect on all three spheres of

$86 \mathrm{~N}$ Craik 'The international law of environmental impact assessment: process, substance and integration' 196 Cambridge: Cambridge University Press (2008) 178.

87 C Vasconcelos, A Hamilton \& P Barrett 'Public participation in EIA: A study from a Portuguese perspective’ (2000) 2.04 Journal of Environmental Assessment Policy and Management 562.

88 Glasson et al (n 67 above) 155.

89 Glasson et al (n 67 above) 156. 
government: legislative, executive and judicial and should, therefore, be approached with care as any consequence may have a ripple effect on either the EIA process or environmental law as a whole. The major factors that influence the effectiveness of the EIA system include the public participation process and the identification of those who should be involved. ${ }^{90}$

There seems to be uncertainty among academics on who should be involved in the public participation process as there is no fixed definition and terms such as 'public', 'stakeholders' and 'citizens' are used interchangeably when this matter is addressed. ${ }^{91}$ The only consensus is that it definitely includes any person, group or organisation that will be affected by the development in an either beneficial or harmful manner. This consensus, though narrower than the general inclusion, only aims to exclude those who will not be able to constructively contribute to the process. ${ }^{92}$ This notion makes perfect sense as the involvement of such individuals will be inefficient and result in wasted time and money; however, in ElA practice, anyone who has interest in a given project is invited to participate. Even though this practice is democratic and reasonable in its nature, it will lead to many expectations not realised or met. ${ }^{93}$

Another constraint the legislature has on an effective public participation system is that of the amount and extent of information that has to be made available to the participants in the process. In terms of PAIA, the developer must disclose any and all information that may be an imminent and serious environmental risk to the participants as they have a constitutional right to the relevant information. ${ }^{94}$ This sometimes creates difficulties to both the developer and the public. The information supplied by the developer usually consists of technical concepts and complex data that requires more than even basic literacy skills that must be analysed and judged by a, sometimes even illiterate, laymen. ${ }^{95}$ The developer, through the supply of this information, also immediately incriminates itself as sensitive information, by way of the PAIA, can subject the company to an environmental audit. Companies do not enjoy the same constitutional protection of self-incrimination as natural persons do making them susceptible to a criminal conviction. ${ }^{96}$

It is therefore clear that the EIA process in South Africa is implemented with a rigid regulatory framework but the practice

92 As above.

93 As above.

94 Fuggle \& Rabie (n 19 above) 215.

95 Vasconcelos et al (n 88 above) 573.

96 Hayes \& Tshabalala, SA Media for the University of the Free State Business Day 'Conflict over environmental information' (13 October 2003) 6. 
thereof needs attention and thought. If South Africa can combine its quick processing time, to deliver an EIA authorisation, with efficient and effective public participation, it will improve community involvement and eventually stimulate economic development.

\subsection{Possibility of alternatives and environmental courts}

The possibility to move away from an EIA system does not constitute a practical solution in the slightest. Participation in EIA is considered vital in environmental management and is required for international recognition. South Africa must therefore not consider alternatives to the EIA system and its components, but rather consider ways to enhance the potential it may yield. As extensively discussed in part 4, the South African environmental system is in need of practical directives to complement the comprehensive legislative framework and make the entire process as efficient and comfortable as possible. Currently, the general courts are burdened with complex environmental prosecutions and intricate EIA interpretations for which they are neither trained nor experienced in, resulting in cases being decided on facts proved beyond any doubt rather than reasonable doubt. ${ }^{97}$

The South African judiciary has frequently been called upon to apply, interpret and pronounce the validity of environmental statutory provisions. These applications are heard by a local court as no explicit constitutional provision has been made for environmental courts. ${ }^{98}$ The past 20 years saw two specialised environmental courts, situated in Hermanus and Port Elizabeth respectively, being shut down due to an unwillingness from the Department of Justice and Constitutional Development despite its success. ${ }^{99}$ As of May 2017, no reconsideration has been done to reinvoke these specialised courts or a similar forum or tribunal as envisaged in the Constitution.

It is my respected view that for the EIA process to be as efficient as theoretically possible, the improvements have to start prior to the implementation of public participation. If greater emphasis is placed on the reasoning and method of the scoping process, both the developer and decision maker will be more open to an extensive public participation process. An enhanced public participatory process will yield a more valuable outcome for the developers and encourage members of the general public to become involved in their own communities. This pure and ideal, yet extremely limited recommendation, craves empirical research that cannot be obtained in a worthy manner at an undergraduate level. 


\subsection{Social impact assessment}

Public participation essentially provides a framework for community empowerment by addressing socio-economic problems through consideration of a Social Impact Assessment. ${ }^{100}$ However, South African communities do not harness a belief in public participation making it inherently more difficult to promote meaningful participation, especially in disadvantaged communities. Social impacts are not treated as a priority issue in the EIA process as socioeconomic factors are not taken into consideration when assessing public participation. Many community members targeted for public participation are not properly educated about their rights contained in either NEMA or the Constitution or struggle to grapple the basic concepts of the proposed activities. ${ }^{101}$

Social impacts are those impacts stemming from the everyday way in which people and communities work, live and interrelate to one another to meet the needs of a society. ${ }^{102}$ A Social Impact Assessment (SIA) refers to the process to assess the potential social consequences that are likely to follow from the proposed action whether it be intended, unintended, positive or negative. ${ }^{103} \mathrm{SIA}$ can be used to assess the costs and benefits of the activity and how and when they will likely be distributed among the different stakeholders over the course of the development. SIA, therefore, is a complementary process as it incorporates all key shareholders and not just those who will be involved in the public participation process making it a more democratic and transparent system. ${ }^{104}$ In South Africa, as with other developing countries, the SIA process is considered to be incorporated within the EIA regulatory framework and aim to alleviate socioeconomic problems, yet is also lost in the balance in obtaining the global goal of EIA. ${ }^{105}$

A possibility to consider can be the complementary process of SIA to assess the costs and benefits of the activity and how and when they will likely be distributed among the different stakeholders over the course of the development. In South Africa, as with other developing countries, the SIA process is considered to be incorporated within the EIA regulatory framework and aim to alleviate socio-economic problems yet is also lost in the balance in obtaining the global goal of

100 JA Du Pisani \& LA Sandham. 'Assessing the performance of SIA in the EIA context: A case study of South Africa' (2006) 26.8 Environmental Impact Assessment Review 718.

101 As above.

102 As above.

103 As above.

104 Du Pisani et al (n 101 above) 708.

105 Du Pisani et al (n 101 above) 711. 
EIA and therefore not recognised or valued for the collective value it can represent. ${ }^{106}$

\subsection{Conclusion}

EIA has been part of the South African legislative framework since 1997 and has been extensively revised on at least 3 occasions (2006, 2010 and very recently in 2017) in its pursuance of sustainability. However, the mere inclusion of the sustainability principles in our legislation has not yet ensured success in practice leaving an undesirable gap implementation gap. ${ }^{107}$ South Africa does not require any additional or extensive legislative amendments to ensure greater compliance with NEMA or EIA Regulations but rather a more practical and hands-on approach by the EIA practitioners already on hand. If our EIA practitioners were to change their regular EIA process by actively searching and acquiring sustainability, the passion will spread to other peers, colleagues, and communities ${ }^{108}$. The real value of EIA and public participation needs to be re-established among the developers and the executive body to actively better the process.

Due consideration must also be given to the social impacts that the EIA process yields by empowering disadvantaged communities and strengthening democratic processes. Furthermore, South Africa needs to find a proper balance between the participatory processes and decision-making responsibility if we are to obtain social justice, democracy, and sustainable development. ${ }^{109}$ If public participation were to be conducted in a very prudent an conscientious manner it will add value to the EIA process by enhancing environmental awareness and strengthening active citizenship resulting in a society that is concerned with the sustainability of their environment and that of the future generations. ${ }^{110}$

\section{$5 \quad$ Final thoughts and conclusion}

Even though the EIA process has changed over the years, the fundamental principle of sustainable development that requires accountability forms the basis of environmental legal compliance.

The current EIA practice in South Africa does not need any exhaustive legislative adjustments but must rather be better aligned under NEMA with a democratic approach - for the people and by the

106 Du Pisani et al (n 101 above) 708 \& 711.

107 A Morrison-Saunders \& F Retief 'Walking the sustainability assessment talk Progressing the practice of environmental impact assessment (EIA)' (2012) 36 Environmental Impact Assessment Review 12 (Morrison-Saunders et al.).

108 Morrison-Saunders et al (n 108 above) 13.

109 Du Pisani et al (n 101 above) 720.

110 Vasconcelos et al (n 88 above) 578. 
people. ${ }^{111}$ South Africa seems to lack appreciation for the need of various and comprehensive EIA Regulations to address socio-economic problems. It seems as if public participation will remain a weak and, sometimes, neglected aspect of the EIA process until it is clear to everyone involved that the benefit of public participation can exceed the cost thereof. Public participation will only become an invaluable commodity to the community if it seeks to conform to the public's needs and realistic abilities.

One of the major areas of law that will require further research and planning is public participation. Public participation in EIA assists in redistributing power from sole-government control to the general public. Participation in environmental decision making is an effective tool to environmental legal compliance and effective solutions to environmental challenges by identifying key stakeholders and even negotiation parties. It enhances the decision-making process by identifying, anticipating, recognising and avoiding of potential impacts and risks that would otherwise not have been identified solely by the developer. ${ }^{113}$ Moreover, it has proved to assist developers to think and react in new ways by offering innovative suggestions and concepts that are usually forthcoming from a new and fresh perspective. 


\title{
A COMPARATIVE ANALYSIS OF THE UNCITRAL MODEL LAW ON CROSS-BORDER INSOLVENCY AND EU INSOLVENCY REGULATION 2017, AGAINST THE BACKGROUND OF VARIOUS SOURCES OF CROSS- BORDER INSOLVENCY LAW
}

\author{
by Primrose E.R. Kurasha*
}

\section{Introduction}

In this investigation, I will compare and contrast the UNCITRAL model law on cross-border insolvency law (hereafter referred to as 'UNCITRAL model law') with the EU Insolvency Regulation against the backdrop of various sources or dispensations of cross-border insolvency law. In this comparison, I will highlight the similarities and differences between the two, as well as discuss the other sources in depth, as they largely inform my research. My main aim in including the other sources in this comparative study is to provide deeper insight into these two sources of international cross-border insolvency law, as provided for by academics and sages in the field of insolvency law. These other sources include legislation, common law, treaties and regional dispensations.

\section{Comparative analysis}

\subsection{Definitions}

The term 'insolvency' is not defined in the South African Insolvency Act of 1936 (hereafter referred to as 'the Insolvency Act'). The terms 'insolvent' and 'insolvent estate' are, however, defined as nouns. In terms of section 2 of the Insolvency Act, an 'insolvent' refers to a debtor whose estate is under sequestration, including such a debtor before the sequestration of his estate according to the context. An 'insolvent estate' is simply defined as an estate under sequestration. ${ }^{1}$ Insolvency is ultimately succinctly defined in American case law as 'the condition of a person who is unable to pay his debts as they fall due, or in the usual course of trade and business." 2 Summarily,

\footnotetext{
* BA (Law), LLB, LLM (University of Pretoria) LLM in International Trade and Investment Law in Africa (University of Pretoria).

1 Section 2 of the Insolvency Act 24 of 1936.

2 Dewey $v$ St Albans Trust Co, 56 Vt. 475. 48 Am. Rep. 803.
} 
insolvency law is therefore the law regulating the sequestration of an insolvent debtor. Cross-border insolvency law can be defined as the rules and regulations that administer the treatment of financially distressed debtors if such debtors have assets or creditors in more than one country. ${ }^{3}$ In other words, the nexus between insolvency and cross-border insolvency lies in the fact that in both scenarios there is an insolvent. However, in the case of (domestic) insolvency law, the treatment or sequestration of the insolvent's estate is managed by the relevant local insolvency laws, while in the case where the insolvent owns assets internationally, sequestration of his or her estate will be regulated by laws on cross-border insolvency which are specific to each jurisdiction. Nonetheless, these domestic (or jurisdiction-specific) insolvency laws may indeed be similar to the local laws, as various countries have adopted the UNCITRAL model law into their domestic insolvency legal regime, while the $28 \mathrm{EU}$ member countries have adopted the EU Insolvency Regulation.

In terms of terminology, it is also worth noting that the sequestration of an insolvent's estate can interchangeably mean the liquidation of an insolvent or a bankrupt company.

The UNCITRAL model law is defined as the model law on CrossBorder Insolvency of the United Nations Commission on International Trade Law. It is set out in the Annexure to the United Nations General Assembly Resolution. ${ }^{4}$ The UNCITRAL Model Law does not define 'insolvency', nor does the Insolvency Act. However, the two instruments are similar in their purpose, namely to provide a law that is used to administer the sequestration of an insolvent's estate. The UNCITRAL Model law takes it a notch higher by prescribing a template that is suggested to be used as the common law by the courts of various jurisdictions to administer the sequestration of an insolvent's estate, with automatic recognition of a foreign trustee by a foreign court.

\subsection{Sources}

In principle, the sources of cross-border insolvency law are comprised of legislation, treaties, model laws (such as the UNCITRAL model law), case law, academic opinions, regulations (such as the EU Insolvency Regulation of 2017) and regional dispensations.

It should be noted, however, that the EU Insolvency Regulation of 2000 was amended by the EU Insolvency Regulation of 2017, which came into force on 26 June 2017. As such, in this discussion I shall focus on the EU Insolvency Regulation of 2017.

3 I Fletcher Insolvency in private international law (2005) 3.

4 Model Law on Cross-Border Insolvency of the United Nations Commission on International Trade Law A/RES/52/158 (1997). 


\subsection{Cross-border insolvency law: Motivation and jurisprudence}

As a point of departure, it is necessary to explain the rationale behind the need for cross-border insolvency law.

Cross-border insolvency law was necessitated by the conflict of laws and private international law systems existent in different jurisdictions worldwide. When an insolvent debtor faces claims from many creditors and owns property in various nations, it was (and is still) necessary that the insolvency order by the court of the debtor's so-called 'Centre of Main Interest' (COMI) be made enforceable in these other countries. Cross-border insolvency law is meant to mitigate such conflicts through sources such as the UNCITRAL model law and the EU Insolvency Regulation. These instruments seek to achieve the automatic recognition of foreign estate representatives in different jurisdictions, the inherent enforceability of the insolvency order and the co-operation of the various courts in liquidating the estate of the insolvent debtor and paying his creditors. The foreign estate representative will place an outward bound request before the court of the foreign jurisdiction in order to be recognised and enforce the insolvency order made by the court of the insolvent debtor's COMI.

Moreover, cross-border insolvency law was created to equate the 'playing and claiming field' of foreign and domestic creditors. In his article 'Legal Treatment of Foreign and Domestic Creditors', Nadelmann highlights the challenges faced by creditors in their participation in insolvency claims against insolvent debtors. ${ }^{5}$ The problems he articulates include discriminatory rules in treatment between foreign and domestic creditors, a lack of notification that enables creditors' compliance with procedural requirements, the 'race of diligence', obliging creditors to pursue the execution of judgments and the attachment of claims hurriedly in order to prevent competing interests from acquiring priority. ${ }^{6}$

The rationale behind the publication of the UNCITRAL model law as a source of insolvency law is that if United Nations member states adopt the UNCITRAL model law, then at least amongst those nations, there will be some level of knowledge and predictability in terms of how to go about applying for a recognition order. Furthermore, they will have knowledge on how to open up concurrent proceedings in various jurisdictions that might be involved in the estate of a particular insolvent debtor.

$5 \mathrm{~K}$ Nadelmann Legal treatment of foreign and domestic creditors (1946).

$6 \quad$ Nadelmann (n 5 above) 698. 
In my opinion, the aforementioned legal reasoning behind the creation of various sources of cross-border insolvency law is vital in order to enable one to appreciate the vital role that cross-border insolvency law plays in foreign trade, thus highlighting its significance as an initiative. Furthermore, it aids one in understanding the constant evolution of cross-border insolvency law, as is evidenced by the EU Insolvency Regulation of 2017, which is an improved version of the EU Insolvency Regulation of 2000. The EU Insolvency Regulation of 2017 is a metamorphosis of its predecessor and thus reflects and regulates the modern trends in cross-border insolvency law more effectively. This progression is imperative, especially in a globalised world economy characterised by an open market where an increasing number of people own foreign property and where events such as the Financial Crisis of 2007-2008 may result in the insolvency and bankruptcy of many such foreign property owners. The aforementioned Global Financial Crisis of 2008 subsequently resulted in many claims being filed against insolvents worldwide, a phenomenon that the EU Insolvency Regulation of 2000 inadequately catered for. For instance, the Regulation did not clearly define fundamental concepts such as 'insolvency' or adequately address the requirements of initiating an insolvency procedure across the board. It also failed to sufficiently cater for restructuring and cash-flow issues. These oversights are, however, understandable, as such an economic crisis had not been experienced in the few years preceding the Regulation's conception and it was not necessarily foreseeable in the new millennium. Speaking to these current trends, the new EU Insolvency Regulation of 2017 caters for such cross-border insolvency catastrophes comprehensively.

Having discussed the development of cross-border insolvency law, the next section analyses and evaluates other sources of cross-border insolvency law.

Omar's contribution is instrumental to this discussion. ${ }^{7}$ In his article, 'The Landscape of International Insolvency Law', he discusses the theories of territoriality and universality. ${ }^{8}$ These two theories fall under the insolvency concept of predictability. Universality is an American school of thought which proposes the unity of cross-border insolvency proceedings. It is deemed to be a more successful alternative to territoriality by its protagonists. Consider for example the following illustration of universality:

A debtor named Paul is declared insolvent in South Africa by the Western Cape High Court, as his COMI is Paarl, Cape Town, where he owns vineyards and runs a wine business. Paul has outstanding debts

7 PJ Omar 'The landscape of international insolvency law' (2002) 11 International Insolvency Review 1.

8 Omar (n 7 above) 176. 
with many different creditors. Paul also owns numerous other properties in 20 different countries, each with their own domestic insolvency laws. It logically follows that Paul's estate representative, Victor, must travel abroad to these various jurisdictions to sell these properties in order to pay off Paul's creditors with the proceeds thereof. However, Victor will need recognition as a foreign estate representative in each of the 20 different courts, which is time consuming.

The universality theory involves the unity of proceedings and holds that the South African law of insolvency should be applicable in each of the 20 other jurisdictions. In other words, the South African insolvency law is the law that must be applied during the main sequestration proceeding.

On the other hand, territoriality is a notion that demands the recognition of a foreign estate representative by the courts of a foreign jurisdiction in order to enable the enforceability of a foreign insolvency order against a debtor in a foreign nation in which an insolvent owns property. ${ }^{9}$ If territoriality is applied to the above scenario, in order to gain recognition as a foreign estate representative in each of the countries, territoriality would require Victor to go and file for recognition proceedings (called outward bound requests), in the insolvency courts of each of the 20 jurisdictions. This principle was applied by the South African Supreme Court of Appeal (hereafter 'the SCA') in the case of Lagoon Beach Hotel $v$ Lehane. ${ }^{10}$ In this case, the SCA considered granting a preservation order to a foreign trustee and, in exceptional circumstances, recognition of a foreign trustee. A further example of territoriality in cross-border insolvency is found in the American case of Maxwell Communication Corp, Societe Generale (In re Maxwell Communication Corp) as decided by the US Court of Appeals. ${ }^{11}$ This case is the lex classicus of cross-border insolvency, as it concretised the principle of co-operation between foreign courts in cases of crossborder insolvency. In this case, a media empire was headquartered in England with its subsidiaries and assets spread across the United Kingdom, the United States of America and Canada. As a result, a number of legal regimes was applicable to various aspects of the cross-border insolvency dispute, as determined by the various lex loci of the assets of the insolvent company. It is for this reason that territoriality was evident in the case.

The disadvantage of universality is the fact that it threatens the sovereignty of countries. This is the main reason many legal

9 Omar (n 7 above) 176

10 (235/2015) [2015] ZA SCA 2010 (21 December 2015).

11 Maxwell Communication Corp, Societe Generale (In re Maxwell Communication Corp) 93 F.3d 1036 (2d Cir. 1996). 
jurisdictions' apathy towards universality. It is seen to be offensive to apply South African insolvency laws and impose its legal notions within other jurisdictions and their courts. Furthermore, universality demands a high level of reciprocity in terms of intergovernmental and interstate co-operation. This is problematic due to the lack of trust that often exists between many states. Territoriality is therefore a better alternative from a political perspective.

Be that as it may, territoriality is not without flaws either in my opinion. Firstly, territoriality may lead to a situation where we would ultimately run out of options with regard to international laws on claiming against an insolvent. Secondly, the territoriality theory has negative consequences from an economic perspective. If many different concurrent insolvency proceedings are initiated, different foreign estate representatives will have to be appointed in each of the domestic jurisdictions. As such, this insolvency proceedings can become more expensive and complex. Inevitably, those appointed as foreign estate representatives will charge their own fees towards the estate and this will diminish the assets or proceeds that actually go to the creditors. Whilst this might be justified (or made up for) by the fact that there are assets that are to be realised in these countries, financial maximisation is not guaranteed.

In light of such of a dilemma, the phenomenon of concurrent jurisdiction has been hatched as a pragmatic solution by the courts and legislatures of various countries such as France and Germany. In terms of concurrent legislation, in the above example the insolvency order against Paul as an insolvent will be enforceable in all other jurisdictions without a need for Victor, Paul's foreign estate representative, to apply for recognition in all 20 foreign jurisdictions. The principle behind concurrent jurisdiction is that of comity, ${ }^{12}$ which fosters the co-operation of courts in different jurisdictions in crossborder insolvency law.

It is in this spirit of co-operation and in accordance with this principle of comity that the sources of cross-border insolvency law, such as the UNCITRAL model law and the EU Insolvency Regulation, are modelled. The UNCITRAL model law is a legislative framework that a country may choose to incorporate into its legislation. When incorporated, it outlines when that country's domestic courts should recognise foreign insolvency proceedings. ${ }^{13}$ Having granted such recognition, the court may then provide particular assistance to the foreign estate representative. The UNCITRAL model law does not

12 BE Leonard \& CW Besant Current issues in cross-border insolvency and reorganisation (1994).

13 Thomson Reuters Practical Law 'UNCITRAL Model Law on Cross-Border Insolvency' February 2017 https://uk.practicallaw.thomsonreuters.com/0-502-6976?transi tionType $=$ Default\&contextData $=(\mathrm{sc}$. Default $) \&$ firstPage $=$ true\&bhcp $=1 \quad($ accessed 28 June 2017). 
therefore seek to unify insolvency law across all borders, as any nation can choose whether or not to adopt it. ${ }^{14}$ The EU Insolvency Regulation establishes a common legal framework for EU insolvency proceedings. ${ }^{15}$ It establishes the common rules for a court that is competent to open insolvency proceedings, the applicable law and the recognition of the decisions of the court upon the debtor's insolvency. ${ }^{16}$ Like the UNCITRAL model law, the EU Insolvency Regulation does not seek to harmonise insolvency law in the EU.

Ultimately, it is in light of this background that the cross-border insolvency law schools of thought, being territoriality and universality, led to the conception and birth of more harmonised and integrated sources of cross-border insolvency law in the forms of the UNCITRAL model law and EU Insolvency Regulation.

Chapter 15 of the American Bankruptcy Code of 1978 ('the American Bankruptcy Code') is an example of the UNCITRAL model law being adopted into local legislation. It thus brought the UNCITRAL model law into force in the United States of America (the USA). Summarily, Chapter 15 enables a foreign estate representative of a foreign insolvency proceeding (which took place outside of the USA) to gain access to American courts. Chapter 15 provides for cooperation between American courts and foreign courts, as well as other authorities of foreign jurisdictions that participate in crossborder insolvency cases. In other words, the USA is a good example of a major jurisdiction that has adopted the UNCITRAL model law into its legislation.

The Australian Cross-border Insolvency Act of 2008 is a further example of the UNCITRAL model law being adopted into local legislation. It is akin to Chapter 15 of the American Bankruptcy Code, as both pieces of legislation are based on the UNCITRAL model law. Article 13 of the Australian Cross-border Insolvency Act of 2008 provides for the recognition of a foreign estate representative in the Australian jurisdiction and the subsequent enforcement of the foreign insolvency order.

Section 426 of the English Insolvency Act of 1986, which provides for assistance and recognition of foreign estate representatives seeking to enforce insolvency orders in its jurisdiction, is an imitation of a fully developed cross-border insolvency statute nonetheless, which applies to a smaller scale, i.e. domestically. This is due to the fact that it only applies to certain designated countries, excluding some key global players in trade such as the USA. The designated countries are Anguilla, Australia, the Bahamas, Bermuda, Botswana,

14 Thomson Reuters (n 13 above).

15 European Commission 'Insolvency proceedings' http://ec.europa.eu/justice/ civil/commercial/insolvency/index_en.htm (accessed 28 June 2017).

16 European Commission (n 15 above). 
Brunei, Canada, Cayman Islands, Falkland Islands, Guernsey (modified), Gibraltar, Hong Kong, the Republic of Ireland, Malaysia, Montserrat, New Zealand, South Africa, St Helena, Turks and Caicos Islands, Tuvalu and the Virgin Islands.

Nevertheless, the English Cross-border Insolvency Regulation of 2006 (hereafter 'the CBIR of 2006') applies to the non-designated states. The CBIR of 2006 therefore seeks to bridge the gap created by the aforementioned Act and facilitates a more efficient cross-border insolvency law by recognising those once excluded foreign estate representatives of foreign insolvency proceedings that took place in non-designated countries.

Among the international instruments, the UNCITRAL model law has become a popular source of cross-border insolvency law in the sense that it is a legal framework against which many national laws are being developed and reformulated. ${ }^{17}$ South Africa is a case in point. The South African Insolvency Act enforces South African insolvency law only and is therefore not a source of cross-border insolvency law. Such cases of entrenched domestic laws have stifled the harmonisation of insolvency laws in Southern Africa as a region. Nonetheless, the South African judiciary and legislature have made progressive attempts to reframe a new South African Insolvency Act that is based on the UNCITRAL model law, in order to facilitate harmonisation and co-operation of cross-border insolvency law in Southern Africa and eventually Africa as a whole. ${ }^{18}$

The OHADA Treaty (signed on 17 October 1993) is also a source of cross-border insolvency law. It binds the majority of Francophone African countries to the same trade practices, including cross-border insolvency law and enforcement thereof, across the Francophone African terrain.

Having explained some of the sources of cross-border insolvency law globally, the next section compares the UNCITRAL model law with the EU Insolvency Regulation.

\subsection{Comparison between the UNCITRAL model law of insolvency and the EU Insolvency Regulation}

The UNCITRAL model law is not binding, as it is merely a template and framework that countries may choose to adopt and incorporate into

17 UNCITRAL 'UNCITRAL Model Law on International Commercial Arbitration (1985), with amendments as adopted in 2006' January 2017 http://www.uncitral.org/ uncitral/en/uncitral_texts/arbitration/1985Model_arbitration.html (accessed 28 June 2017).

18 'Model Law Adapted for Enactment in South Africa: Annexure B' http://www. justice.gov.za/salrc/media/1998_crossbannexb.pdf (accessed on 9 November 2017). 
their domestic insolvency laws. An apt illustration is the incorporation of the UNCITRAL model law into the American Bankruptcy Code in the form of Chapter 15, as previously discussed.

A similarity between the UNCITRAL model law and the EU Insolvency Regulation is the purpose that each serves. The EU Insolvency Regulation is not in place to harmonise substantive insolvency law, because it has no bearing on sections of national insolvency law. It is a private international law instrument seeking to promote a solution to conflicts of jurisdictions and applicable law. For instance, it prescribes the applicable law for finding an answer to a legal question in a particular case. The applicable law may be the law of the country where the insolvency proceedings were opened. It is then left to that national insolvency law to determine the outcome of the legal issue. The EU Insolvency Regulation will not override that national insolvency law, as it just points to the applicable national law that one should look at in order to find the answer to the legal issue or question at hand.

Similarly, the UNCITRAL model law rules do not harmonise the national insolvency laws of the different jurisdictions that adopt it. It does not alter the intrinsic insolvency law principles of the various jurisdictions of the countries that adopt it and each country maintains its own sovereignty regarding national insolvency laws. For example, South Africa still has the Insolvency Act of 1936 and England still has the Insolvency Act of 1986, despite having adopted the UNCITRAL model law for enactment in South Africa. This reinforces the idea that the UNCITRAL model law serves only as a template for a predictable procedure that a foreign estate representative can use in order to apply for recognition or to open up concurrent insolvency proceedings in a foreign jurisdiction.

The UNCITRAL model of law and the EU Insolvency Regulation differ with regard to the application of recognition. The UNCITRAL model law provides for assistance to a foreign estate representative in approaching the court to request recognition for his proceeding. ${ }^{19}$

Under the EU Insolvency Regulation, recognition is automatic. ${ }^{20}$ The foreign estate representative does not need to apply for recognition of his insolvency proceeding in another EU jurisdiction. As soon as an insolvency proceeding has been opened in, for example, the Netherlands, it is also effective in all other EU member states and no prior court application or publicity is required. The fact that a

19 Thomson Reuters Practical Law 'UNCITRAL model law on cross-border insolvency' February 2017 https://uk.practicallaw.thomsonreuters.com/0-502-6976?transi tionType $=$ Default\&contextData $=($ sc. Default $) \&$ firstPage $=$ true\&bhcp $=1 \quad($ accessed 28 June 2017).

20 INSOL Europe Proposals by INSOL Europe: Revision of the European Insolvency Regulation (2011) 21. 
Dutch judgment opening insolvency proceedings against an insolvent debtor with assets in Italy, has not been published in Italy, does not alter the fact that the effects of the Dutch insolvency proceedings apply in Italy from the moment that they are effective in the Netherlands. This request for recognition is another conceptual difference that exists between the UNCITRAL model law and the EU Insolvency Recognition.

A similarity between the UNCITRAL model law and the EU Insolvency Regulation is the fact that they are both centred on the concept of a COMI and the establishment of grounding jurisdiction of two types, namely main and secondary proceedings. According to the EU Insolvency Regulation jargon, the main and secondary proceedings are referred as the 'main' and 'secondary proceedings' whilst on the other hand, the UNITRAL model law calls it the 'main' and the 'nonmain' proceedings.

However, a difference between the UNCITRAL model law and the EU Insolvency Regulation is their respective spheres of influence. The UNCITRAL model law is a suggested (hence non-binding) legal framework for the cross-border insolvency system of any UN member state wishing to follow it, while the EU Insolvency Regulation is a binding cross-border insolvency law on the $28 \mathrm{EU}$ member states only.

A further subtle similarity exists between the EU Insolvency Regulation and the UNCITRAL Model Law. According to Omar, the EU Insolvency Regulation is characterised by a 'constellation' paradigm striving to establish a hierarchy and coordination between proceedings that involve the same debtor, while a similar but lighter structure is prevalent within the UNCITRAL model law. ${ }^{21}$

\section{Conclusion}

In conclusion, the above comparison between the UNCITRAL model law and the EU Regulation highlights a common aim of easing the liquidation process of an insolvent for the aggrieved creditors. This is done with the ultimate goal of providing justice to creditors by paying to them the insolvent's debts.

It is apparent that cross-border insolvency law mitigates the complexities of extra-jurisdictional insolvency proceedings through provisions that encourage co-operation between states. The EU Insolvency Regulation provisions, for example, encourage concurrent jurisdictional insolvency proceedings that ameliorate burdensome legal applications, such as the outward bound requests of foreign estate representatives seeking recognition. Summarily, predictability 
is established by these sources of cross-border insolvency law through such provisions. It is in this predictability that the beauty of crossborder insolvency law lies, as predictability and legal certainty fosters international trade through the security of business and investments. Be that as it may, this beauty will not be fully realised if countries do not adopt the UNCITRAL model law. Furthermore, in the case of Europe, the positive far-reaching effect of the EU Insolvency Regulation is limited by the fact that only 28 European states can enjoy the ease of concurrent insolvency proceedings. However, the further evolution of cross-border insolvency law should increasingly fill these legal fissures. 


\title{
ANTI-DOPING: THE CREDIBILITY OF THE WHEREABOUTS RULE
}

\author{
by Primrose E.R. Kurasha*
}

\section{Introduction}

The month of February 2003 saw the World Anti-Doping Agency (WADA) adopt the World-Anti Doping Code in Copenhagen, Denmark as it sought to create an independent anti-doping body and to also coordinate the harmonisation of doping regulations. ${ }^{1}$ The Code encompasses the principles around which the international fight against doping in sport is going to revolve in the future. ${ }^{2}$ South Africa is one of the many countries which is a signatory to the Copenhagen Declaration. ${ }^{3}$ The inclusion of governments in the adoption of the Copenhagen Declaration was an effort by WADA to involve governments in the international fight against doping in sport.

In this article, I identify and analyse potential problem areas, from a legal and human rights perspective, regarding the international fight against doping in sport. My focus is specifically on the 'Whereabouts rule' laid down by WADA and as enforced in South Africa by the South African Institute for Drug-Free Sport (SAIDS).

I begin with an explanation of the Whereabouts rule. This has been necessitated by a large outcry from the media and athletes who not only question its purpose as a doping test but also ask what it is, as a considerable portion of them are yet to be fully enlightened on this WADA 2009 amendment. This theoretical background that I give on the Whereabouts rule is my way of educating my readership and thus living what I preach, as will be evident in my recommendations below, which is mainly the gospel of athletes and media engagement on the Whereabouts rule through education and enlightenment of its content.

To enable a deeper understanding of my position on the aforementioned issue, I first define key concepts and acronyms as this

* BA (Law), LLB, LLM (University of Pretoria) LLM in International Trade and Investment Law in Africa, University of Pretoria.

1 World Anti-Doping Agency 'Copenhagen Declaration' 3 January 2003 https:// www.wada-ama.org/en/resources/world-anti-doping-program/copenhagendeclaration (accessed 15 July 2016).

2 Art 5 of the Copenhagen Declaration on Anti-Doping in Sport of 2003.

3 World Anti-Doping Agency (n 1 above). 
will enable me to have a common foundation with the reader, following which I will address the main issue of this article.

\section{Contextualisation}

\subsection{Definitions: Key concepts}

WADA is an anti-doping agency which was established in $1999 .{ }^{4}$ It is the international body which guards against doping in sport by enforcing certain safeguards, such as the Athletes' Handbook which details the particular substances athletes are banned from consuming. ${ }^{5}$ It was established because there was no specific antidoping body which was responsible for preventing doping in sport. WADA ruthlessly confronts doping in the international sporting community as was confirmed in the case of World Anti-Doping Agency (WADA) v. United States Anti-Doping Agency (USADA); United States Bobsled \& Skeleton Federation (USBSF); Zachary Land and Federation Internationale de Bobsleigh et de Tobogganing (FIBT) (as 'Interested Party') (2 February 2006), when WADA launched an appeal to the Court of Arbitration for Sport (CAS) against the United States AntiDoping Agency (hereafter referred to as 'USADA')'s decision not to treat Lund as 'a cheat' because he had been using a banned substance for medical purposes. ${ }^{6}$

SAIDS is a public entity which was established by an Act of Parliament, namely Act 14 of $1997 .{ }^{7}$ SAIDS is the national body which is responsible for doping in South Africa. SAIDS is responsible for the testing of athletes, the testing of samples and the implementing of disciplinary action against those athletes who were tested positive. ${ }^{8}$ SAIDS is based in Newlands, Cape Town. It receives the majority of its funding from Sport and Recreation South Africa (SRSA). ${ }^{9}$

The Bill of Rights, enshrined in the Constitution of the Republic of South Africa, 1996, defines human rights as the rights of all people in South Africa. ${ }^{10}$ Human rights are one's fundamental entitlements which are bestowed on him or her by virtue of human nature as opposed to an animal for example. There are various human rights but those relevant to Sports Law and the issue of doping are the following according to their order of appearance in the Constitution; section 9-

4 World Anti-Doping Agency 'WHO WE ARE' 3 January 2003 https://www.wadaama.org/en/who-we-are (accessed 15 July 2017).

5 As above.

6 Arbitration No CAS OG 06/001. In this case, WADA's appeal was upheld and an appropriate two year ban was imposed on Lund.

7 South African Institute for Drug-Free Sport 'About Us' 16 July http:// www.drugfreesport.org.za/about-us/ (accessed 16 July 2017).

8 As above.

9 SAIDS Annual Report 201414.

10 Ch 7 of the Constitution of the Republic of South Africa, 1996, (the Constitution). 
the Equality clause; section 10-right to human dignity; section 12(e)right to freedom and security of the person; section 14-right to privacy; section $35(3)(\mathrm{h})$-the right to be presumed innocent until proven guilty; and section 36-limitation of rights.

There is no common legal definition for doping. Doping is defined in two ways namely the abstract definition and the pragmatic definition.

The abstract definition of doping defines doping as the use of a substance which is potentially harmful or capable of enhancing their performance. ${ }^{11}$ This definition has been adopted by the International Olympic Committee (IOC) Code. However, the definition is unanswerable and is, therefore, not legally binding. Be that as it may, we still have to refer to this abstract definition of doping because most people believe that doping is only about performance enhancing drugs, but on the list of prohibited substances itself, only about $50 \%$ items are performance enhancing drugs but the other $50 \%$ are actually harmful to the human body and they will not enhance an athlete's performance, hence it is prohibited. In other words, it is harmful and it might kill you. So this abstract definition of the IOC is both either harmful or performance enhancing substances.

The pragmatic definition of doping defines doping as the presence in the athlete's body of a prohibited substance (and related substances) or evidence of the use thereof. ${ }^{12}$ This definition is based on a list of prohibited substances, unlike the abstract definition which is unanswerable and therefore, is not legally binding. We use this pragmatic definition in South Africa. The pragmatic definition has also been adopted in the WADA definition.

The pragmatic definition of doping operates in the following way; WADA will publish on the 2nd of January of every year, a list of prohibited substances. The list is reviewed and amended by WADA annually as new substances are added to the list whilst others are removed. Every sports federation should have this new list. However, this list is not user friendly because the content of the list is illegible and incomprehensible for most athletes. In order to resolve this issue, the anti-doping bodies such as SAIDS publish the 'Athletes' Handbook.' The Athletes Handbook is an application which is available on every smartphone and it is more user-friendly. By creating this legible Athletes' Handbook, the athletes' section 32(1) right of access to information is protected and implemented. Athletes have access to the banned substances and can, as a result, know about them. The application of this pragmatic definition of doping would be evident if, for example, an athlete goes to consult a doctor

11 K Vieweg \& C Paul 'The definition of doping and the proof of a doping offence' (2002) 1 The International Sports Law Journal 2.

12 As above. 
or a chemist and he is prescribed medication which he must check for under the banned list. The athlete must simply type in the name of the medicine, for example, 'Vicks Medinite', and if it shows up in red then it is a banned substance. So the Athletes' Handbook application actually uses the pharmaceutical name of the product which the athlete can understand, e.g. 'Vicks Medinite'.

The law which governs the enforcement of WADA and SAIDS operations in South African sports law is the World Anti-Doping Code, which was incorporated into South African anti-doping law through the Drug-Free Sport Amendment Act 25 of 2006 (hereafter referred to as 'the Act'). Section 11(2)(a) of the Act expressly provides that SAIDS 'shall adopt and implement anti-doping rules and policies which conform to the WADA Code including the WADA Prohibited List'.

\subsection{Procedural law}

The procedural aspect of a doping hearing is evident in the way in which doping is proven through evidence. A doping offence, especially in the case of over-the-counter doping, is proven in the following way: The sanction for doping is not a criminal sanction but it is a disciplinary sanction. ${ }^{13}$ The burden of proof lies with the sports organisation which is the accusing party. ${ }^{14}$ The evidence of doping is the finding of the prohibited substance in the urine or blood sample which is sent to accredited laboratories for testing. ${ }^{15}$ The urine or blood sample is compared to the prohibited list. If there is a match then the athlete would have tested positive for doping. ${ }^{16}$ The standard adopted by WADA is that of strict liability. ${ }^{17}$

In the light of this background knowledge I am now proceeding to identify and analyse potential problem areas, from a legal and/or human rights perspective, inherent in the international fight against doping in sport, in terms of the rules laid down by WADA and as enforced in South Africa by SAIDS.

13 P Greene 'Case Note: United States Anti-Doping Agency v Montgomery: Paving a new path to conviction in olympic doping cases' (2007) 59 Maine Law Review 154155.

14 Art 3.1 of the WADA Code, 2015.

15 SAIDS At-a-glance https://www.drugfreesport.org.za/wp-content/uploads/2014/ 09/SAIDS_Anti_Doping1.pdf (accessed 1 April 2017).

16 As above.

17 Rule 2.1 of the WADA Code, 2015 provides that the strict liability standard that is applied to positive tests, in terms of which the mere 'presence of a prohibited substance or its metabolites or markers in an athlete's bodily specimen' is sufficient to establish a doping violation, and intent, fault, negligence, or knowing use need not be demonstrated. 


\subsection{Potential problem areas}

\subsubsection{Non-analytical evidence:Whereabouts rule}

The anti-doping test procedure presents a potential problem area, from a legal perspective, in the admissibility of non-analytical evidence. Non-analytical evidence includes the testimony of witnesses, social media platforms such as Facebook or Twitter, the testing procedure (Doping Control Officer [DCO]) and the Whereabouts rule. I am going to focus on the Whereabouts rule in this article.

\section{Definition of the Whereabouts Rule}

The Whereabouts rule relates to a form of doping testing called outof-competition testing. ${ }^{18}$ Out-of-competition testing has become a vital component of the WADA program.

\section{Purpose of the Whereabouts Rule}

The Whereabouts rule was created in order to combat systematic doping which always remained a challenge to in-competitiontesting. ${ }^{19}$ Systematic doping is essentially a form of doping in which athletes and their coaches employ banned substances and methods of training during hard training and post-competition season in order to catalyse the athletes' recovery process and thereby strengthen their physical capacity and enhance their winning chances in the world competitions.

It logically follows that in-competition-testing could never catch out such systematic doping because by the time of the competitions the banned substances would have been flushed out of the athlete's system. Therefore, out-of-competition testing becomes a legal and ethical necessity in order to catch out the offenders and promote fair play for sportsmen.

\section{Operation and characteristics of the Whereabouts rule}

The doping officials who apply the Whereabouts rule do not give the athlete who is to be tested advance notice of the test. Furthermore, the athlete must have, beforehand, provided the doping officials with detailed information concerning his/her whereabouts at a particular time.

18 Art 20 of WADA Code, 2015.

19 LawTeacher 'WADA's Whereabouts System' https://www.lawteacher.net/freelaw-essays/sports-law/wadas-whereabouts-system.php (accessed 1 April 2017). 


\section{Characteristics of the Whereabouts rule}

A harmonised system of out-of-competition testing in terms of the WADA Code comprises of;

(i) the group of athletes to be tested; ${ }^{20}$

(ii) the kind of whereabouts information to be provided; ${ }^{21}$ and

(iii) the circumstances which result in anti-doping violations. ${ }^{22}$

In terms of the first characteristic namely, the group of athletes who are to be tested, registered testing pools with the specific athletes to be tested are to be established by the International Federations (IFs) and National Anti-Doping Organisations (NADOs).

There are two Registered Testing Pools namely:

(i) The International Registered Testing Pool- This one is laid down by the IFs and includes top athletes. ${ }^{23}$

(ii) The National Registered Testing Pool- This one is established by the NADOs. ${ }^{24}$ It includes athlete as informed by the International Standard of Testing (ISI) and these are;

(a) Athletes who are part of national teams in Olympic, Paralympic or other sports of high national priority (or who may be selected for such teams);

(b) Athletes who train independently but perform at Olympic or Paralympic or World Championship level and may be selected for such events.

Therefore, WADA does not assign the athletes to be tested but only IFs and NADOs do so by establishing relevant characteristics and select a significant or meaningful circle or pool of athletes who become part of WADA's Whereabouts system.

\section{Whereabouts Information}

Athletes are required to complete forms and provide Anti-Doping Organisations (ADOs) with the details and these must be given to NADOs and/or IFs every three months through the Anti-Doping Administration and Management System (ADAMS). ${ }^{25}$ The IST dictates the information to be filled in by the athletes as comprising of;

(i) athlete's residences; 26

(ii) athlete's agenda for the next three months which contains; ${ }^{27}$

Art 2.4 of the WADA Code, 2015.

Art 5.2.2 of the WADA Code, 2015.

Art 5.2.1 of the WADA Code, 2015.

Art 5.6 of the WADA Code, 2015.

As above.

27 As above. 
(a) contact details;

(b) confirmation that other potential testing authorities such as ADOs have access to the athlete's Whereabouts filings;

(c) athlete's addresses of all locations where the athlete will be residing, e.g. homes and hotels, and carrying out regular activities, e.g. work, training, studying and school;

(d) athlete's schedules of all regular activities and competitions during that three-month period have to be added.

The aim of this agenda is to keep the WADA doping officials informed as the athlete's agenda changes often due to future competitions. So Whereabouts information gives the expected information in the form of the particular time and place for the athlete's testing.

(iii) A daily 60-minute time slot between 6 am and $11 \mathrm{pm}$ for the athlete must be given. ${ }^{28}$

Conclusively, as can be seen from the aforementioned characteristics and operation of the Whereabouts rule, the athlete must be easily accessible to the doping officials at a particular place and time. Moreover, he/she must guarantee an unproblematic test procedure through the detailed Whereabouts information they would have given. An athlete can delegate to a $3^{\text {rd }}$ party, via a written notice, his or her duty to furnish his or her Whereabouts information. Nonetheless, the athlete remains ultimately responsible for the provision of accurate and correct details and his/her accessibility thereof as per the guarantee he/she would have given. Such that if he or she misses a doping test or commits a filing failure courtesy of a third party that he or she would have delegated, the athlete still remains liable. This is also justifiable in terms of the strict liability rule. ${ }^{29}$ This provides an interesting jurisprudential intersection between strict liability and the Whereabouts rule. It is intriguing because the criticism of the violation of fundamental rights is brought into question when strict liability enters the fray. Nonetheless, my debate about rights in the following sections will focus on their connection and co-existence with the Whereabouts rule.

\section{Violations of Whereabouts rule}

Article 2.4 of the WADA Code, 2009 provides that violations of the Whereabouts rule is constituted out of missed tests or a filing failure, in other words, a failure to file required whereabouts information. A filing failure may be ascertained in two ways namely -

28 As above.

29 The rule which provides that under Art 2.1 and Art 2.2 of the WADA Code, 2015 it is not necessary that intent, fault, negligence, or knowing use on the athlete's part be demonstrated by the anti-doping organization in order to establish an anti-doping rule violation. 
(i) if a doping official fails to allocate a listed athlete outside the 60 minute time slot due to insufficient information; and

(ii) $\mathrm{ADO}$ is able to determine insufficiency of the information itself. ${ }^{30}$

What constitutes a missed test is an athlete's absence at a given location within the 60 minute period. For example, if Usain Bolt said he will be at Ramada Inn, New York City on 12 January 2016 between 7 am and 8 am and the doping officials arrive and do not find him there, this constitutes a missed test. Ultimately an anti-doping rule violation in terms of the Whereabouts rule is the sum of three missed tests or filing failures within twelve months from the first offence.

This establishes the essence of the Whereabouts rule. It does give the impression of thoroughness in the fight against doping through the harmonisation of the out-of-competition testing. Be that as it may, criticism has been penned and voiced about the Whereabouts rule and the out-of-competition testing. In the next section, analyse the potential problem areas inherent in the Whereabouts rule.

\section{Criticism: Analysis}

The criticism that has been laid out against the Whereabouts rule by athletes and other observers has been that it is too demanding and too complex a legal regime to understand, let alone comply with. This is not as surprising as out-of-competition testing, of which the Whereabouts rule is a component, is part of advanced intelligence testing. ${ }^{31}$ This inclusion of the word 'intelligence' highlights the discreet and state-of-the-art nature of the operation and application of the Whereabouts rule.

As Robin Sharma once said, "victims recite problems, leaders provide solutions.' It is in this spirit of leadership that I would recommend to WADA, as a solution to this problem, athletes' engagement in this anti-doping war. I recommend that WADA engages athletes and other stakeholders by educating them on the purpose and inherent benefits of out-of-competition testing, which mainly aims at levelling the playing field and promoting fairness by testing the athletes at all times. This backwards-forwards approach will facilitate an easier understanding of the out-of-competition testing and compliance to the Whereabouts rule will improve. For instance, not only should athletes be enlightened on the consequences of a filing failure but they must also be enlightened on what constitutes a filing, i.e. whether it is the omission of all types of information concerning the athlete's whereabouts during the quarterly testing or 
whether it is committed by the omission of particular information concerning the athlete's whereabouts.

The procedure of employing the Whereabouts rule presents a potential problem area with regards to the invasion of an athlete's rights to privacy from a human rights perspective, in the anti-doping fight. ${ }^{32}$ This right is entrenched in section 14 of the South African Constitution's Bill of Rights. Indeed the Whereabouts rule is intrusive. As Singh would say, 'Athletes ... do not abandon their human rights once they enter the boundary of lines onto the field of play. ${ }^{33}$ It is in this way that the procedure of employing the Whereabouts rule presents a problem area with regards to the invasion of an athlete's right to privacy from a human rights perspective in the anti-doping fight.

However, it is not so highly intrusive in a way that makes it a travesty of justice because the athlete need only provide a quarterly 60 minute time slot in which the doping officials can come and test him/her.

Moreover, the intrusion is justifiable considering the severity of doping in sports and the evasive manner in which doping athletes are always ten steps ahead of WADA, especially at the Olympics and in sports prone to doping such as cycling and athletics. This argument revolves around the proportionality test which I discuss later on in the next section under the Limitation clause.

Another source of conflict that arises with the Whereabouts rule is the possible violation of the right to freedom of movement of an athlete in terms of section 12 (e) of the Constitution of South Africa. Since athletes give a 60 minute time slot between 6 am and $11 \mathrm{pm}$ every day, that means that they have to squeeze their training, recovery time and running errands into a shorter day as they have to give away an hour for the doping officials, just in case they show up. The uncertainty of whether or not they will pay an unexpected visit makes this daily demand of an hour rather insensitive because if they do not, the athlete will just find him/herself stuck at home instead of training and the athlete cannot protest because this is a WADA regulation which he/she must comply with.

Another point of criticism is with regards to the right to equality in terms of section 9 of the equality clause in the sense that, not all athletes are selected for the doping test according to the Whereabouts rule. This is rather discriminatory considering that the chances for doping exist across the board in all sports, although in

32 Cropp v A Judicial Committee and Anor SC 68/2007 [17 June 2008]. In this case, the violation of privacy by the doping test was challenged and Cropp won her case.

33 P Singh 'Human Rights and Sport' 2006 http: / / www.docstoc.com/docs/19767069/ SPORT-AND-HUMAN-RIGHTS\# (accessed 18 April 2016). 
some more than others, such as cycling. ${ }^{34}$ This inequality is evident in the selection of athletes to be tested in the Registered Testing Pools, as determined by the IFs and NADOs. For starters, not all athletes are chosen to be in these pools for testing as the focus is mainly on Olympians and Paralympians. Therefore, those athletes who perform in provincial teams or national teams but who do not make the cut for the national Olympic team of a particular nation can virtually walk off scot free after doping and they do dope as was unearthed by Nairn, the Australian Journalist. ${ }^{35}$ One might argue that there is a greater need to mainly, and perhaps only, test the Olympians and Paralympians because the chances of doping are higher at this stage because of the pressure that the athletes face of having to give their best performance ever on a world stage and break world records. Therefore, doping tests such as the Whereabouts rule would deter athletes from doping and considering that this is also an international stage, it would send a loud message to future global athletes no to dope after they see the consequences of doping on their counterparts and role models. This is a sound argument because it is practical and realistic nonetheless, inequality still ravages the Whereabouts rule doping system because there are still some athletes who are not tested whilst others are. This becomes more unfair when one looks at the fact that there are sports which are prone to doping more than others, regardless of whether it is at a national or provincial level such as boxing, weightlifting and cycling. ${ }^{36}$ Therefore, ignoring the provincial or district cycling teams for instance just because they are a level lower than those of the pole vault Olympic teams is impractical especially considering that doping is not as rife in pole vault or diving.

Be that as it may, the unfairness is mitigated by the justification on the limitation of the right to equality as necessitated by rampant doping in certain sports and at certain levels of sporting competitions. Again the proportionality test argument is seen to kick in here and as I pointed out it is thoroughly discussed below.

As I conclude my analysis of the problems inherent in doping definitions from a human rights and justice perspective, it is evident that the conceptualisation of doping presents problem areas, not only from a practical legal perspective which concerns investigation but also from a human rights perspective. The legal and the human rights facets in this case of definitions are inter-woven hence, they also present a chicken and egg situation.

34 P Sullivan 'What Sports Have the Worst Doping Problems?' 29 June 2013 http:// foreignpolicy.com/2013/06/29/what-sports-have-the-worst-doping-problems/ (accessed 2 September 2017).

35 J Nairn 'Junior Australian athletes as young as 12 admit to doping' 8 July 2014 http://www.abc.net.au/news/2014-07-08/junior-athlete-doping-uncovered-byresearch/5581930 (accessed 1 September 2017).

36 Sullivan (n 34 above). 


\subsection{The legal implications of the doping fight in South Africa}

\subsubsection{Section 36-Limitation Clause}

Section 36 of the Constitution provides a limitation clause. According to this limitation clause, the human rights which are entrenched in the Bill of Rights are not absolute however, they can be limited and encroached upon in a way that is justifiable in an open and democratic society such as South Africa. Section 36 provides; $^{37}$

The rights in the Bill of Rights may be limited only in terms of law of general application to the extent that the limitation is reasonable and justifiable in an open and democratic society based on human dignity, equality and freedom, taking into account all relevant factors, including;-

(a) The nature of the right;

(b) The importance of the purpose of the limitation;

(c) The nature and extent of the limitation;

(d) The relation between the limitation and its purpose; and

(e) Less restrictive means to achieve this purpose.

The limitation on the aforementioned human rights, one might argue, is to preserve the integrity of sports. However, there is the reality that sports is entertainment and therefore, a thriving business. This is what leads athletes to dope as they are under pressure to win and earn a lot of money. Be that as it may, in an open and democratic South Africa, which is founded on the constitutional values of fairness and equality, the courts are likely to prioritise sports integrity, health, honesty, fair play and sports education and this will definitely outweigh the business aspect into which sports has degenerated. This is called a proportionality test. ${ }^{38}$ Proportionality refers to the balancing of different interests and the weighing up of competing values. It is in light of these constitutional priorities that the courts will be willing to limit the constitutional human rights of athletes in terms of the limitations clause.

The proportionality test was also applied in the case of Cropp $\vee A$ Judicial Committee and Anor. ${ }^{39}$ In this case, it was held that the right to privacy as entrenched in the Bill of Rights of New Zealand (BORA), had been unjustifiably limited by the doping test on Cropp. This was because the purpose of the test was to prevent horse riders who had doped prior to the race from participating in the race and unfairly winning the competition. Therefore, testing Cropp some time after the race did not establish this purpose of excluding and penalising

37 Sec 36 of the Constitution, 1996.

38 S v Makhwanyane and Another 1995 (3) SA 391 (CC) [104].

39 Cropp (n 32 above). 
offenders. It logically follows, therefore, that Cropp's privacy had been unjustifiably encroached upon.

It is likely that this purpose orientated approach, coupled with the constitutional value orientated approach, will be applied by courts when deciding on how to determine encroachment of athletes' human rights in terms of the limitation clause.

\section{Conclusion}

In conclusion, the perception of the problem of doping as defined by WADA and enforced by SAIDS is a problem area from a legal and human rights perspective. Doping has resulted in the majority of the public's losing faith in the results of Olympic events because of the use of drugs and doping in sports. For example, one would question the prowess of an athlete. One might ask whether Usain Bolt's 9.58 seconds performance of the $100 \mathrm{~m}$ is real and natural especially when it comes to his unprecedented speed. Some of the astronomical heights that are being jumped by the athletes nowadays, for example in pole vault or in long jump, make one also question whether the athlete is not guilty of doping. A poll which was carried out by the British Broadcasting Corporation (BBC) One's 'Inside Sport' found that $58 \%$ agreed that they had lost faith in the credibility of these sporting events and performances and only $20 \%$ had not lost faith. ${ }^{40}$ This negative perception of sports, due to rampant doping, is a problem which has been caused, to a certain extent, by the global anti-doping fight in the sense that, athletes' hard work and stellar performances have been drowned by the news of their colleagues who would have been found guilty and doping. This negative perception is unfair on those honest athletes who would have worked hard to win and end up doing so. A great example would be Usain Bolt of Jamaica or Veronica Campbell Brown, particularly since the latter was eventually cleared after initially being accused of a doping offence. These are recordsetting athletes whose prowess many have questioned due to their unprecedented world class performances on the track. The truth is that, in their case, not only does hard work play a role but genetics play an even bigger role. The population of the Caribbean is famous for its athleticism and this sets them apart from the start. Therefore, their great performances can be considered genuine especially since none of them has ever been found guilty of doping. WADA, in its quest to end doping, must immensely protect its athletes from suffering unwarranted prejudice. Indeed it is a balancing act required of WADA and SAIDS as both bodies must fiercely fight doping on a global scale

40 British Broadcasting Corporation 'BBC Annual Report and Accounts 2015/16' http://downloads.bbc.co.uk/aboutthebbc/insidethebbc/reports/pdf/bbcannualreport-201516.pdf (accessed 25 September 2017). 
but at the same time save the image of athletes who are just genetically superb.

My sincere hope is that not only have I analysed potential problem areas inherent in the Whereabouts rule, from a legal and/or human rights perspective, as enforced in South Africa by SAIDS, but that I have also provided solutions and recommendations to these problems, or at the very least, ideas to solutions. 


\title{
TAX MORALITY: EXAMINING THE BEPS DEBATE, WORK OF THE OECD AND ITS IMPACT ON AFRICA
}

\author{
by Daniel Godson Olika*
}

\section{Introduction}

International tax issues have never been at the forefront of international politics as they are today. ${ }^{1}$ This is due in large part to the realization that the current international tax system in existence allows multinational corporations to plan their taxes in such a way that they will be able to pay little or no taxes at all. They are able to do this through certain loopholes and gaps that currently exist in the system. These loopholes and gaps are seen as creating opportunities for taxpayers who are involved in cross-border activities to aggressively structure their activities to mitigate potential tax exposure or achieve no tax liabilities. ${ }^{2}$ They do this by exploiting; the hybrid-mismatch arrangements, shortcomings of the transfer pricing rules in jurisdictions where they operate and shifting profits from countries where their profits are made to countries with low tax rates. ${ }^{3}$ Consequently, some multinationals pay as little as five percent in corporate taxes, even as smaller domestic businesses pay up to 30 percent. ${ }^{4}$ The result of this activity is what is known as; base erosion and profit-shifting (BEPS) and it has the potential to deprive all countries of significant tax revenues. ${ }^{5}$ It is worthy to note that this problem is not new at all as it has been in existence for a long time now. What is new however; is the attention it is getting from both the media and policy makers alike. This has led to an intense debate between both the media and policy makers as to whether the international tax planning activities of multinationals is moral.

It should be borne in mind that the tax planning strategy of multinationals is tantamount to tax avoidance and therefore not

* $\quad$ LLB (Hons) University of Lagos.

1 KPMG 'Don't underestimate BEPS' impact on indirect tax' https:// assets.kpmg.com/content/dam/kpmg/pdf/2016/06/global-indirect-tax-beps.pdf (accessed 23 February 2017).

2 Deloitte "Changing international tax landscape: Local impact of base erosion and profit shifting (BEPS) project' https://www2.deloitte.com/ng/en/pages/tax/ articles/local-impact-base-erosion-profit-shifting-abti-tax-avoidance.html (accessed 23 February 2017).

3 J Zeder "Making international tax laws just: Professor Diane King gives voice to emerging nations' concerns' https://www.lawmagazine.bc.edu/2015/02/makinginternational-tax-laws-just/ (accessed 24 February 2017).

4 Zeder (n 3 above).

5 Zeder (n 3 above). 
illegal. This principle is a trite principle of tax law and was elucidated by the Nigerian Supreme Court in Federal Board of Inland Revenue $v$ American International Insurance Company Nigeria Plc: ${ }^{6}$

Tax is an obligation not a duty. One is not a bad citizen if one can organise his business or trade in a legal manner to minimise his tax liability. He could and he should resist within legal means any unduly wide interpretation or unconventional implication of legislative intent of a tax law that might increase that burden. He can do so without being ashamed of walking in the street as a patriotic citizen. A shrewd business acumenship and a legitimate protection of sweat of labour are not a dishonest act or an act having any moral turpitude. It is pragmatic and practical. Being capitalistic might leave much to be desired but among what is left is not illegality.

Whilst this position of the law is easily understood by tax experts, policy makers, business men and lawyers; this principle is neither easily understandable nor easily explainable to the public especially when considered against the backdrop of how much countries lose to this tax planning strategy. An estimate of between US $\$ 100$ Billion and US $\$ 200$ Billion is lost annually due to BEPS and this equates to between four percent and ten percent of global revenues from corporate income tax. ${ }^{7}$ These statistics further compound the problem of the BEPS debate and makes the legality of the tax planning strategy of multinational corporations difficult for the public to swallow.

This rave debate and harsh criticism from the public influenced the intervention of the Organisation for Economic Co-operation and Development (OECD) to start its now famous BEPS Project. The OECD BEPS Project aims to provide governments or tax administrators with clear international solutions for fighting aggressive corporate tax planning strategies that artificially shift profits to locations where they are subjected to more favourable tax treatment. ${ }^{8}$ Consequently, in 2015, the OECD released the final draft of its 15 action plans to help address the problem of base erosion and profit-shifting. This project has been received differently by various stakeholders and jurisdictions. For instance, its impact on Africa and how African nations will react to the project has been the subject of intense debate. This paper shall address the various strands of the BEPS debate, the OECD BEPS project, the impact of the project in Africa and Nigeria. The next section shall address the various strands of the debate.

6 [1999] 1 NLRN 50.

7 L Brunto 'The OECD/G20 base erosion and profit shifting (BEPS) project - an informed perspective' https://www.cliffedekkerhofmeyr.com/en/news/publica tions $/ 2015 /$ tax/tax-alert-16-october-the-oecdg20-base-erosion-and-profit-shift ing-beps-projectan-informed-perspective.html (accessed 23 February 2017). 


\section{Morality and legality: The twin perspectives to the base erosion and profit-shifting (BEPS) debate}

The Courts have from time immemorial stated that tax avoidance is neither immoral nor illegal. ${ }^{9}$ This position was aptly captured by the UK Court in Levene $v I R C,{ }^{10}$ where the Court stated that:

No man in this country is under the smallest obligation, moral or otherwise, to arrange his legal relations to his business or to his property so as to enable the Inland Revenue to put the largest possible shovel into his stores. The Inland Revenue is not slow - and quite rightly - to take advantage, which is open to it under the taxing Statutes for the purpose of depleting the taxpayer's pocket. The taxpayer is in the like manner, entitled to be astute to prevent, so far as he honestly can, the depletion of his means by the Revenue.

This position has always been the position of the law. However, with the recent developments in international tax law and the attitude of multinational corporations in creating artificial structures for the purpose of shifting profits from high tax jurisdictions to low tax jurisdictions (tax havens); it is highly questionable whether this position can withstand the intense public criticism. This position is aptly captured by the statement of Margaret Hodge, a British MP, when questioning the tax paying morale of some multinationals (Starbucks, Amazon, and Google). Hodge stated; 'Yeah, we're not accusing you of being illegal; we're accusing you of being immoral.'11 The statement was made in response to Matt Brittin's (Vice President, Google UK) defence that their tax paying activities in the UK were legal and in compliance with the relevant UK tax laws. Although, the position is highly controversial; it is reflective of the emerging principle of 'tax morality.' We shall now turn to examine the two perspectives to the debate.

\subsection{The policy makers' perspective}

The position of the courts, over the years, has been reflective of the policy position on the tax planning activities of multinational corporations, i.e. these strategies are neither illegal nor necessarily immoral. However, that has not stopped policy makers from constantly seeking ways to provide solutions to the myriad of problems plaguing international tax law, such as; Base Erosion and

9 FBIR (n 6 above).

10 [1928] AC 217.

11 H Ebrahimi 'Starbucks, Amazon and Google accused of being "immoral"' https:// www.telegraph.co.uk/finance/personalfinance/tax/9673358/Starbucks-Amazonand-Google-accused-of-being-immoral.html (accessed 23 February 2017). 
Profit-Shifting (BEPS) and specifically double non-taxation. The efforts of policy makers to curb these problems have been on for close to a century. They began with the efforts of the League of Nations in the 1920 s to curb the problems of international juridical doubletaxation. This led to the emergence of a Uniform Model Tax Treaty. However, following the collapse of the League of Nations, the work was continued by the Organisation for European Economic Cooperation (OEEC) the OECD's predecessor. In the years that followed, a Model Tax Convention was developed by the OECD. The United Nations also delved into this area and emerged with the United Nations Model Tax Convention as well. It should be borne in mind that the structures that emerged from these treaties defined the residence/source basis for taxation which is in existence today. This helped to significantly abate the problems of international double taxation. Although this brought a new problem to light; international double non-taxation, as multinationals began exploiting the loopholes in the system to avoid paying taxes altogether or pay little tax in some cases.

However, with respect to the specific issues relating to BEPS; the OECD has been the most active. As a result, there have been efforts to tackle these issues by the various technical working groups at the OECD for years. Notable efforts of the OECD to combat this problem can be seen in: ${ }^{12}$

- a 1998 report on Harmful Tax Competition by countries and follow up work to curb harmful tax practices;

- work done between 1998 and 2006 addressing treaty abuse; and

- a directory of aggressive tax planning schemes that began in 2006 and is shared among tax administrators.

Tax policy experts in academia and parliaments of various countries have also contributed significantly to attempts at curbing the BEPS issue over the years through academic literature and legislative proposals. The underlying theme in the efforts of policy experts is the need for a long-lasting change. However, irrespective of the efforts over the years, only little has been achieved until recently when the G20 called on the OECD to produce a report on 'Base Erosion and Profit Shifting' (BEPS), which it published in February 2013 and which it followed up with an Action Plan in July of the same year. ${ }^{13}$ This OECD BEPS project eventually led to a final draft in 2015 which has the potential to change the future of international tax law for

12 MS Corwin 'Sense and sensibility: The policy and politics of BEPS' 134 https:// kpmg-us-inst.adobecqms.net/content/dam/kpmg/taxwatch/pdf/2014/bepscorwin-tillinghast-tn-100614.pdf (accessed 27 February 2017).

13 M Devereux \& J Vella 'Are we heading towards a corporate tax system fit for the 21st century?’ http://ssrn.com/abstract=2532933 (accessed 26 February 2017). 
decades to come. This sudden change was influenced by one thing only; the public and media outcry.

\subsection{The public/media perspective}

The public outcry and media coverage of issues in international tax law has reached astounding proportions in the last decade. This state of affairs was influenced largely by the global financial crisis and the austerity measures that were adopted in most advanced economies. Consequently, there emerged a growing sense of outrage by the public about the role of large multinationals (particularly in the financial services industry) in triggering the crisis, and a heightened awareness and increasing sense of indignation as to whether multinationals were paying their "fair share of tax." 14 Nothing else better captures this public indignation than Margaret Hodge's infamous statement at the UK Parliament Public Accounts Committee. ${ }^{15}$

This public rage has been heightened by the activities of NGOs, politicians in countries where the debate is intense, public hearings, and the media. In Europe, the public responded with protests and boycotts, politicians responded with commitments to take immediate actions, and companies went into damage control mode. ${ }^{16}$ Undeniably, this politically charged environment fuelled by the public outcry has had its advantages. However, it must be noted that the demerits of mainstreaming this debate far outweighs the advantages. This is because, the new international tax regime that will emerge from this period needs clear and coordinated tax rules that cannot possibly be formulated by the raging public as they lack a clear understanding of the complexities of international tax rules and policies. For instance, try explaining to a reporter not familiar with tax rules why 'transfer pricing' is not in fact the name of an evil planning strategy conjured up by businesses and their advisors to avoid paying taxes, as opposed to simply the name given to prices charged between related parties that must be set based on a series of complex domestic and international rules which are themselves based on the arms-length standard. ${ }^{17}$

Furthermore, the emerging principle of 'tax morality' forces multinationals into desperate situations as they are more concerned with paying more taxes in jurisdictions where the criticism is harsher than in cooperating with the authorities to bring lasting changes. The concept of 'tax morality' also lacks clearly defined parameters as it is incapable of defining how much tax multinational corporations should 
pay and which jurisdictions should have the right to tax. Thus, the lack of understanding of these long-standing tax rules by the media/ public makes it impossible for them to be capable of bringing the desired changes and any change that emerges from this process will be at best poor and hastily conceived.

However, it is worthy of note that the media/public's involvement in this debate; if properly coordinated, has the potential to bring the desired change. This can be done through involving all the stakeholders; states, multinationals, NGOs and the media. This strategy will help avoid any unilateral action by States which has the potential to further obscure the rules and make them more complex. The only coordinated activity on the international scene thus far, that appears to be responding to the call for change in international tax rules and running on the energy of the media/public's involvement in the debate is the OECD's BEPS project. The next section shall examine the work of the OECD on BEPS in detail.

\section{The OECD BEPS project}

In light of the political tensions surrounding BEPS, the OECD claims that BEPS distorts competition - thus giving multinationals an advantage over local operations. ${ }^{18}$ It also claims that it results in economic inefficiency as investment decisions are made for tax (as opposed to commercial) reasons, and that it undermines voluntary compliance, as 'ordinary' taxpayers will see this advantage given to multinationals as being unfair. ${ }^{19}$ This led to its commissioning of the BEPS project. In July 2013, the G20 endorsed the BEPS project, and it identifies 15 key areas in order to address loopholes and gaps in the current domestic and international tax system. ${ }^{20}$ The objective of the BEPS Project is to close gaps in international tax rules, effectively eliminating or substantially reducing BEPS; and to secure government revenues by ensuring that profits are taxed in the jurisdiction where the economic activities generating such profits are performed and where value is created. ${ }^{21}$ The BEPS Project involves input from the 34 member countries of the OECD, all G20 members, and more than 40 developing countries. 22

B Ger 'South Africa: How will BEPS affect the 2014 budget?' http:// www.thesait.org.za/news/163983/South-Africa-How-will-BEPS-affect-the-2014budget.html (accessed 27 February 2017).

19 Ger (n 18 above).

20 Deloitte ( 2 above).

21 Brunto (n 7 above).

22 Brunto (n 7 above). 
On 5 October 2015, the OECD released final reports on all 15 focus areas of its Action Plan on BEPS. ${ }^{23}$ The BEPS Action Plans are;

(i) Action 1: Addressing the Tax Challenges of the Digital Economy;

(ii) Action 2: Neutralising the Effects of Hybrid Mismatch Arrangements;

(iii) Action 3: Designing Effective Controlled Foreign Company Rules;

(iv) Action 4: Limiting Base Erosion Involving Interest Deduction and Other Financial Payments;

(v) Action 5: Countering Harmful Tax Practices More Effectively, Taking Into Account Transparency and Substance;

(vi) Action 6: Preventing Granting of Treaty Benefits in Inappropriate Circumstances;

(vii) Action 7: Preventing the Artificial Avoidance of Permanent Establishment Status;

(viii) Actions 8-10: Aligning Transfer Pricing Outcomes with Value Creation;

(ix) Action 11: Measuring and Monitoring BEPS;

(x) Action 12: Mandatory Disclosure Rules;

(xi) Action 13: Transfer Pricing Documentation and Country-by-Country Reporting;

(xii) Action 14: Making Dispute Resolution Mechanisms More Effective; and

(xiii) Action 15: Developing a Multilateral Instrument to Modify Bilateral Tax Treaties.

We shall now briefly examine each of the OECD BEPS Action Plans.

\subsection{Action 1: Addressing the tax challenges of the digital economy}

The Task Force on the Digital Economy (TFDE), was established in September 2013 to develop a report identifying issues raised by the digital economy and detailed options to address them by September $2014 .^{24}$ This action plan sets out to identify the tax challenges that result from the digitalisation of many business models including increased digital presence without a physical taxable presence. ${ }^{25}$ Another problem of taxation that the TFDE identified in relation to the digital economy is with respect to the broader tax challenges for policy makers. This identified problems relating to Value Added Tax collection particularly where goods, services and intangibles are

$23 \mathrm{~J}$ Liebenberg \& M Hewson 'BEPS developments in Africa' http://www.ey.com/za/ en/newsroom/news-releases/news-ey-beps-developments-in-africa (accessed 27 February 2017).

24 OECD 'OECD/G20 base erosion and profit shifting project: Executive summaries 2015 final reports' https://www.oecd.org/ctp/beps-reports-2015-executivesummaries.pdf (accessed 27 February 2017).

25 PwC Nigeria 'Impact of the OECD BEPS project on companies operating in Nigeria' http://pwcnigeria.typepad.com/files/pwc-tax-alert_impacts-of-beps-onnigeria.pdf (accessed 27 February 2017). 
acquired by private consumers from suppliers abroad. ${ }^{26}$ In relation to this Action Plan, the OECD does not necessarily recommend a new set of tax rules for the digital economy. ${ }^{27}$ Rather it is believed that the recommendations from other action plans regarding changes to the Transfer Pricing Guidelines, Permanent Establishment (PE) definitions and Controlled Foreign Corporation (CFC) rules will help address the BEPS risks associated with the digital economy. ${ }^{28}$ The OECD also proposed that continuous work be carried out on these issues and that developments be monitored over time. It further proposed that future work will be carried out in conjunction with a broad range of stakeholders and that a report reflecting the future work to be carried out be produced by 2020 .

\subsection{Action 2: Neutralising the effects of hybrid mismatch arrangements}

The work of the OECD on this issue sets out to resolve BEPS issues, such as; double non-taxation and double deductions that result from hybrid entities or transactions. ${ }^{29}$ It defines Hybrid Mismatch Arrangements as arrangements that exploit differences in the tax treatment of an entity or instrument under the laws of two or more tax jurisdictions to achieve double non-taxation, including long-term deferral. ${ }^{30}$ A common example of a hybrid transaction is an instance where the return on a financial investment escapes tax in the country of the investor and investee entities because it qualifies as deductible interest in the paying jurisdiction but is treated as non-taxable dividend in the receiving jurisdiction. ${ }^{31}$ In addressing the problems under this Action Plan, the OECD divided its report into two Parts. Part one contains recommendations for changes to domestic tax law in order to effectively tackle the issue, while part two sets out recommended changes to the OECD Model Tax Convention.

\subsection{Action 3: Designing effective controlled foreign company rules}

Controlled foreign company (CFC) rules respond to the risk that taxpayers with a controlling interest in a foreign subsidiary can strip the base of their country of residence and, in some cases, other countries by shifting income into a CFC. ${ }^{32}$ With respect to the OECD's work under this Action Plan, it sets out recommendations in the form

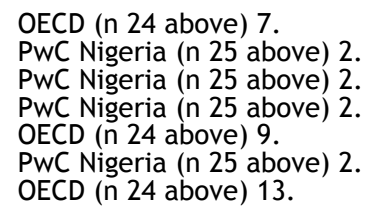


of building blocks. The recommendations do not seek to create minimum standards but to ensure that jurisdictions who seek to implement them are able to effectively prevent Companies from shifting profits to foreign subsidiaries. The report has six recommendations which it describes as the six building blocks for effective CFC rules. The recommendations are as follows;

(i) With respect to the definition of CFC, it provides recommendations on how best to determine when shareholders have sufficient influence over a foreign company for it to qualify as a CFC. It also provides recommendations on how non-corporate entities and their income should be brought within CFC rules; ${ }^{33}$

(ii) With respect to CFC exemptions and threshold requirements, the report recommends that CFC rules only apply to controlled foreign companies that are subject to effective tax rates that are meaningfully lower than those applied in the parent jurisdiction; ${ }^{34}$

(iii) With respect to the definition of income, the report recommends that CFC rules include a definition of CFC income, and it sets out a non-exhaustive list of approaches or combination of approaches that CFC rules could use for such a definition; ${ }^{35}$

(iv) With respect to the computation of income, the report recommends that CFC rules use the rules of the parent jurisdiction to compute the CFC income to be attributed to shareholders. It also recommends that CFC losses should only be offset against the profits of the same CFC or other CFCs in the same jurisdiction; ${ }^{36}$

(v) With respect to the attribution of income, the report recommends that, when possible, the attribution threshold should be tied to the control threshold and that the amount of income to be attributed should be calculated by reference to the proportionate ownership or influence; ${ }^{37}$ and

(vi) With respect to prevention and elimination of double taxation, the report emphasises the importance of both preventing and eliminating double taxation, and it recommends, for example, that jurisdictions with CFC rules allow a credit for foreign taxes actually paid, including any tax assessed on intermediate parent companies under a CFC regime. It also recommends that countries consider relief from double taxation on dividends on, and gains arising from the disposal of, CFC shares where the income of the CFC has previously been subject to taxation under a CFC regime. ${ }^{38}$ 


\subsection{Action 4: Limiting base erosion involving interest deduction and other financial payments}

It is common practice for multinationals to achieve favourable tax results by adjusting the amount of debt in a group entity. This can easily be done by multiplying the level of debt at the level of individual group entities via intra-group financing. Financial instruments can also be used to make payments which are economically equivalent to interest but have a different legal form, therefore escaping restrictions on the deductibility of interest. ${ }^{39}$ BEPS risks in these areas can arise in three basic scenarios; Groups placing higher levels of third party debt in high tax countries; Groups using intragroup loans to generate interest deductions in excess of the group's actual third party interest expense; and Groups using third party or intragroup financing to fund the generation of tax exempt income. ${ }^{40}$ In addressing these issues, the recommended approach is based on a fixed ratio rule which limits an entity's net deductions for interest and payments economically equivalent to interest to a percentage of its earnings before interest, taxes, depreciation and amortisation (EBITDA) ${ }^{41}$ As a minimum this should apply to entities in multinational groups. ${ }^{42}$

\subsection{Action 5: Countering harmful tax practices more effectively, taking into account transparency and substance}

In addressing the issue of Harmful Tax Practices, the Forum on Harmful Tax Practices (FHTP) focused on agreeing and applying a methodology to define the substantial activity requirement to assess preferential regimes, looking first at intellectual property (IP) regimes and then other preferential regimes. ${ }^{43}$ The work has also focused on improving transparency through the compulsory spontaneous exchange of certain rulings that could give rise to BEPS concerns in the absence of such exchanges. ${ }^{44}$ In addressing the requirement of substantial activity for preferential regimes, the 'nexus approach' was recommended. This approach was developed in the context of IP regimes, and it allows a taxpayer to benefit from an IP regime only to the extent that the taxpayer itself incurred qualifying research and development (R\&D) expenditures that gave rise to the IP income. ${ }^{45}$ The nexus approach uses expenditure as a 
proxy for activity and builds on the principle that, because IP regimes are designed to encourage R\&D activities and to foster growth and employment, a substantial activity requirement should ensure that taxpayers benefiting from these regimes did in fact engage in such activities and did incur actual expenditures on such activities. ${ }^{46}$ This same principle can also be applied to other preferential regimes so that such regimes would be found to require substantial activities where they grant benefits to a taxpayer to the extent that the taxpayer undertook the core income-generating activities required to produce the type of income covered by the preferential regime. ${ }^{47}$

Furthermore, in the area of transparency, a framework covering all rulings that could give rise to BEPS concerns in the absence of compulsory spontaneous exchange has been agreed. ${ }^{48}$ The framework covers six categories of rulings: (i) rulings related to preferential regimes; (ii) cross border unilateral advance pricing arrangements (APAs) or other unilateral transfer pricing rulings; (iii) rulings giving a downward adjustment to profits; (iv) permanent establishment (PE) rulings; ( $v$ ) conduit rulings; and (vi) any other type of ruling where the FHTP agrees in the future that the absence of exchange would give rise to BEPS concerns. ${ }^{49}$ Best Practices for cross-border rulings are also set out in the report.

\subsection{Action 6: Preventing granting of treaty benefits in inappropriate circumstances}

This Action Plan identifies treaty shopping and treaty abuse as some of the most important sources of BEPS concerns. ${ }^{50}$ Taxpayers engaged in treaty shopping and other treaty abuse strategies undermine tax sovereignty by claiming treaty benefits in situations where these benefits were not intended to be granted, thereby depriving countries of tax revenues. ${ }^{51}$ The report includes new treaty anti-abuse rules that provide safeguards against the abuse of treaty provisions and offer a certain degree of flexibility regarding how to do so. ${ }^{52}$ These new treaty anti-abuse rules first address treaty shopping, which involves strategies through which a person who is not a resident of a State attempts to obtain benefits that a tax treaty concluded by that State grants to residents of that State, for example by establishing a letterbox company in that State. ${ }^{53}$ The recommended approach to tackling these issues are through; the creation of a Limitations-on-

46 As above.

47 As above.

48 OECD (n 24 above) 20.

49 As above.

50 OECD (n 24 above) 21.

51 As above.

52 As above.

53 As above. 
Benefits (LOB) Rule ${ }^{54}$ and the inclusion of the rule in the OECD Model Tax Convention; an inclusion of the Principal Purposes Test (PPT) in the OECD Model Tax Convention to cover cases not covered by the PPT test.

\subsection{Action 7: Preventing the artificial avoidance of permanent establishment status}

As a result of the strategy employed by multinationals to avoid the payment of taxes through the existing loopholes in the definition of; 'Permanent Establishment,' the BEPS Action Plan recommended an amendment to the definition to avoid shifting profit out of the jurisdiction where the profit was derived through the loopholes in the definition. Multinationals usually achieve this objective through the creation of so-called commissionaire arrangements. These are arrangements through which a person sells products in a State in its own name but on behalf of a foreign enterprise that is the owner of these products. ${ }^{55}$ This Action Plan makes recommendations to address; artificial avoidance of permanent establishment status through commissionaire arrangements and similar strategies; artificial avoidance of permanent establishment status through the specific exceptions in Article 5(4) of the OECD Model Tax Treaty; other strategies for the artificial avoidance of permanent establishment status; and follow-up, including on issues related to attribution of profits to permanent establishments. With regards to the first recommendation, changes are to be made to the existing definition of permanent establishment status to ensure as a matter of policy that intermediaries that conclude contracts on behalf of a foreign enterprise are deemed to have a taxable presence unless they are carrying out independent business. ${ }^{56}$ The second recommendation also ensures that multinational enterprises only enjoy the exceptions to permanent establishment status contained in Article 5 (4) of the OECD Model Tax Treaty when they are of a 'corollary or auxiliary nature.' It also recommends the Principal Purposes Test to ensure that the practice of splitting-up contracts between closely related parties to shift profits is effectively managed and avoided.

\subsection{Actions 8-10: Aligning transfer pricing outcomes with value creation}

Actions eight to ten target the misapplication of the existing international standards for transfer pricing, to ensure that transfer 
pricing outcomes are aligned with value creation. ${ }^{57}$ It stressed the arm's length principle used by many countries has proven useful as a practical and balanced standard for tax administrations and taxpayers to evaluate transfer prices between associated enterprises, and to prevent double taxation. However, with its perceived emphasis on contractual allocations of functions, assets and risks; the existing guidance on the application of the principle has also proven vulnerable to manipulation. This manipulation can lead to outcomes which do not correspond to the value created through the underlying economic activity thus the guidance on the arm's length principle to be clarified and strengthened. Furthermore, if transfer pricing risks remain after clarifying and strengthening the guidance, the BEPS Action Plan foresaw the possibility of introducing special measures either within or beyond the arm's length principle.

The plan focused on three key areas. Work under Action eight looked at transfer pricing issues relating to transactions involving intangibles, since misallocation of the profits generated by valuable intangibles has contributed to base erosion and profit shifting. ${ }^{58}$ Action nine considered the contractual allocation of risks, and the resulting allocation of profits to those risks, which may not correspond with the activities actually carried out. ${ }^{59}$ It also addressed the level of returns to funding provided by a capital-rich multinational enterprises (MNEs) group member, where those returns do not correspond to the level of activity undertaken by the funding company. ${ }^{60}$ Action ten focused on other high-risk areas, like; the scope for addressing profit allocations resulting from transactions which are not commercially rational for the individual enterprises concerned, the scope for targeting the use of transfer pricing methods in a way which results in diverting profits from the most economically important activities of the MNE group, and neutralising the use of certain types of payments between members of the MNE group to erode the tax base in the absence of alignment with value creation. ${ }^{61}$

\subsection{Action 11: Measuring and monitoring BEPS}

Action eleven proposes the establishment of methodologies to gather and analyse data on BEPS. This Action Point aims to monitor and examine the effectiveness and economic impact of the action points. It also analyses all the problems associated with BEPS which the current available data provides. In light of this, the Action Plan makes recommendations that will improve the analysis of available data. It 
states that some of the information that is needed to improve the measurement and monitoring of BEPS is already collected by tax administrations, but not analysed or made available for analysis. ${ }^{62}$ The focus of the report's recommendations in this area is on improved access to and enhanced analysis of existing data, and new data proposed to be collected under Actions five, thirteen and, where implemented, Action twelve of the BEPS Project. ${ }^{63}$

The report finally recommends that in order to effectively address this issue, the OECD should work with governments to report and analyse more corporate tax statistics and present them in a way that is internationally consistent. ${ }^{64}$ The goal of this Action Point is to enable future researchers and Governments to be able to effectively, analyse and tackle the problems posed by BEPS.

\subsection{Action 12: Mandatory disclosure rules}

Action twelve identified the lack of timely, comprehensive and relevant information on aggressive tax planning strategies as a major problem faced by tax authorities worldwide. Early access to such information provides the opportunity to quickly respond to tax risks through informed risk assessment, audits, or changes to legislation or regulations. ${ }^{65}$ It recognised the benefits of tools designed to increase the information flow on tax risks to tax administrations and tax policy makers. It therefore called for recommendations regarding the design of mandatory disclosure rules for aggressive or abusive transactions, arrangements, or structures taking into consideration the administrative costs for tax administrations and businesses; and drawing on experiences of the increasing number of countries that have such rules. ${ }^{66} \mathrm{~A}$ modular framework that enables countries without mandatory disclosure rules to design a regime that fits their need to obtain early information on potentially aggressive or abusive tax planning schemes and their users was provided for.

\subsection{Action 13: Transfer pricing documentation and country-by- country reporting}

This report contains revised standards for transfer pricing documentation and a template for Country-by-Country Reporting of income, taxes paid and certain measures of economic activity. This Action Plan requires the development of 
[R]ules regarding transfer pricing documentation to enhance transparency for tax administration, taking into consideration the compliance costs for business. The rules to be developed will include a requirement that multinational enterprises (MNEs) provide all relevant governments with information on their global allocation of the income, economic activity and taxes paid among countries according to a common template. ${ }^{67}$

In response to this requirement, a three-tiered standardised approach to transfer pricing documentation has been developed. First, the guidance on transfer pricing documentation requires MNEs to provide tax administrations with high-level information regarding their global business operations and transfer pricing policies in a 'master file' that is to be available to all relevant tax administrations. 68 Second, it requires 'a local file' specific to each country, identifying material related party transactions, the amounts, and the company's analysis of the transfer pricing determinations they have made with regard to those transactions. ${ }^{69}$ Third, large MNEs are required to file an annual Country-by-Country Report that will provide for each tax jurisdiction in which they do business; the amount of revenue, profit before income tax and income tax paid and accrued among others. ${ }^{70}$ These three documents (master file, local file and Country-by-Country Report) should make it easier for tax administrations to identify whether Companies have engaged in transfer pricing and other practices that have the effect of artificially shifting substantial amounts of income into tax-advantaged environments.

\subsection{Action 14: Making dispute resolution mechanisms more effective}

Countries agreed that the introduction of the measures developed to address Base Erosion and Profit Shifting pursuant to the Action Plan on Base Erosion and Profit Shifting (BEPS Action Plan, OECD, 2013) should not lead to unnecessary uncertainty for compliant taxpayers and to unintended double taxation. Improving Dispute Resolution mechanisms is therefore an integral component of the work on BEPS issues. $^{71}$

Article 25 of the OECD Model Tax Convention (OECD, 2014) provides for the Mutual Agreement Procedure (MAP) - a mechanism, independent from the ordinary legal remedies available under domestic law, through which the competent authorities of the Contracting States may resolve differences or difficulties regarding 
the interpretation or application of the Convention on a mutuallyagreed basis. ${ }^{72}$ This ensures that taxpayers entitled to the benefits of the Treaty are not subject to taxation by either of the Contracting States. The measures developed under Action 14 of the BEPS Action Plan aim to strengthen the effectiveness and efficiency of the MAP process. They aim to minimise the risks of uncertainty and unintended double taxation by ensuring the consistent and proper implementation of tax treaties, including the effective and timely resolution of disputes regarding their interpretation or application through the mutual agreement procedure. ${ }^{73}$ Through the adoption of this Report, countries have agreed to important changes in their approach to dispute resolution, in particular by having developed a minimum standard.

\subsection{Action 15: Developing a multilateral instrument to modify bilateral tax treaties}

Action fifteen provides for an analysis of the tax and public international law issues related to the development of a multilateral instrument to enable countries that wish to do so to implement measures developed in the course of the work on BEPS and amend bilateral tax treaties. ${ }^{74}$ Using the analysis, interested countries will develop a multilateral instrument designed to provide an innovative approach to international tax matters, reflecting the rapidly evolving nature of the global economy and the need to adapt quickly to this evolution. The goal is to streamline the implementation of the tax treaty-related BEPS measures. This is an innovative approach is unprecedented. ${ }^{75}$

The 2014 Report, was cited as it explored the technical feasibility of a multilateral hard law approach and its consequences on the current tax treaty system. It identified the issues arising that could emanate from such an instrument, providing an analysis of the international tax, public international law, and political issues that arise from such an approach. It also concluded that a multilateral instrument is desirable and feasible, and that negotiations for such an instrument should be convened quickly. A mandate for the formation of a voluntary ad hoc group (the Group) to develop a multilateral instrument on tax treaty measures to tackle BEPS, was approved by the OECD Committee on Fiscal Affairs and endorsed by the G20 Finance Ministers and Central Bank Governors in February 2015. 


\section{Impact of the OECD BEPS project on Africa}

The OECD BEPS Project has the potential to reform the international corporate tax system for centuries to come. In light of this fact, countries have begun to restructure their corporate tax systems to meet the recommendations emanating from the OECD BEPS Project. The African continent is falling in line to achieve this much needed change to the tax planning strategy of multinationals. This part of the paper shall analyse the effects of BEPS on the African continent and the impact of the OECD BEPS Project on Africa.

\subsection{Effect of BEPS on Africa}

The tax planning strategy of multinationals which has formed the crux of the work of the OECD significantly affects the revenue base of many African states. This is due to the fact that most African states rely heavily on corporate tax income. ${ }^{76}$ Corporate tax income has been estimated to account for more than $25 \%$ of total revenue in African states. The resultant effect of this is a loss in corporate tax revenue caused by BEPS related activities. Another important issue BEPS raises in Africa is the issue of illicit financial flows. ${ }^{77}$ The term generally implies the movement of money in a way that contravenes the laws or regulations of a country. ${ }^{78}$ Such movements of money can be a product of illegal activities, such as tax evasion, organised crime, customs fraud, money laundering, terrorist financing and bribery. However, some controversial definitions of illicit financial flows may include; certain corporate tax-avoiding practices, such as BEPS, which are legal. ${ }^{79}$ Reports by the Global Financial Integrity estimates that tax and illicit capital flight from Africa is between $\$ 50$ billion and $\$ 80$ billion per annum, and in some cases revenue lost exceeds the level of aid received. ${ }^{80}$

Interestingly, it is worthy of note that although; civil society organisations have equated BEPS to illicit financial flows and the activity itself negatively affects revenue collection in Africa, both terms are in principle, different. This is due largely to the inaccuracy

$7670 \%$ of the corporate tax income of Rwanda comes from multinationals. This figure is as high as $88 \%$ in Nigeria and $20 \%$ in Burundi. See; A Mathur, 'Why $70 \%$ of Companies paid zero in corporate taxes' https://www.forbes.com/sites/ aparnamathur/2016/04/20/why-70-of-company-paid-zero-in-corporate-taxesthey-had-zero-profits/\#a288fbe56e36 (accessed 19 October 2017)

77 R Baker Capitalism's Achilles heel: Dirty money and how to renew the freemarket system (2005) 25.

78 AW Oguttu 'Tax base erosion and profit shifting in Africa - part 1: Africa's response to the OECD BEPS action plan' http://www.ictd.ac/publication/2working-papers/127-tax-base-erosion-and-profit-shifting-in-africa-part-1-africas-response-to-the-oecd-beps-action-plan (accessed 21 July 2017) 13.

80 Oguttu (n 78 above) 14. 
of the assertion in light of international tax law norms. Whilst, BEPS is a result of perceived weakness in international tax laws, coupled with lack of administrative capacity to fully assess and audit international tax risks that are exploited by MNEs; illicit financial flows are a result of a wide range of illegal flows of money, such as from organised crimes, money laundering, terrorist financing, bribery and customs fraud. ${ }^{81}$ Thus, equating BEPS with illicit financial flows fosters confusion in understanding international tax principles, and in finding solutions to the problem of capital flight. ${ }^{82}$

This notwithstanding, BEPS undermines the integrity of the tax system, raises concerns about tax morality and also affects the morale of the tax payers and their compliance rate. The adverse effect of this is that it leads to serious underfunding of public projects in Africa. The situation with BEPS is influenced by a number of factors which include, lack of relevant international tax laws or an unclear understanding of how the laws work and limited administrative capacity, etc. ${ }^{83}$

In light of the dire situation with BEPS in Africa and the developing world in general, concerns have been raised about the level of involvement of Africa in the OECD BEPS Project and whether the continent is reacting to the ongoing changes in international tax law. The next part of this paper shall address the impact of the OECD BEPS Project in Africa.

\subsection{The impact of the OECD BEPS project on Africa}

The OECD Action Plan noted in 2013 that in order to achieve a consensus with the BEPS Project, it will be important to take the concerns of developing countries into consideration. In this light, regional bodies such as the African Tax Administration Forum (ATAF) have been reacting positively to the Action Plans released by the OECD. 84

In March of 2014, the African Tax Administration Forum held a conference in Johannesburg on the Global Tax Agenda for heads of African tax administrations and Ministries of Finance. The participants from 29 African countries and OECD officials deliberated on the 'New Rules of the Global Tax Agenda' and the G20/OECD-driven project on BEPS, and considered an African response to these developments. 85 The ATAF noted that the development of rules for global taxation should address the concerns of all countries and that it should be

\footnotetext{
Oguttu (n 78 above) 15.

As above.

Oguttu (n 78 above) 15.

As above.

Oguttu (n 78 above) 22.
} 
inclusive, to ensure that the international tax rules can be applied effectively by developed, emerging and developing countries. ${ }^{86}$ ATAF recognized that a lot to be done to improve; administrative capacity, broaden the tax base, and increase tax revenue in Africa as a proportion of GDP. ${ }^{87}$ Consequently, it made a commitment to facilitate African participation in the Global Tax Agenda, and to put in place structures to enable on-going dialogue about BEPS on the continent and internationally. To this end, ATAF developed an African Work Plan on the Global Tax Agenda, for which a 'Cross-Border Taxation Technical Committee' was established to provide guidance on an African BEPS approach and to give input into the OECD BEPS process. ${ }^{88}$

Furthermore, in April of 2015 in Johannesburg, the ATAF convened another conference on 'Cross-Border Taxation in Africa.' 89 The conference focused on an African position on the BEPS Action Points, and on providing African countries an opportunity to define the baseeroding practices that are most relevant to Africa. ${ }^{90}$ The South African Minister of Finance remarked at the Conference that it was time for the African Continent to establish a Tax Policy and Tax Administration Commission which he claims is missing within the structure of the African Commission.

Apart from the regional efforts, the Revenue and Tax Authorities of different African Countries have also begun to implement the OECD BEPS Action Plan. Nigeria has responded positively, especially in the area of Transfer Pricing. This is due to the fact that the Nigerian Federal Inland Revenue Service (FIRS) has followed OECD BEPS Project closely and has contributed to its development through the ATAF. The Nigerian tax authorities have commenced a painstaking review of companies' Transfer Pricing policies and compliance documentation. ${ }^{91}$ The process also involves interviewing taxpayers' officers that perform key functions in the related party transactions. Some of the short and long term impacts of the OECD BEPS Project are; immediate application of changes to the OECD Guidelines since Regulation 11 of the Nigerian Transfer Pricing Regulations allows changes to the OECD Guidelines to automatically apply; ${ }^{92}$ potential legislative and regulatory amendments to incorporate other

86 As above.

87 As above

88 As above.

89 As above.

90 As above.

91 KPMG 'Base erosion and profit shifting: Explanatory note and implications for Nigeria' https://home.kpmg.com/content/dam/kpmg/pdf/2015/11/tnf-nigeriabeps-nov18-2015.pdf (accessed 21 July 2017).

92 PwC Nigeria "Impacts of the OECD BEPS project on companies operating in Nigeria” http://pwcnigeria.typepad.com/files/pwc-tax-alert_impacts-of-bepson-nigeria.pdf (accessed 21 July 2017). 
recommendations which are not part of the OECD Guidelines; ${ }^{93}$ increased scrutiny of preferential tax regimes and tax incentives provided to Nigerian businesses with a view to establishing instances where they have been granted inappropriately as well as whether the provision of those incentives provide any real economic benefit to the country; ${ }^{94}$ an increase in the demand (by the FIRS) for financial and other information of offshore related parties. This could include demands made to the local subsidiary (e.g. master file information) as well as demands made to the tax authorities of the Head Office (e.g. Country-by-Country reports) or non-resident affiliate through the mechanisms of the Convention on Mutual Administrative Assistance in Tax Matters; ${ }^{95}$ increase in transfer pricing audits and more focus on substance in evaluating the appropriateness of transfer prices; ${ }^{96}$ increase in the ability of the FIRS to identify and challenge instances of abusive transfer pricing. ${ }^{97}$

\section{Conclusion and recommendations}

An analysis of the OECD BEPS Project and its impact on Africa reveals that although Africa seems to be responding positively to the Action Plans proposed by BEPS (both regionally and individually), a lot still has to be done in relation to other areas. Action one of the OECD BEPS Project which deals with taxing the digital economy is yet to receive the attention it deserves in Africa. This poses a major challenge due to the fact that the tech revolution going on in Africa has led to the establishment of online businesses in their tens of thousands. The writer proposes that this problem should be addressed by African Countries through the establishment of a comprehensive indirect tax regime, in light of the recommendations proposed by the OECD.

Furthermore, the approach adopted by the Nigerian Transfer Pricing Regulations which makes changes to the OECD Transfer Pricing Guidelines to apply automatically should be adopted by other African Countries. The writer also recommends that the ATAF should create a framework which would ensure that the revenue authorities (in conjunction with the Legislature) of the various African states create policies to ensure that the Country-by-Country Reporting is effective. This would also require that the revenue authorities actively compile the relevant fiscal data of Multinational Corporations operating within their jurisdictions and make them readily available.

93 PwC Nigeria (n 91 above).

94 As above.

95 As above.

96 As above.

97 As above. 
Finally, although major public outcries which have plagued Europe and North America in relation to the fairness of international tax law rules are yet to hit Africa, it is proposed that the various revenue administrators in Africa, under the auspices of the ATAF should try to tackle these issues in a proactive manner through the strategies proposed in this paper. 


\section{MARIKANA, A PAST NEVER TRULY ESCAPED: A CRITIQUE ON THE COMMODIFICATION OF THE LEGAL SYSTEM AND THE LAW AS AN INSTRUMENT OF JUSTICE IN POST-APARTHEID SOUTH AFRICA}

by Vaughn Rajah*

\section{Introduction}

The 16th of August 2017 will mark the 5th year since South Africa's Marikana tragedy. In August of 2012, miners in the employment of one of South Africa's biggest platinum mines, situated in the mining town of Marikana and headed by Lonmin (a British mining company based in South Africa) initiated a strike for wage increases. A mere 6 days later, South African police fired live ammunition to violently halt the strikers, killing 44 workers in the process and injuring many more. ${ }^{1}$ It was the first recognised massacre in post-apartheid South Africa. In the aftermath, media and analysts labelled the event a 'turning point ${ }^{2}$ in South African history. This phrase implies a change, a deviation from the path previously trodden. A question arises on the notion of a turning point by considering the other ways in which impoverished black South Africans have historically been oppressed.

This article demonstrates that the Marikana tragedy was not a departure from the norm, but a continuation of state and corporate behaviour that has oppressed black South Africans for hundreds of years. This will be done through an analysis of the historically discriminatory socio-economic patterns of South African society, and how they subjugate the poor by limiting their access to legal and physical protection. These trends portray a history of commodification of the legal system. I discuss a notable documentary on the massacre, Miners Shot Down, and examine its depiction of the causes and effects of the events. The film provides no mention of the historical context of the killings, nor does it comment on many of the factors contributing to the massacre. Despite this, it succeeded in bringing the events to the attention of the broader public. I analyse the notions of justice, the rule of law and their application in South

* Second year LLB student, University of Pretoria.

1 N Buitendag \& N Coetzer 'History as system of wrongs - examining South Africa's Marikana tragedy in a temporal legal context' (2015) 37 Strategic Review for Southern Africa 94.

2 M Legassick 'South Africa: Marikana Massacre - a turning point?' 27 August 2012 http://links.org.au/node/3002 (accessed 21 August 2017). 
Africa as well as norms in the nation's legal culture. Additionally, I examine the Farlam Commission, and how its procedures and conclusions hindered the course of justice in the context of our democracy. Ultimately, I demonstrate how the Marikana massacre was not a change in dynamic, but a reminder of a past we have never truly escaped.

\section{Marikana in context: Historical state- corporate collusion and legal commodification}

My main argument, as stated, is that the Marikana killings were a pervasion of structural inequalities and systems of oppression that have existed in South African society for hundreds of years. The massacre itself occurred within an industry that has enjoyed financial success over a considerable period in South African history. ${ }^{3}$ Mining has a long tradition in the country. In 1867 diamonds were discovered in Kimberley. ${ }^{4}$ It was on these mines that the foundations for future discriminatory labour practices in South Africa were laid. With the tools of extraction being in the hands of white capitalists and government, black labourers were exploited and subjugated, so as to create a servile workforce and diminish illicit trade. ${ }^{5}$ Both of these results increased profitability. ${ }^{6}$ The socio-economic impact this had on black labourers was dire. Their families became dependent on the money earned on the mines, therefore workers remained migrant labourers until they could no longer work. ${ }^{7}$ This dependency on white capital led to a deepening poverty cycle amongst black labourers. ${ }^{8}$ This trend has been entrenched in our history for a very long time. These events served as a catalyst for the creation of conditions that make 'a Marikana' possible even in a non-racial democracy. This link between government and the corporate world, for better or worse, is undeniable throughout South African history. Not only during periods of colonisation and apartheid, but also when negotiations to end apartheid took place as well as post-1994. ${ }^{9}$ Pre-1994, systems of white dominance empowered white South Africans and impoverished black South Africans. ${ }^{10}$ Terreblanche asserts that this legacy of 'racial

3 R Ross A Concise history of South Africa (2008) 54-87.

4 R Turrell 'Diamonds mines and migrant labour in South Africa' in History Today (1980) 45

5 Turrell (n 4 above) 45-48.

6 As above.

$7 \quad$ L Callinicos Gold and workers (1980) 29.

8 Callinicos (n 7 above) 31.

9 R Hamann 'South Africa: The role of history, government, and local context' in W Fihlo \& S Idowu (eds) Global Practices of Corporate Social Responsibility (2009) 435-460

10 Consciousness Admin 'Book Review - Lost in Transformation - Sampie Terreblanche' 3 November 2014 http://consciousness.co.za/book-review-losttransformation-sampie-terreblanche/ (accessed 22 August 2017). 
capitalism,11 has not been adequately addressed and that corporations have always had an overwhelming influence on state policy and decisions. ${ }^{12}$ He argues that during transitional negotiations big business 'bought off' 13 the ANC to ensure that profitable arrangements could be made for both parties. ${ }^{14}$ The ANC allowed the unequal structures of land and capital ownership in the country to continue. ${ }^{15}$ Most relevant to Marikana, the ANC was influenced to dispense with its proposed policy of nationalising mines, banks and other key economic industries and institutions. ${ }^{16}$ In this way large corporations have been protected from paying their 'apartheid debt." 17 It is not a given that nationalisation would have led to an adequate restructuring of the economy. However, I would argue that what has actually transpired has made that task an even tougher one.

The pressures exerted on the post-apartheid political leadership by multinationals have led to the creation of an environment where these corporations are still able to profit at the expense of most of the population. ${ }^{18}$ This can be seen to have had a direct impact on why the Marikana workers were striking for wage increases. Platinum prices have increased by over $300 \%$ since the turn of the century. ${ }^{19}$ There was clearly enough money to contribute to worker wage increases. Instead, profits were directed back to the Lonmin head offices in London. ${ }^{20}$ Nicolson and Marinovich argue that the police clearly acted in the interests of big business and its associated political actors by firing live ammunition. ${ }^{21}$ This was done with the intention of halting the strike as soon as possible. ${ }^{22}$ Furthermore, quelling the strikes was an attempt to protect the profits of the company. This exhibited a complete disregard for the safety of the impoverished workforce. ${ }^{23}$ Due to special interest groups having such a large influence on government, combined with the poor's

11 As above.

12 As above.

13 P de Vos 'Some thoughts on the Marikana Massacre' 18 August 2012 https:// constitutionallyspeaking.co.za/some-thoughts-on-the-marikana-massacre/ (accessed 22 August 2017).

14 As above.

15 C Modisane 'How Mandela's ANC sold out the economic struggle' 22 April 2014 http://www.news24.com/ (accessed 21 August 2017).

16 Modisane (n 15 above).

17 de Vos (n 13 above).

18 Consciousness Admin (n 10 above).

19 Carolyn 'Sampie Terreblanche's Lost in Transformation looks at inequality in South Africa' 28 November 2012 http://bookslive.co.za/ (accessed 22 August 2017).

20 As above.

21 G Nicolson \& G Marinovich 'Marikana massacre: SAPS, Lonmin, Ramaphosa \& time for blood. Miners' blood' 24 October 2013 www.dailymaverick.co.za (accessed 21 August 2017).

22 As above.

23 As above. 
dependency on the state, the legal system has become commodified with the impoverished being treated as if they are beneath the law. ${ }^{24}$

In the documentary Miners Shot Down, on which I elaborate below, the AMCU leader implored the workers to cease strike action. The AMCU leader further stated that big business and the government had colluded to defeat the miners' plight, and worsen their current conditions, commenting 'the life of a black man is so cheap in South Africa. ${ }^{25}$ In essence, it required money to guarantee legal assistance. In a notable case, Jaftha $v$ Schoeman and Others, Van Rooyen v Stoltz and Others ${ }^{26}$ (where the law favoured the poor) attorneys seeking the houses of two poor parties, sold due to their defaulting on small loans, was ruled unconstitutional. However, instances of radical lawyers willing to fight for the poor are certainly not the South African norm. ${ }^{27}$ This inequality has led to strike-action becoming commonplace amongst the working class, who display a willingness to fight for their constitutional rights. ${ }^{28}$ Our Constitution seeks to redress imbalances of the past by promoting transformation above retribution, and justification over authority. ${ }^{29}$ Yet it is apparent that material redistribution has not been sufficient, ${ }^{30}$ and that a culture of authority was utilised in dealing with the Marikana protests. Even after the advent of democracy, and despite clear recent political and legal victories, economic realities have not changed in South Africa. ${ }^{31}$ From this, it is apparent that the Marikana tragedy was a continuation of historical systemic oppression in South African society.

\section{A brief analysis of Miners Shot Down}

The most well-known documentary on the massacre is the 2014 film Miners Shot Down by Rehad Desai. The film brought the events to the attention of the wider public, highlighting the police brutality and strong evidence of state collusion. ${ }^{32}$ By placing the killings in their historical context, the film falls short as it silences many of the factors contributing to, and that come about because of, the massacre. Schutte claims there is no mention of the white capitalist

24 S Zikode 'Poor People's Movements and the Law' 2 December 2011 http:// abahlali.org/node/8551/ (accessed 8 May 2017).

$25 \quad \mathrm{~N}$ Davies 'Marikana massacre: the untold story of the strike leader who died for workers rights' 19 May 2015 www.theguardian.com/world/2015/may/19/ marikana-massacre-untold-story-strike-leader-died-workers-rights (accessed 20 August 2017).

262005 (2) SA 140 (CC).

27 Zikode (n 24 above).

28 Zikode (n 24 above).

29 P Langa 'Transformative constitutionalism' (2006) 17 Stellenbosch Law Review 351-360.

30 As above.

31 Zikode (n 24 above).

32 G Nicolson "'Miners Shot Down": Still the film every South African should see' 5 August 2014 http://www.dailymaverick.co.za (accessed 8 May 2017). 
powers that were involved in the situation, neither was there a discussion regarding the plight of wives of mineworker families. ${ }^{33}$ । would agree with this assertion as the points that the film raises- the use of force by the police were excessive, and there is evidence pointing to the involvement of African National Congress (ANC) associates (particularly Cyril Ramaphosa) - are of importance. However, exclusively citing these factors holds the piece dangerously close to perpetuating an anti-black sentiment. ${ }^{34}$

Historical context is especially important in my opinion, because what is startling about the conditions encapsulated in the Marikana massacre is how similar they are to circumstances prevalent in South African society since 1652; unskilled black labourers being underpaid by white managers. Structurally, the Lonmin mining managers did not create family units and black labourers became migrants, leading to frustration amongst the workforce (this anger often conveys itself in the form of domestic violence against women as well as forcing women into prostitution to maintain the household while the men are away). ${ }^{35}$ This should have been highlighted in the film. Therefore, the causes and consequences of the killings can be analysed via the common-thread of the unequal and oppressive socio-economic conditions that have dominated South African labour patterns, and society at large throughout the nation's history.

\section{The role of South African legal culture}

In analysing the causes and consequences of Marikana, it is also important to examine the South African legal culture, as well as the interpretation of South African law employed in the aftermath of the killings. To do so a distinction must be made between a society governed by laws and a society governed by the rule of law. The law is a set of rules for society, designed to protect basic rights and freedoms, and to treat everyone fairly. ${ }^{36}$ The World Justice Project ${ }^{37}$ provides a comprehensive definition of the rule of law: The rule of law is a system of rules and rights that enables fair and functioning societies in which the following four universal principles are upheld:

(1) The government and its officials and agents, as well as individuals, and private entities are accountable under the law:

33 G Schutte “"Miners Shot Down” an unequal representation of the bigger picture' 22 August 2014 http://mg.co.za (accessed 1 June 2017).

34 As above,

35 M Dywili 'Marikana: Causes and effects' 2 April 2014 http://www.wri-irg.org (accessed 3 May 2017).

36 Organisation of American States 'What is the law?' https://www.oas.org/ juridico/mla/en/can/en_can_mla_what.html (accessed 20 May 2017).

37 World Justice Project 'What is the rule of law?' https://worldjusticeproject.org/ about-us/overview/what-rule-law (accessed 10 May 2017). 
(2) The laws are clear, publicized, stable and just; are applied evenly; and protect fundamental rights, including the security of persons and property;

(3) The process by which laws are enacted, administered and enforceable is accessible, fair and efficient;

(4) Justice is delivered in a timely fashion by competent, ethical, and independent representatives and neutrals that are of sufficient number, have adequate resources and reflect the makeup of the communities they serve.

Throughout history, there are many examples where the laws have not embraced the rule of law and have served to oppress, such as the 'Jim Crow' segregation laws in the United States and Zimbabwe's recent anti-gay laws. ${ }^{38}$ In listing such instances, Harman specifically refers to pre-1994 South African as a recognisable event in this regard. ${ }^{39}$ A state governed by laws without using the rule of law as a guiding principle has the potential to become a police state. ${ }^{40}$ Laws being uniform in their application is essential to their doing justice. ${ }^{41}$ Unequal protection constitutes injustice and injustice oppresses. ${ }^{42}$ Society must value persuasion over coercion in order to engender a culture of justification. ${ }^{43}$ It is well known, that the coercive elements of fear and force were favoured in the oppressive apartheid state. From this lens, South Africa can be considered a nation whose legal norms and culture have been historically informed by systems of exclusion and oppression. This culture is comparable with South Africa's historical labour patterns. If these practices were to persist into the 21st century, it would be evident as to how a tragedy such as Marikana would be able to occur.

The Marikana massacre, however, took place in post-apartheid South Africa. The nation today is consistently described as one that is working towards becoming a non-racial democracy. ${ }^{44}$ The Constitution of the Republic of South Africa, $1996^{45}$ is the supreme law of the South African post-apartheid legal order. ${ }^{46}$ The founding provisions of this document invoke the rule of law as a governing principle of South African society. ${ }^{47}$ If the 'new' South Africa has truly

J Harman 'The rule of law - law as an instrument of justice and a tool of oppression' 2014 http://www.federalcircuitcourt.gov.au/ (accessed 12 May 2017).

39 Harman (n 38 above) 4.

40 Harman (n 38 above) 2.

41 Harman (n 38 above) 4.

42 Harman (n 38 above) 6.

43 E Mureinik 'A bridge to where? Introducing the Interim Bill of Rights' (1994) 10 South African Journal on Human Rights 31-32.

$44 \mathrm{~J}$ Jeffery 'Our vision remains of a non-racial, united South Africa' 14 November 2016 http://anctoday.org.za/vision-remains-non-racial-united-south-africa/ (accessed 20 August 2017).

45 (the Constitution).

46 Sec 1 of the Constitution, 1996.

47 As above. 
transformed, and is informed by the rule of law, it would have imbibed a culture of justification. ${ }^{48}$ Elements of a dictatorship or police state should not be a present and hence the occurrence of a tragedy such as Marikana would be regarded as unthinkable. ${ }^{49}$ This was clearly not the case, and is proof of a clear disconnection between enacted legislation and the realities of South African society and the legal system that governs it. ${ }^{50}$ This has resulted in many of the aforementioned factors present in the apartheid state still being evident today. ${ }^{51}$ In light of this, it is important to examine the interpretation of South African law employed in the aftermath of the killings. The forum used has been informally named 'the Farlam Commission'.

\section{Aftermath: Assessing the Farlam Commission}

President Jacob Zuma appointed the Marikana Commission of Inquiry on 23 August 2012, and was headed by retired Supreme Court judge, Ian Farlam, its mandate was to investigate the incident and provide resolutions and recommendations. The South African apartheid and post-apartheid social justice landscapes are filled with 'commissions of inquiry.' While advantages of allowing greater participation aids in lessening the impact of legal commodification, as well as being able to provide a wider scope of recommendations, these findings remain mere recommendations. ${ }^{52}$ The evidence accumulated was vast, which culminated in investigating the five major actors of Lonmin, AMCU, NUM, SAPS and Others, four in loco investigations over 300 days yielded 39719 pages of evidence, ${ }^{53}$ enough for the miners' counsel to make an allegation of state collusion. Based on this, a wide array of recommendations were put forth to the Director of Public Prosecutions in the North-West Province, providing a mandate applying to all relevant actors. ${ }^{54}$ Yet, as is often the case with such tribunals, key political and corporate figures (including Deputy President Ramaphosa) were exonerated. Consequently, reparation suggestions are not enforceable in many instances. ${ }^{55}$

48 Langa (n 29 above) 351-360.

49 Harman (n 38 above) 2.

50 Zikode (n 24 above).

51 J Dana 'Post-apartheid, inequality still rules in South Africa' 25 October 2015 www. thenational.ae (accessed 21 August 2017).

52 D McKinley 'Commissions of Inquiry or Omission?' 14 April 2015 http:// sacsis.org.za (accessed 3 May 2017).

53 'Marikana Commission of Inquiry: Report on matters of public, national and international concern arising out of the tragic incidents at the Lonmin Mine in Marikana, in the North-West Province'.

54 Farlam Commission: Summary of the key findings and recommendations made by the Farlam Commission http://www.marikanajustice.co.za/wp-content/uploads/ 2016/10/Summary-of-the-Farlam-Commission-Report.pdf (accessed 5 May 2017).

55 G Nicolson 'Marikana report: Key findings and recommendations' 26 June 2015 http://www.dailymaverick.co.za (accessed 3 May 2017). 
Much like the results of the Truth and Reconciliation Commission, reparations are not guaranteed, and the findings of the committee are not binding. Prior to the massacre, the State declared the strike illegal, preventing access to justice in this regard. ${ }^{56}$ In addition, Legal Aid initially refused to provide funding for the miners' legal counsel, severely hindering efforts to make a case for the impoverished workforce. ${ }^{57}$ Although one could argue that the wider scope of the forum extended access to justice to a greater number of actors, this access firmly depends on availability of legal representation. ${ }^{58}$ From a social justice perspective, a criminal trial; where a charge is laid, a decision to prosecute is taken and (through the use of substantive and appropriate evidence) binding enforceable outcomes are obtained via the judgment (subject to appeal and/ or review). ${ }^{59}$ This would have been more in line with South Africa's post-apartheid constitutional mandate of transformative justice, based on material reparations. ${ }^{60}$ Justice for the oppressed and impoverished parties has yet to be delivered, while political and corporate figures have been exonerated. The Farlam Commission was thus another pervasion of South Africa's structural inequalities and systems of oppression.

\section{Conclusion}

From the above, it can be concluded that the Marikana massacre was not a diversion from the South African social norm. The massacre was rather a devastating flashpoint that reminds us all the systemic racism and structural inequalities that have oppressed black South Africans and been signatures of South African society for hundreds of years. It can be reasonably demonstrated that an analysis of prevailing discriminatory socio-economic trends in the country reveal the foundations for the conditions which led to the Marikana massacre and its subsequent effects. Additionally, an examination of our legal system unveils that the inextricable link between big business and government has led to a commodification of the law. This systemically hinders social justice, and calls for transformation as enshrined in our Constitution. Miners Shot Down, although a flawed and biased piece, succeeded in bringing the events to the attention of the wider public.

Although the Constitution declares that South African society is informed by the rule of law, this is not the case. According to universally accepted definitions of this concept, if this were a reality, the conditions needed for a tragedy such as Marikana to occur would

56 McKinley (n 52 above) (accessed 3 May 2017).

57 'Constitutional court clarifies the right to legal aid representation in commissions of inquiry' http://www.legal-aid.co.za/ (accessed 3 May 2017).

58 Zikode (n 24 above).

59 T Humby et al Introduction to Law and Legal Skills in South Africa (2012) 227-241

60 Langa (n 29 above) 351-360. 
not be present. The Farlam Commission was also, inevitably, a pervasion of South Africa's structural inequalities. With justice for the victims yet to be delivered, normal criminal procedure may have yet proved more effective in this regard. The tag-line in Miners Shot Down is 'South Africa will never be the same again." 61 I would argue that, from colonial South Africa to the present day, we have hardly changed.

61 S Vollenhoven 'Emmy for "Miners Show Down" doccie' http://www. thejournalist.org.za/spotlight/emmy-for-miners-shot-down-doccie-2 (accessed 16 October 2017). 


\section{ADMINISTRATIVE LAW - A TOOL FOR SOCIAL JUSTICE AND TRANSFORMATIVE CONSTITUTIONALISM: THE IMPLICATIONS OF MELANI V THE CITY OF JOHANNESBURG}

by Nelsie Siboza*

\section{Introduction}

This case note will consider the decision of the High Court in the case Melani $v$ City of Johannesburg. ${ }^{1}$ I ask whether the Court's decision is in accordance with progressive substantive aspirations of the Constitution of the Republic of South Africa, $1996 .{ }^{2}$ In particular, I consider whether the Court's decision was overly formalistic, whether it met with the requirements of transformative constitutionalism within the context of administrative law and whether the decision furthered social justice. I will start with a brief summary of the facts, the legal question and the decision of the Court in section 2. Section 3 will follow with a consideration of the notion of transformative constitutionalism regarding adjudication within the context of administrative law and social justice. An analysis of whether the Court did in fact further transformative constitutionalism will be discussed in section 4. Finally, I will conclude my discussion in section 5.

\section{Summary of the case}

The applicants in the Melani case were approximately 10000 poor people living in households in Slovo Park. ${ }^{3}$ They have been residing in Slovo Park for a number of years and have been living in deplorable health and safety conditions. ${ }^{4}$ The legislative and policy framework ${ }^{5}$ provides in section 9(a)(i) of the National Housing Act 107 of 1997 (the Housing Act) that the City needs to take all reasonable steps within the framework of national and provincial housing legislation and policy to ensure that the inhabitants of its area have access to

3rd year LLB student at University of Pretoria.

[2016] ZAGPJHC 55, 22 March 2016.

Act 109 of 1996.

Melani (n 1 above) para 3.

As above.

5 The Housing Act requires the Minister to determine national housing policy by approving projects that are consistent with it and the City to implement national housing policy. 
adequate housing on a progressive basis. The Act $^{6}$ consists of a wide range of procedures, plans and fundamental instruments which are designed to facilitate the delivery of adequate housing to people who are in need, such as the residents of Slovo Park. ${ }^{7}$

The main issue of contestation in this case was whether the decision taken by the City to relocate the residents of Slovo Park to Unaville met with the administrative law standards of lawfulness and fairness. ${ }^{8}$ The Court found the City's decision to relocate the residents of Slovo Park to Unaville to be unreasonable and unlawful. The Court held further that this decision was taken outside the scope of the relevant legislative and policy framework.

\section{Transformative constitutionalism, administrative law and social justice}

Because of South Africa's past institutionalised and legitimised racism, ${ }^{9}$ poverty eradication forms an integral part of the conception of South Africa's post-apartheid constitutionalism. ${ }^{10}$ It is indisputable that the right to have access to adequate housing aids in the eradication of poverty and thus furthers social justice. ${ }^{11}$ The Constitution evinces a deep concern for the material inequality closely associated with past exclusion and poverty that is manifested by the lack of proper housing. ${ }^{12}$ The residents of Slovo Park are a clear example of the unchanged living conditions for many black citizens to whom apartheid's multiple legacies continue to be a lived and living reality. ${ }^{13}$ The question thus is whether the Court in this case adopted a transformative and progressive approach in its interpretation in aiding poverty eradication and thus advancing social justice and transformative adjudication or whether it succumbed to a formalistic approach.

Transformative constitutionalism involves the eradication of systematic forms of domination and material disadvantages based on race, gender, class and other forms of inequality. ${ }^{14}$ Adopting a transformative approach entails both social and economic change ${ }^{15}$ which echoes both Klare's and Langa's call for a change in the legal

Act 107 of 1997.

Melani (n 1 above) para 6.

Melani (n 1 above) para 24.

1995 (3) SA 391 para 262.

10 S Sibanda 'Not purpose-made! Transformative constitutionalism, postindependence constitutionalism and the struggle to eradicate poverty' 20113 Stellenbosch Law Review 483.

111998 (1) SA 765 (CC) para 8.

122010 (3) SA 454 (CC) para 142.

13 Sibanda (n 10 above) 485.

14 P Langa 'Transformative constitutionalism' 20063 Stellenbosch Law Review 352.

15 Sibanda (n 10 above) 485. 
culture in order to realise transformative constitutionalism. In essence, it further encapsulates Moseneke's ideal of transformative adjudication $^{16}$ as it promotes a thorough engagement with the Constitution and its progressive and social aspirations. ${ }^{17}$ It is the complete departure from conservative legal culture ${ }^{18}$ which also involves a change in legal education by changing the mindset of legal scholars and legal practitioners; not just simply changing the laws. ${ }^{19}$

The Constitution's transformative mandate entails a commitment to 'social transformation' through 'substantive adjudication,'20 particularly in cases such as the Melani case, concerning the right of access to adequate housing, because it is one of the most prevalent social issues in South Africa. ${ }^{21}$ This transformative mandate is achievable by means of transformative adjudication, ${ }^{22}$ which requires an evolved, updated and politicised account of the rule of law ${ }^{23}$ as opposed to the rigidity of formalism. ${ }^{24}$ The notion of transformative constitutionalism places a responsibility on judges to justify their decisions not only by reference to authority, such as policy and legislative framework, but also by reference to values enshrined in the Constitution. ${ }^{25}$ This is an imperative aspect of transformative constitutionalism in its commitment to substantive equality and improving socio-economic conditions. ${ }^{26}$

The Constitution holds both substantive and progressive aspirations, ${ }^{27}$ which are ultimately intended to advance social justice. One of the substantive and progressive aspirations that the Constitution holds is to realise the right to access adequate housing. Social justice can be given many definitions but, for purposes of this article, the definition of social justice is limited to the eradication of poverty and the realisation of the constitutional right of access to adequate housing, which aids in the eradication of poverty, and thus advances social justice as entailed in section 26(1) of the Constitution.

16 D Moseneke 'Fourth Bram Fischer memorial lecture: Transformative adjudication' 200218 South African Journal on Human Rights 310.

17 C Hoexter 'Judicial policy revisited: Transformative adjudication in administrative law' 200824 South African Journal on Human Rights 286.

18 Langa (n 14 above) 356.

19 As above.

20 M Murcott 'A future for the doctrine of substantive legitimate expectation? The implications of KwaZulu Natal Joint Liaison Committee $v$ MEC for Education, KwaZulu Natal' 2015 (18)1 Potchefstroom Electronic Law Journal 3143.

21 Melani (n 1 above) para 3.

22 Moseneke (n 16 above) 310.

23 K Klare 'Legal culture and transformative constitutionalism' 1998 (14) South African Journal on Human Rights 188.

24 Murcott (n 20 above) 3143.

25 Langa (n 14 above) 356

26 As above.

27 Klare (n 23 above) 188. 
The question therefore is whether the Court's reasoning and its manner is substantive as opposed to formalistic and, furthermore, whether the Court furthered transformative constitutionalism, and consequentially, advanced social justice?

\section{Did the Court in the Melani case further transformative constitutionalism and social justice?}

The Court in the Melani case reasoned that the City's failure to apply the Upgrading of Informal Settlements Policy (the UISP) was unreasonable and unlawful. The decision by the City to relocate the residents of Slovo Park was taken outside the legislative and policy framework intended to apply to informal settlements such as Slovo Park. ${ }^{28}$ Furthermore, the Court found the City's actions to be unreasonable because it deprived the residents' right to just administrative action, procedurally, and substantively, deprived the residents' right of access to adequate housing in terms of section 26(1) of the Constitution. ${ }^{29}$

The Court here has acknowledged the interconnectedness of rights. ${ }^{30}$ These rights are the right to just administrative action as envisaged in section 33 of the Constitution and the right to access adequate housing. These two rights are not pigeonholed ${ }^{31}$ and need not be treated as mutually exclusive. Instead, the Court used the right to just administrative action to advance for the right of access to adequate housing and therefore social justice.

The doctrine of legitimate expectation entails that a reasonable expectation, based on a well-established practice or an express promise by an administrator acting lawfully, gives rise to legal protection when the practice or promise is clear, unambiguous and unqualified. ${ }^{32}$ Furthermore, the legal protection afforded usually takes the form of ordering that a fair procedure be followed before a decision is made in respect of the expected conduct. ${ }^{33}$

The legitimate expectation of the residents of Slovo Park in the Melani case was the City's obligated conduct to follow the procedures stipulated in the UISP regarding the upgrading of Slovo Park. The City's failure to take a decision to act in terms of the UISP was unlawful due to the fact that the City was in breach of the applicable

30 C Hoexter Constitutional Court' 2008 (1) Constitutional Court Review 228.

31 Hoexter (n 30 above) 228.

32 Murcott (n 20 above) 3136.

33 As above. 
statutory framework for the upgrading of informal settlements. ${ }^{34}$ At the time the application was launched, the City had neither refused to apply the UISP nor agreed to do so - the only decision the City had taken was to relocate the residents to Unaville, stating that it was suitable for development. ${ }^{35}$ The UISP makes it clear that relocation of informal settlements should be the exception and not the rule. It also states that relocation must take place at a location as close as possible to the existing settlement and within the context of community approved strategies. ${ }^{36}$

The Court in the Melani case further found the City's conduct to be subject to the reasonableness criterion. 37 The reasonableness criterion echoes the justification principle that all arms of government are expected to adhere to. ${ }^{38}$ When assessing whether the government meets with its obligations to act reasonably under section 26(2) of the Constitution, the measure it adopts must be comprehensive, coherent, inclusive, balanced, flexible, transparent and properly conceived and properly implemented. This therefore promotes transparency and accountability, which are two of the few democratic values that the Constitution enshrines.

The Court further stated that the measure adopted must be tailored to the particular context (as opposed to a mere formal application) in which they apply, as what may be appropriate in a rural area may not be appropriate in an urban setting. ${ }^{39}$ The Court found the City's unilateral decision to relocate only qualifying beneficiaries to Unaville to be unreasonable and not inclusive. ${ }^{40}$ The Court further found that this decision completely contradicted the established constitutional jurisprudence regarding the need for engagement in instances where the right to adequate housing is concerned. ${ }^{41}$

It is clear that the Court not only took the legislative and policy frameworks of the UISP into account but also considered the substantive surrounding circumstances. One of the substantive surrounding circumstances was the fact that the residents had been told for a period of more than 20 years that their households would be upgraded. ${ }^{42}$ Based on the procedural requirements set out in the UISP as well as the substantive surrounding circumstances in this matter,

As above.

As above.

Melani (n 1 above), para 47.

Melani (n 1 above), para 48. 
the Court's order that the City's refusal or failure to apply the UISP has to be reviewed and set aside in a substantively informed order. ${ }^{43}$

\section{Concluding remarks}

The Court in the Melani case grasped the ideal of transformative adjudication by not merely applying the UISP formalistically, but also conscientiously taking account of the surrounding political and social circumstances. The Court therefore eloquently displayed transformative constitutionalism and furthered social justice by making the right of access to adequate housing realisable, aiding in the eradication of poverty and, consequentially, advancing the constitutional and progressive aspiration that is social justice. 


\section{REFLECTION AND COGITATION ON THE FALLACY OF POST-APARTHEID JURISPRUDENCE AND THE RESIDUE OF APARTHEID JURISPRUDENCE: THE MARIKANA MASSACRE}

by Tshepo Twala*

\section{Introduction}

This article reflects on the fallacy of post-apartheid jurisprudence (particularly, the Marikana Massacre as a cornerstone of this 'fallacy') in South Africa. For the purposes of this article, the term 'fallacy' is used in its literal sense - that is, the so-called 'post-apartheid jurisprudence' is a mistaken belief, because there is still residue of apartheid economic policies in the 'post'-apartheid legal dispensation. This mistaken belief is demonstrated below considering the events that took place prior (i.e. economic policies), during (i.e. law from below) and after (i.e. access to Justice) the Marikana Massacre, and how one of the instrumental projects of post-apartheid legal dispensation, that of transformative constitutionalism, was hindered during these events.

This fallacy is reiterated by the post-apartheid legal dispensation's commitment to social security, as set out in section 27(1)(c) of Constitution, ${ }^{1}$ and to transformative constitutionalism, set out in the preamble of the Constitution, ${ }^{2}$ in order to narrow the socioeconomic gap that was caused by apartheid. However, government action in the economic field to combat the scope of social injustices, has yielded less than fruitful results. The economic policies that were given effect by the apartheid legal order are still prevalent in the 'post'-apartheid era. This reiterates why post-apartheid jurisprudence is a fallacy. On paper, a particular picture is portrayed while in reality, these kinds of provisions fail to make an impact. For example, during apartheid, employees were placed in hostels and paid minimal salaries, however, this practice is continuing in the democratic dispensation. ${ }^{3}$ This troubling trend manifests itself with

Second Year LLB student, University of Pretoria.

Constitution of the Republic of South Africa, 1996 (the Constitution).

Preamble of the Constitution, 1996.

Mail \& Guardian, 25 November 2016 'A minimum wage must restore the dignity of black people', https://mg.co.za/article/2016-11-25-00-a-minimum-wage-mustrestore-the-dignity-of-black-people (accessed 9 October 2017). 
the Marikana miners' placement in hostels and low salaries. It is these reasons which led to Marikana protests.

Now the question that comes into play is; but how is this a 'fallacy'? The message conveyed here is that the commitment to social security, set out in the Constitution, is only on paper. The Marikana Massacre has portrayed to us how the state failed to take reasonable measures to achieve the progressive realisation of the right to social security after it, (the state) ended up being found in the pockets of big businesses. In other words, the practice of monopoly capitalism.

For example, given the economy in South Africa, remuneration should at least be parallel with the inflation rate (or the constant rise of the consumer price index). For example, if an employee receives a R20 increment in a particular year while the increase of bread is R5 and dependents' school fees increase is R40 for that particular year, then the pay increment should be aligned with the inflation rate. Thus, should the increment be below the inflation rate, it is only fair for employees to be dissatisfied with the status quo, and commence the negotiation process with employers for better remuneration.

As will be examined below, the key question is: when the state becomes a barrier to this negotiation progress, does this action of becoming a barrier not amount to the thwarting of the right of access to social security as well as transformative constitutionalism? This can be seen through the use of the strategic lawsuit against public participation tactic through the denial of access to legal aid service by the Legal Aid Board, and the promoting of interests of big business above marginalized citizens. The same practices that the apartheid state exercised are perpetuated by our current state.

During apartheid, South Africa was characterised by discrimination, deep inequality, poverty and strife, which were rooted in, and enforced through the laws and policies of the apartheid government. ${ }^{4}$ Apartheid was entrenched in the economy, employment and political life. The fruit of this oppression was the denial of justice. Justice was a commodity accessible only to the privileged and rich, to the detriment of marginalized, the weak and the poor. It was for this reason that apartheid was declared a crime against humanity and threat to world peace by the United Nations during their 1973 General Assembly. ${ }^{5}$ The reference to Legal Aid South Africa $v$ Magidiwana and Others $^{6}$ is an attempt to cogitate the denial of access

4 For example, see Group Areas Act 41 of 1950 and the Separate Representation of Voters Act 46 of 1951.

5 Accord, 19 August 2011, 'The historic contribution of the United Nations to the resolution of conflicts in Southern Africa', http://www.accord.org.za/ajcrissues/the-historic-contribution-of-the-united-nations-to-the-resolution-ofconflicts-in-southern-africa/ (accessed 9 October 2017).

6 (2015) 6 SA 494 (CC). 
to justice in the post-apartheid era. Lack of access to courts in the democratic era provides a solid foundation for the need to re-think transformation - particularly with the state and judiciary - to facilitate the need to promote this project as provided for in the Constitution.

For the purposes of this article, the South African Police Service, (SAPS) as an organ of state, is viewed through the lens of the state's inextricable link with big businesses 'post'-apartheid. This inextricable link is manifested by the collusion between the Executive of Lonmin mines, SAPS, and a member from the executive branch of government, the current Deputy President, Dr Cyril Ramaphosa.

The 'new' South African Constitution has egalitarian commitments superimposed on a formalistic legal culture, without a strong tradition of substantive political discussion and contestation through the medium of legal discourses. ${ }^{7}$ An opening to transformation requires South African legal officers to harmonise judicial methods and legal interpretation with the Constitution's substantively progressive aspirations. ${ }^{8}$ The worth of the study of law should not be determined by its conformity with the needs of the legal fraternity, but rather its contribution to what the post-apartheid jurisprudence should entail on socio-political and legal transformation of South Africa. This article intends to critically examine perceptions of what the post-apartheid jurisprudence should entail, thereby reflecting on the intentions of the workers and the gravity of what they sought to achieve and the alleged collusion between the monopoly capital and the state. It also aims to investigate the various conceptions of social transformation as an important mechanism for the post-apartheid jurisprudence. The reflection on the ascendancy of jurisprudence in this article is further linked with the apprehension of the law as the broader reflection of what post-apartheid jurisprudence should entail. The dissection of the link between the Truth and Reconciliation Commission ${ }^{9}$ and commissions of inquiry is to reflect on how these bodies promote the culture of social injustices and whether or not they dismiss justice and accountability.

Apartheid left a legacy of great economic inequality. The commitment of the Constitution to social transformation can be read in the preamble and section 27 of the Constitution. Ideal social justice would necessitate political, economic and social transformation, reparations, the materialisation of substantive equality and a

$7 \quad$ Klare 'Legal culture and transformative constitutionalism' (1998) 14 South African Journal on Human Rights 188.

$8 \quad$ Klare (n 7 above) 188.

9 Truth and Reconciliation Commission, (TRC). 
dignified life for all, epistemic decolonisation, as well as the inculcation of active, and democratic and publicly oriented politics. ${ }^{10}$

\section{Locating the fallacy[ies]: From objective jurisprudence to a normative or 'democratic' jurisprudence}

Twenty years into 'the new South Africa', the question still (now maybe more than before) begs: What do the ideal of democracy and human rights really mean for people living in post-apartheid South Africa? To answer this question, we cannot only take these ideals at face value. ${ }^{11}$

Jurisprudence is described as the conscience of law and entails exploring law's justice and determining the 'ideal law.' ${ }^{12}$ In this article, the fallacy in post-apartheid jurisprudence should be construed as the one that has been, and is, influenced significantly by the so-called 'analytical jurisprudence', 'legal modernism', the political and moral content of the law as well as the non-progressive ideological content of law. ${ }^{13}$

In South Africa, despite an explicit constitutional commitment to democracy, transformation, substantive equality, social reconciliation, plurality, horizontality, and purposive interpretation, we still experience a legal culture overwhelmingly dominated by formalism, legalism, and liberalism. These approaches to law which have been shown to be unsuited to the development of a post-formal constitutional jurisprudence, and an active post-apartheid politics and ethics. The future of South African jurisprudence is shaped by the sequence of present-day events and how immensely we, as legal scholars, academics and citizens, contribute towards addressing our jurisprudential crisis. It is necessary to draw a brief account of Van Marle's descriptions on the state of our jurisprudence during and after the apartheid era. ${ }^{14}$ Understood very broadly and tentatively, the main approaches to law during apartheid can be identified as: (i) the scientific approach (legal formalism) adopted from a historical moment in Western Europe; and (ii) the legal positivist of Bentham and Austin. ${ }^{15}$ These approaches outline the apartheid legal dispensation, characterised by the oppressive and fallacious system

10 J Modiri 'The crises in legal education' (2014) 46(3) Acta Academia 3.

11 A Heyns 'The inoperative community of law students: rethinking the foundations of legal culture' (2014) 46(3) Acta Academia 79.

12 A Boloko 'A critical analysis on the law's ability to eradicate racism in (post) apartheid South Africa' (2016) 10 Pretoria University Law Press 47.

13 J Modiri 'Transformation, tension and transgression: reflections on the culture and ideology of South African legal education' (2013) 24 Stellenbosch Law Review 3.

14 K Van Marle 'Reflections on legacy, complicity, and legal education' (2014) 46(3) Acta Academia 200.

15 As above. 
that only recognised facts, observable phenomena, and indeterminacy of decisions taken by the apartheid judiciary.

In 1994, South African society underwent a major political and legal change that disclosed new possibilities for critique. ${ }^{16}$ These political changes signalled the constitutional project of transformation. 'Transformationists' perceive formalist legal practices as those practices which warrant being despised, destroyed and prejudiced. ${ }^{17}$ The enactment of the Constitution posed a radical challenge to this practice of formalism, legalism, purity and positivism, by establishing a new legal framework within which the law is to be understood. ${ }^{18}$ The promotion of democracy in the Constitution goes hand-in-hand with the promotion of basic human rights such as human dignity, equality and freedom. ${ }^{19}$ The acknowledgement of human rights in post-apartheid South Africa provided the potential for acknowledgement of those marginalised by apartheid. ${ }^{20}$ Thus, it is important that transformative constitutionalism facilitates social transformation in the society for the marginalised.

Ramose argues that many legal academics and legal practitioners in South Africa approach their respective scopes of the legal profession as though apartheid and colonialism has never occurred; as though new conceptions of politics, ethics and legality were not called for by the new dispensation. Furthermore, these legal academics and legal practitioners are somehow impervious to the imperatives of transformation and social justice within their legal practices and profession. ${ }^{21}$ A predicament that society experiences is the ideological difference as to what is, was, or should be the most appropriate means to bring about true social justice in our society. One ideological conflict is the establishment of the TRC. ${ }^{22}$ The TRC failed to facilitate true social justice and that it should not have functioned in our post-apartheid legal order.

The grapple against the practice of legal positivism is critical to apprehend the horizon of apartheid jurisprudence, as the current state of our 'democratic' jurisprudence reflects the legacy of apartheid jurisprudence. Ramose advances that there is an essential need for reconciliation where a conflict has emerged. ${ }^{23}$ The reconciliation acknowledges the need to restore the society, avoid inarticulate premises advanced by feminists, and equal dignity for all

16 As above.

17 As above.

18 J Fedler \& I Olckers Ideological Virgins and Other Myths (2001) 7.

19 Heyns (n 11 above) 82.

20 As above.

21 Modiri (n 13 above) 6.

22 MB Ramose 'Reconciliation and Reconciliation in South Africa' (2012) 5 Journal on African Philosophy 21-22.

23 Ramose (n 22 above) 21-22. 
citizens and families of the victims of apartheid malpractices (for example families of assassinated political activists for non-legitimate purposes) by the apartheid regime. There must be transformation through the socio-legal processes that advance reconciliation, such as the TRC, for reconciliation to take place. ${ }^{24}$ It should be noted that reconstructing our society and creating a climate of reconciliation is a long-term process and a balance between revolution and reformation. ${ }^{25}$ Sachs expostulates that the TRC should not have been facilitated within the legal framework, and by so doing the Constitution was not used properly to protect victims of past injustices. ${ }^{26}$ The Marikana Massacre is a reflection of the logical progression of apartheid policies and practices.

McKinley has argued that the rise of social movements is due to the 'push for more inclusive and more meaningful forms of direct participatory democracy that have little to do with the institutional forms of representation, within a bourgeois democratic society. ${ }^{27} \mathrm{He}$ further argues that "these movements have arisen out of the very failures of the "main currents," and the institutional framework that gives the contemporary legitimacy. 28

Apartheid left a legacy of economic inequalities and poverty. ${ }^{29}$ South African's firmly believed that the long-overdue struggle for social justice was won when the Constitution became the supreme law of the country in 1993, and reaffirmed in 1996. However, ordinary citizens did not foresee the impact of the inertia of the old apartheid order and its consequences on the wounds it caused. For example, the majority of black people are still stuck in undesirable conditions- such as living in shacks in townships, which amplify the consequential effect impact that the Group Areas Act (as already mentioned above) has had despite 'the end of the life of apartheid.' Moreover, citizens failed to foresee how the legacy of policies would impact on the national capacity to realise the dream of justice for all, and true equality. ${ }^{30}$ Due to the horrors occasioned by neoliberalism, poor communities (for the purposes of this article, the miners, ) throughout the country have banded together to challenge the effects of the state's macroeconomic policy.

24 Ramose (n 22 above) 35.

25 A Krog Country of my skull (2002) 110.

26 A Sachs The Strange Alchemy of Life and Law (2009) 76.

27 D McKinley 'Democracy, power and patronage: Debate and opposition within the African National Congress and the Tripartite Alliance since 1994' in Opposition and Democracy in South Africa, ed. R Southall (2001) 183-206, at 92.

28 T Madlingozi 'Post-apartheid social movements and the quest for the elusive 'new' South Africa' (2007) 34(1) Journal of Law and Society 80.

29 As above 78.

30 Fedler \& Olckers (n 18 above) 7.

31 Madlingozi (n 28 above) 80. 
The objective of the notion of 'transformative constitutionalism' is to achieve a true equal society, and that the commitment to transform our society lies at the heart of the new constitutional order. ${ }^{32}$ However, the tragedy of the Marikana Massacre left a lot to be desired regarding this objective and commitment. As such, it comes into consideration that the paramount aim of 'social justice' on the Marikana Massacre can never be realised if the roots of the conflict are political, economic and social are not addressed.

\subsection{A brief background of the Marikana massacre: The prisoners of hope}

The Marikana Massacre has been described as one of the most lethal uses of force to be perpetrated by South African forces, against the ordinary citizens, since the so called 'end of apartheid.' The history of South Africa has been characterized by conflict between the monopoly capitals and their ordinary exploited employees. The main objective of these exploited employees was to acquire a place at the driving-seat of the substantive distribution of wealth. The Marikana activists' unsettling presence helps call into memory those who are not immediately present, and those who are deliberately made to be absent. ${ }^{33}$ The value of [constitutional] jurisprudence should not be indexed by how well it serves the needs and expectations of the legal profession and judiciary, but by how it contributes to a new jurisprudence suited to the legal, social and political transformation of South Africa. ${ }^{34}$ The causes of this tragedy extend well beyond police training and who gave the orders and planned - or failed to plan - police action. ${ }^{35}$ These causes also extend beyond the rivalry between, primarily, the National Union of Mineworkers ${ }^{36}$ and the Association of Mineworkers and Construction Union, ${ }^{37}$ the attitude and approach of management. ${ }^{38}$ Above all, the massacre should not be seen in isolation from frequent and often violent protests around the country. ${ }^{39}$ The mineworkers' socio-economic conditions, coupled with a perceivably 'cosy' relationship between the long-established NUM leadership and the mine's management (for example, the miners felt that their concerns were not stimulated effectively as NUM wanted the workers to settle for a lesser increase than they wanted

32 P Langa 'Transformative constitutionalism' (2006) 17(3) Stellenbosch Law Review 351-353.

33 Van Marle (n 14 above) 209.

34 Modiri (n 13 above) 1.

35 Terry Bell, 27 August 2014, ‘A background to Marikana', https://terrybell writes.com/2012/08/23/a-background-to-marikana/ (accessed 2 November 2016).

36 National Union of Mineworkers (NUM).

37 Association of Mineworkers and Construction Union (AMCU).

38 Bell (n 35 above).

39 As above. 
- which is what caused the miners to title the NUM executive members as having a 'cosy' relationship with the Lonmin management) ${ }^{40}$ provided the opportunity for the emergence of newer unions; one such was AMCU which was founded by disgruntled members of the NUM. ${ }^{41}$ Amid squalor and hopelessness; anger and resentment festered and unless addressed, more tragedy is likely to follow in future. ${ }^{42}$

\subsection{The facts of the Marikana massacre}

The workers demanded a salary increase of from R5 000 to R12 000 per month from their employers. ${ }^{43}$ As anticipated, the Lonmin Marikana mine described the demands of the workers of R12 000 as impossible and denied going beyond a $10 \%$ wage increase during their negotiations with AMCU. The massacre at Lonmin constitutes 'the bloodiest tragedy' of the post-apartheid era. ${ }^{44}$ The over-reaction by a heavily armed police force which resulted in so many deaths and injuries is an obvious focus for the victims demanding accountability. ${ }^{45}$ According to Bell, questions should be asked as to why the two police helicopters did not drop teargas if there was a danger of armed conflict; why barbed wire entanglements were not set up and why live ammunition was issued and who gave the order to shoot? ${ }^{46}$

\subsection{The alchemy of apartheid: The law from below}

\subsubsection{The use of the SLAPP tactic}

A SLAPP is a lawsuit that purports to intimidate and censor critics by burdening them with the cost of a legal defence until they abandon their criticism or opposition. The SLAPP plaintiff does not intend to succeed with the lawsuit but to censor the opposition.

The purpose of the law is to attain justice. 47 This, in conjunction with the philosophy of Ubuntu, demands the restoration of the equipoise to attain justice in South African communities. ${ }^{48}$ Ramose submits that if the Constitution reflects the moral and political

\footnotetext{
40 As above.

41 As above.

42 As above.

43 As above.

44 As above.

45 As above.

46 As above.

47 MB Ramose 'I conquer therefore I am the sovereign: Reflections upon sovereignty, constitutionalism, and democracy in Zimbabwe and South Africa' in PH Coetzee \& APJ Roux (eds) The African Philosophy Reader (2003) 488.

48 As above.
} 
convictions of the people, then there is no reason why Ubuntu should not be basic to Constitutional democracy in South Africa. ${ }^{49}$ To rectify the logical progression of social injustices through Ubuntu, the restoration of the equipoise is required. In Biowatch Trust $v$ Registrar Genetic Resources and Others ${ }^{50}$ the SLAPP tactic was used to deter Biowatch from making further progress with its application. ${ }^{51}$ In casu, the High Court had ordered Biowatch to pay Monsanto's costs because Biowatch 'had compelled' Monsanto to intervene. ${ }^{52}$ This ruling was absurd because the case was between Biowatch and the State, not Monsanto. Monsanto intervened on behalf of the State to prevent Biowatch from obtaining 'sensitive' information. ${ }^{53}$ Monsanto used this tactic knowing that Biowatch was an NGO and would not have money continue with a lengthy court battle. ${ }^{54}$ The application of the SLAPP tactic in casu creates a platform to link this case to the tragedy of Marikana where the Lonmin Mines used the legal route (through collusion with the SAPS) ${ }^{55}$ not to seek social justice, but to intimidate the protesters by victimizing them. This victimization is recapitulated when it is evident that the two miners that were shot were fleeing for their lives were 300 to 800 metres away from the scene and running through the bank on the other side, but they were pursued by police officers. ${ }^{56}$ Thus, the peaceful protesting miners were unlawfully targeted - this was an execution. 57

Zikode argues that the poor are confined to dark corners and that the attack on the poor is a space of unfreedom. ${ }^{58}$ Zikode's argument on the criminalisation of activists is evident by the dispersion of demonstrators by unlawfully shooting at them whilst they posed no threat to the police officers. ${ }^{59}$ The use of the SLAPP tactic comes into place when the miners are arrested with unfounded murder charges ${ }^{60}$ - revealing that the police abused the rule of law to deter the protesting miners. ${ }^{61}$ These actions are inconsistent with section 9(1) of Constitution which states that 'everyone is equal before the law and has the right to equal protection and benefit of the law'62 and section 34 of the Constitution which guarantees that 'everyone has the right to a fair public hearing before a court. ${ }^{63}$ The rule of law

49 As above.

502009 (6) SA 232 (CC).

51 Biowatch (n 50 above) para 23.

52 Biowatch (n 50 above) para 3.

53 As above.

54 Biowatch case (n 50 above) para 2.

55 Afripost News, 24 April 2016, 'Miners Shot Down' https://www.youtube.com/ watch? $v=E N 199 W p X B m U \& t=4322$ s (accessed 02 November 2016).

56 Afripost News (n 55 above).

57 Afripost News (n 55 above).

58 S Zikode 'Poor people's movements and the law' Wits University, 2 December 2011. Accessible at http://abahlali.org/node/8551 (accessed 2 November 2016).

59 Zlkode (n 58 above)

60 Afripost News (n 55 above).

61 Afripost News (n 55 above).

62 Sec 9(1) of the Constitution, 1996. 
demonstrates that no person or institution may exercise a power or perform a function that is not conferred by law, and all public power must therefore be consistent with the Constitution, which includes power provided for in legislation. ${ }^{64}$ The behaviour of SAPS indicates that they acted above the law. Farlam J questioned General Mpempe regarding the implementation of stage-three defence. ${ }^{65} \mathrm{He}$ questioned the necessity for a stage-three defence as there was no indication of an escalation, and for this defence strategy to be implemented there must be an escalation. Referring to paragraph 23 of the SAPS head of arguments, Mpempe responded that there was no escalation. ${ }^{66}$ Mpempe's response amplifies the legacy of apartheid practices and the inextricable link between the state and big businesses in the constitutional era. During apartheid, the poor were being pushed to the dark corners by being deterred from fighting for their social rights by use of force. Unfortunately this is still happening, as portrayed by the Lonmin example.

Ironically, post-apartheid, this event reflects on the historical events that took place under apartheid; the Sharpeville Massacre in 1960 and the Soweto Uprising in 1976, where peaceful protesters were shot while fighting for social justice. ${ }^{67}$ Thus, the images of the Marikana Massacre issue a platform to develop the rethinking of transformative constitutionalism. ${ }^{68}$ Ramaphosa, who was part of the Lonmin executive and the National Executive at the time of the Marikana massacre, had previously called (during his term, in the 1990 s, as the Secretary-General of NUM) ${ }^{69}$ national leaders to remember the role that the Chamber of Mines played in pioneering some of the most oppressive features of apartheid South Africa by using fascist methods to destroy the workers' lives. ${ }^{70}$ His statement is now contradictory, as Ramaphosa is now on the other side of the table, supporting the methods that he had, before this tragedy, critiqued. ${ }^{71}$ This is contrary to constitutionalism as the sacrifice of innocent souls for financial gains reiterates the inextricable historical link between the three arms of the state and big businesses.

63 Sec 23 of the Constitution, 1996.

64 B Bekink Principles of South African Constitutional law (2012) 43.

65 The stage-three defence may only be implemented if protestors disperse into smaller groups, provided that they must be encircled and isolated and all persons properly searched for dangerous weapons and arrests to be initiated. See Farlam Comission Report 154.

66 Afripost News (n 55 above).

67 SA History, 21 March 2017, 'Sharpeville Massacre, 21 March 1961' http:// www.sahistory.org.za/topic/sharpeville-massacre-21-march-1960 (accessed 4 October 2017).

68 Afripost News (n 55 above).

69 National Union of Mineworkers 'About Us' 2017 http://num.org.za/About-Us/ History (accessed 9 October 2017).

70 Afripost News (n 55 above).

71 As above. 
The inability of the impoverished majority to influence the law 'from below' was evident when the National Police Commissioner, Riah Phiyega, argued that 'the SAPS did all in its power, to avoid a situation like this and the police members had to employ force to protect themselves from the charging group. ${ }^{72}$ The question was whether the SAPS have been honest in their account, which is clear enough that they have not. Zikode points out that 'the poor are pushed beneath the law,' which consequently amplifies the plight of the impoverished. ${ }^{73}$ Transformative constitutionalism becomes a pointless mission if the legal culture preserves social injustices and remains conservative. A conservative legal culture allows a judge to avoid substantive reasoning and evade a search for justice, and presents the law as objective when in reality it expresses particular politics and perpetuates the status quo. ${ }^{74}$ The 'protection' that Phiyega refers to is misleading- there was no 'charging group' towards the police nor a life-threatening situation imposed by the protestors. ${ }^{75}$ Through this misleading evidence, it becomes clear that the state formed a collusion with the monopoly capitalists or big businesses (in this case, Lonmin Platinum) ${ }^{76}$ Mthethwa's evidence stated that during one of his conversations with Ramaphosa, the latter said that 'he did not think that what was happening was pure industrial action in the true sense of the word, as it had criminality and violence [embedded in it]. ${ }^{77}$ This statement is troubling, because the workers peacefully regrouped at the communal land. ${ }^{78}$ Advocate Ntsebeza argues that it is monstrous to see the high 'militarisation' and huge police force where the 3000 protesting miners were neither imposing any threat and nor blocking business, national routes or strategic points. ${ }^{79}$ Dlunga, a Marikana miners' leader, reiterated that they instructed workers not to occupy the Stadium as it belonged to the Lonmin Company. ${ }^{80}$ This points towards the peaceful nature of the miners, forcing us the question why law enforcement agencies turned to the use of live ammunition to disperse protestors.

\subsubsection{Bifurcation}

The state's turn to neoliberalism has negated the Constitution's promise to 'improve the quality of life of all citizens and to free the

72 As above.

73 Zikode (n 58 above).

74 Boloko (n 12 above) 46.

75 Afripost News (n 55 above).

76 As above.

77 IG Farlam, 'Marikana Commission of Enquiry: Report on matters of public, national and international concern arising out of the tragic incidents at the Lonmin mine in Marikana, in the North West Province' 31 March 2015240.

78 Afripost News (n 55 above).

79 As above.

80 As above. 
potential of each person. ${ }^{81}$ In line with the logic of neoliberalism, most of the socio-economic rights such as the right of access to justice can only be realised 'progressively' and not immediately, and only when there are available resources to do so. ${ }^{82}$ It is important to define bifurcation as evident in the Marikana Massacre. Bifurcation connotes the inextricable division of the state and capitalists (or big businesses). ${ }^{83}$ Since the mine workers had no issue with the SAPS, it implied that in a democracy, workers are free to negotiate with their employers, and therefore the state should not be a barrier between employees' rights and employers' obligations. ${ }^{84}$ It is clear that the inextricable historical link between the state and capitalists have further obviated the ability of the impoverished majority to influence law 'from below.' Thus, this link deepens post-1994 bifurcation. The division of the branches was another derailing factor towards our post-apartheid transformation and jurisprudence. The use of the SLAPP tactic was implemented to censor the ordinary miners, as NUM had been captured and inside the pockets of the employers which was clearly evidenced by how they had opposed their members' ideologies and were ironically on the side of their members' opposition. ${ }^{85}$ It is problematic to see that post-1994 laws cause further bifurcation of the South African society as our past injustices inform us that the law cannot facilitate social reconciliation. The marginalized need to build a political and economic consciousness in order to resist poverty. ${ }^{86}$

\subsubsection{Bifurcation meets SLAPP tactic: the link between three arms of state and big businesses}

In Marikana, the SLAPP tactic was used by SAPS to deter the protestors from fighting for their social demands, and the redistribution of wealth. The redistribution of wealth is essential to eradicate the inequality gap (class difference) in order to achieve true equality. ${ }^{87}$ Bifurcation also emerged when the state (in this instance, the SAPS) was now found in the pockets of Lonmin, teaming up against the ordinary citizens, that had a clear call for 'pay cheques' that would be equivalent to the efforts. ${ }^{88}$ The Interim Constitution expressly referred to South Africa as a constitutional state. In a constitutional state the constitution reigns supreme - this means that the organs of state may only govern in terms of the prescribed structural limitations, and procedural guarantees entrenched in the 
Constitution. ${ }^{89}$ The collusion of state and the monopoly capital was reiterated on the day of the massacre; the police ordered four vans from the mortuary - a clear statement of anticipation of what was to happen thereafter. ${ }^{90}$ It was clear that the state was used to compromise the workers' demands in favour of the monopoly capital - the inextricable historical link between the arms of state and big businesses.

J Farlam states that the Commission agreed with SAPS that the latter did not have a legal duty to justify the shootings which took place at Marikana, and found that SAPS only had a duty to place evidence before the Commission which explains the circumstances under which the police acted. ${ }^{91}$ This argument by SAPS is contros bonos mores as it is in the public interest to inform the society about their justification of the shootings.

The SAPS did not see any wrongdoing nor show remorse to the setof-events. This was evident when Phiyega stated that whatever had happened showed the police officers responsible policing by ensuring safety. ${ }^{92}$ This shows the inextricable historical link between organs of state and big businesses. Interestingly, what safety was being ensured whilst there was no threat and no harm towards any public space or public's interest? If there was a need for ensuring safety, it was supposed to be minimal, not to escalate nor justify shooting. E-mail communications between the Lonmin Management, Ramaphosa, the Minister of Police, Nathi Mthethwa and Minister of Mineral Resources, Susan Shabangu highlights the inextricable link between the state and the big business because Ramaphosa lobbied the Ministers to extend the police presence to keep pressure on the miners while alerting his peers that there was a need for concomitant action towards this dastardly criminal acts. ${ }^{93}$

Advocate Mpofu argues that at the heart of this, was a 'toxic collusion' of the SAPS and Lonmin and, on a much broader level, this can be called a collusion between the state and capitalists. ${ }^{94}$ Joint operations between Lonmin and the police existed and Lonmin was completely integrated into the police strategy. ${ }^{95}$ This was evident when senior executives of Lonmin 'became part' of the police team and briefed the police officers and senior generals daily. ${ }^{96}$ Furthermore, Lonmin provided a helicopter and facilitated surveillance expeditions with the police, provided detention 
facilities, and provided the Lonmin game farm for the debriefing on the day of the massacre. ${ }^{97}$ Bifurcation had become the major derailing factor, compromising workers lives for money.

\subsubsection{Access to justice: Moving from bumper stickers to substantive interpretation and back again}

When one consults a dictionary to find the definition of Jurisprudence it is often referred to as the scientific study of law. ${ }^{98}$ However, in real South African context, it is safe to say that Jurisprudence 'is a platform of developing a capacity for discretion, a culture of justification and being substantive during adjudication, understanding how rules operate, as well as understanding the fact that when dispensing the law, the social effect of adjudication should be taken into account.' In other words, a contextual approach should be a decisive factor in the decision-making process. ${ }^{99}$

Botha submits that the Constitution contains a material or substantive foundation, which includes a justiciable bill of rights. ${ }^{100}$ The Constitution is the supreme law, and the state is bound by a system of fundamental values such as justice. ${ }^{101}$ Access to justice was hindered by an extensively due to the use of the restrictive approach (the so-called 'bumper stickers') to the interpretation of the Legal Aid Act 39 of 2014. The notion of 'bumper stickers' refers to the interpretation of legislation during the era of parliamentary sovereignty, where only the intra-textual elements were considered, instead of examining the contextual setting and purpose of the legislation. ${ }^{102}$

\subsubsection{Legal Aid South Africa $v$ Magiwana and others: A reflection of the hindring of access to justice and the inability of access to legal representation by the marginalized?}

Access to legal services from the Legal Aid Board was problematic and a central issue during the Farlam commission. ${ }^{103}$ Consequently, the examination of the restrictive approach to interpretation in Legal Aid case is very important. In casu, Mzoxolo Magidiwana, on behalf of and together with other Marikana miners, applied for state-funded

97 As above.

98 Seethe eight edition of Pocket Oxford Dictionary 511.

99 I de Villiers 20 May 2016 'Joel Modiri (JUR 110)' https://www.youtube.com/ watch?v=wacqUWfdDr0 (accessed 2 May 2016).

100 Botha (n 89 above) 186.

101 As above.

102 As above.

103 Afripost News (n 55 above). 
litigation (Legal Aid) to be represented in the commission of enquiry. ${ }^{104}$ This followed after the miners received interim private funding from the Raith Foundation for legal representation before the Commission from October 2012 to March 2013. ${ }^{105}$ After this period, the miners were unable to secure further private funding. ${ }^{106}$ The miners filed an application in the High Court, comprising two parts. Part A was brought on an urgent basis and sought interim funding for the miners' legal representation before the Commission. ${ }^{107}$ On the 30th of July 2013 the High Court dismissed Part A of the miners' application. ${ }^{108}$ This Court dismissed the application for leave to appeal for that decision. ${ }^{109}$ Part $B$, the subject of the application, challenged the failure or refusal of the President, the Minister and Legal Aid to provide the miners with state-funded legal representation. ${ }^{110}$ The High Court concluded that 'no legal framework exists within which the President and the Minister can lawfully, or are authorised to, fund the legal representation' of the miners. ${ }^{111}$ In this instance, the malpractice of legal positivism in the era of constitutionalism is signified. Thus, Klare's argument that the South African legal culture is a conservative legal culture in legal education rings true. ${ }^{112}$ It is for this reason that transformative constitutionalism becomes a pointless mission. A conservative legal culture allows a judge to avoid substantive reasoning, evade a search for justice and presents the law as objective when, in reality, it expresses particular politics and perpetuates the status quo. ${ }^{113}$

Adjudication and legal positivism hinders justice in the sense that the approach to law is formalistic, and fails to consider people's different circumstances. ${ }^{114}$ According to Klare, legal culture denotes the professional sensibilities, habits of mind and intellectual reflexes that occur in the legal setting. ${ }^{115}$ Klare's assertion does not connote that legal culture neither completely stimulates nor creates the necessary platforms to eradicate the issue of social injustice in our society. Rather, the assertion connotes that our legal culture and the platforms created thereof are not open to transforming the status quo of social injustices. ${ }^{116}$

104 Legal Aid (n 6 above) para 25.

105 Legal Aid (n 6 above) para 8.

106 As above.

107 Legal Aid (n 6 above) para 9.

108 As above.

109 As above.

110 As above.

111 Legal Aid (n 6 above) para 10.

112 Boloko (n 12 above) 46.

113 As above.

114 As above.

115 Klare (n 7 above) 166.

116 Boloko (n 12 above) 46. 
Nevertheless, the Court found that the Legal Aid's decision to refuse legal assistance was irrational and inconsistent with sections 9 and 34 of the Constitution. ${ }^{117}$ It further found that the decision to fund the families of the deceased's representation, and not the miners, irrationally and unfairly distinguished between the two groups. ${ }^{118}$ Legal Aid was therefore obliged to fund the miners' legal representation. ${ }^{119}$ The decision is instrumental as the court took into cognisance the purpose of the Legal Aid Act on a broader social scale and interpreted the Legal Aid Act extensively - which highlights the shift from 'bumper stickers' to substantive interpretation. Consistently insisting on justification, which reverberates with the spirit and purport of the Constitution, requires that the judiciary abandon the remnants of a culture of extreme deference to the executive which it has cultivated over years of adjudicating the actions of the sovereign apartheid state. ${ }^{120}$ This is in line with the preamble of the Legal Aid Act, and section 39(2) of the Constitution which demands the need to respect, protect and promote the spirit, purport and objects of the bill of rights when interpreting legislative texts. Judges must demand that branches of government present adequate justification for all their actions that impact on the constitutional rights of the citizenry.

However, in September 2014, Legal Aid appealed to the Supreme Court of Appeal. ${ }^{121}$ Before the hearing of the appeal, Legal Aid reached an agreement with the miners to provide funding for the remainder of the Commission. ${ }^{122}$ Legal Aid appealed on the basis that it laid down incorrect principles of law that would negatively impact on the work of Legal Aid, and limit the ambit of its CEO's discretion. ${ }^{123}$ The SCA dismissed the appeal because the decision would have no practical effect. ${ }^{124}$ The position of the parties would remain unaltered by the outcome of any appeal since the funding had been advanced and Legal Aid had agreed not to claim a refund in the event the appeal was in their favour. ${ }^{125}$

The SCA's interpretation of Legal Aid's argument is essential as it highlights the shift from formalism to a substantive mode of interpretation. This shift in approach is seen in Matiso $v$ Commanding

117 Legal Aid (n 6 above) para 49.

118 Legal Aid (n 6 above) para 10.

119 As above.

$120 \mathrm{M}$ Pieterse 'What do we mean when we talk about transformative constitutionalism' (2005) 20(1) South African Publiekreg/Public Law 165.

121 Supreme Court of Appeal (SCA).

122 Legal Aid (n 6 above) para 13.

123 As above.

124 As above.

125 Legal Aid (n 6 above) para 11. 
Officer, Port Elizabeth Prison, ${ }^{126}$ wherein Sachs J explained the teleological dimension of interpretation: ${ }^{127}$

[We] should not engage in purely formal or academic analysis, nor simply restrict ourselves to ad hoc techniques, but rather focus on what has been called the synergetic relation between the values underlying the guarantees of fundamental rights and the circumstances of the particular case.

When analysing the Legal Aid case, it becomes apparent that interpreting the Legal Aid Act, through a teleological framework, the true purpose of the adoption of the Legal Aid Act was to combat the societal issue of access to justice due to the unequal socio-economic structures in South Africa. Through this interpretation, the purpose of the Legal Aid Act is not to exclude people who do not meet its statutory requirements, but to help economically marginalised South Africans state-funded legal assistance.

Reiterating the need to look at the bigger picture of a legislative piece, In Minister of Safety and Security $v$ Van Duivenboend ${ }^{128}$, the Court held that the legal processes of the community must be informed by the norms and values of the South African society as provided for in the Constitution. ${ }^{129}$ Legal Aid initially distinguished between the families of the deceased miners, injured miners, and arrested miners on the basis that the participation of the former was vital for the Commission. ${ }^{130}$ This distinction is inconsistent with transformative constitutionalism as it discriminates against the surviving miners based on a specific category of a person's interests being more important than the others. ${ }^{131}$ It lacks rational basis as the weighing of certain person's interests above the others was not supposed to have been raised during the provision of state-funded legal representation. The irrationality of Legal Aid's defence was evident when they decided to fund the miners in the end.

It can be argued that Legal Aid intended to protect Lonmin's interests as they attempted all means possible (from incorrect interpretation of the Legal Aid Act to the unjustifiable distinction between the miners and the families of the deceased) to ensure that they do not aid the miners legal representation. This distinction is an example of the obstruction of transformative constitutionalism as Legal Aid justified their reason not to fund the surviving miners by drawing this distinction. Legal Aid's actions highlight that a conservative legal culture obstructs the facilitation of transformative

12619954 SA 631 (CC).

127 Matiso (n 126 above) para 46.

1282002 (6) 431 (SCA).

129 Matiso (n 126 above) para 46.

130 Legal Aid (n 6 above) para 10.

131 As above. 
constitutionalism. ${ }^{132}$ The hindering of access to justice is reiterated by Marcus as he argues that Section 34 of the Constitution did not apply to this commission specifically. ${ }^{133}$ In this matter of public importance, the practice of formalism was a central and disappointing factor present.

\subsection{Distinguishing criminal procedure from a commission of inquiry: Do commissions of enquiry truly facilitate social justice?}

This section intends to demonstrate that the commissions of inquiries have become a 'sub-division' of the TRC because of the malpractices behind their establishment as they have been used as a mechanism to avoid political liability and individual responsibility.

From the beginning and throughout its tenure, the Marikana Commission of Inquiry was mired in controversy over its dominant targeting of the miners, ${ }^{134}$ a subsequent directive from the President preventing the direct questioning of any government department and the abject failure to fully interrogate the specific role of the employer (Lonmin mines) during the commission. ${ }^{135}$ The importance of linking the commissions of inquiry to the TRC is that, like the TRC, they have become a form of 'whitewashing'. Forgiveness by verbal declaration is not enough for serving the interests of justice. ${ }^{136}$ However, if there is an acknowledgement of wrongdoing, forgiveness can be enjoyed. ${ }^{137}$ Amnesty for crimes committed within this scope of apartheid was part of the sacrifice that emerged post-apartheid, as it meant that criminal accountability compromised social justice. ${ }^{138}$ Although commissions of inquiry have the capacity to make recommendations from their findings (thus able to order prosecution as well), ${ }^{139}$ it is appropriate to describe Farlam's Commission as a mirror reflection of the TRC as both commissions reiterated the dismissal of justice over the interests of the so-called 'truth-finding.' To date, no party has been held accountable for the events before and during the massacre. ${ }^{140}$

132 Langa (n 32 above) 356.

133 Afripost news (n 55 above).

134 As above.

135 As above.

136 M Mamdani 'A diminished truth' in W James \& $L$ van der Vijver (eds) After the TRC: Reflections on truth and reconciliation in South Africa (2001) 1.

137 As above.

138 As above.

139 See Preamble of the Commissions Act 8 of 1947 as amended by General Law Amendment Act 49 of 1996.

140 News24 17 August 2017 'Not one police officer prosecuted yet for involvement in Marikana - NPA', http://www.news24.com/SouthAfrica/News/not-one-policeofficer-prosecuted-yet-for-involvement-in-marikana-npa-20170817 (accessed 4 October 2017). 
The establishment of commissions of inquiry has become an instrument that frustrates the interests of the Bill of Rights as set-out under section 34 of the Constitution, as well criminal procedure. Trends have shown that commissions of inquiry have become a tool that deter the marginalised's access to courts because after these inquiries are done, recommendations of prosecutions are often not made, if ever (e.g. The 2004 Hefer Commission set up by Thabo Mbeki). As long-suffering arms deal campaigner Terry CrawfordBrowne has noted, 'Commissions of inquiry have traditionally become places to park a hot potato until it gets cold.'141 The question is whether or not we will keep the potato hot? If not, are we facing another whitewash? Mamdani warned that to prevent the Constitution and Bill of Rights from being nothing but a hobbesian pact, a broad interpretation of rights must be followed according to which individual rights, and the rights of the minority, will have to be breached in order to redress the rights of the majority. ${ }^{142}$ Concurring with Mamdani's views on the TRC, Ramose argues that instead of promoting social cohesion, the TRC contributed to the polarised nature of post-apartheid society. ${ }^{143}$ Since the TRC aimed to promote national unity and reconciliation in a spirit of understanding which transcends the conflicts and divisions of the past, it is essential to acknowledge the past to realise the process of change and healing. ${ }^{144}$ However, the process of reconciliation should never trump the interests of justice in instances of events like the Marikana Massacre. Like its predecessors, the Farlam Commission can be remembered as an expensive and cynical exercise in burying the truth and protecting the powerful.

The TRC can be distinguished from other models of adjudication, because of its beginnings in a debate about how to manage the transition to democracy and that it is designed by a parliament, whilst a commission is established by the President. ${ }^{45}$ Like the TRC, the silence on the prosecution of accountable individuals allows for amnesty for perpetrations committed during apartheid to be part of the sacrifice that emerged in post-apartheid. This is because criminal accountability, as is the case in commissions of inquiry, dismissed justice. ${ }^{146}$

The Farlam Commission, like the TRC, did not take the form of prosecutions in criminal procedure. Resultantly, nothing fruitful has emerged from Farlam's Commission with criminal accountability, nor

141 eNCA 16 August 2017 'Parking a hot potato: Are commissions of inquiry (in)effective?' at http://www.enca.com/opinion/parking-hot-potato-are-com missions-inquiry-ineffective (accessed 4 October 2017).

142 Van Marle (n 14 above) 205.

143 Ramose (n 22 above) 35.

144 Fedler \& Olckers (n 18 above) 33.

145 D Dyzenhaus Truth, Reconciliation and the apartheid legal order (1998) 3.

146 Mamdani (n 136 above) 1. 
as an attempt to hold someone accountable. Commissions of inquiries are regarded as bodies established to investigate a history of violations of human rights in a country. ${ }^{147}$ There are four main characteristics of commissions of inquiry; its focus is on the past, not on a specific event; they aim to investigate patterns of abuse over a period of time, they are empowered and authorized by the state; and it is also a temporary body that ceases its existence by submitting a report. ${ }^{148}$ Farlam's Commission failed to investigate accountability in Marikana. In other words, the state has frustrated the purpose of commissions of inquiries. When a commission of inquiry is established, it is only established solely under the embrace of 'truth-telling' - not for the sake of at least prosecuting the responsible person(s) and promote criminal accountability.

Criminal procedure, on the other hand, is the adjudicative process of the criminal law. This adjudicative process begins with a formal criminal charge and results in the conviction of the accused. ${ }^{149}$ Criminal procedure can be either in form of adversarial or inquisitorial criminal procedure.

The significance of a commission of inquiry is that it is a unique instrument in a democratic country, like South Africa, which has been historically characterized by deep inequalities (as discussed in section 1). The appropriateness of a commission of inquiry, under circumstances such as the Marikana Massacre, is that more parties can be part of the process, and the commission can make wider structural recommendations than finding individuals guilty since it does not take the form of criminal prosecution. The commission of inquiry is unique, because it takes a form of transitional justice, involving non-judicial and judicial measures to redress legacies of rights abuses. Farlam's Commission helped with the healing process of victims, and the country, as it facilitated reconciliation of its people by uncovering the under-lying truth about human rights violations that had occurred during the Marikana Massacre. The Commission focussed on uncovering information and gathering evidence from victims and perpetrators. This was not achieved as the Farlam Commission turned a blind eye on the importance of getting the justification of Lonmin, and SAPS, and failed to criminalise the toxic collusion of Lonmin and the SAPS. Thus, the Commission only provided the state with the necessary and reliable recommendations ${ }^{150}$ on how to deal with

147 PB Hayner 'Fifteen Truth Commissions, 1974 to 1994: A comparative study' (1994) 16(4) Human Rights Quarterly 558. These violations may be committed by government, military or armed opposition forces.

148 PB Hayner Unspeakable truths (2001) 14.

149 T Humby, A Du Plessis \& L Kotze 'Introduction to law and legal skills in South Africa' (2012) 1 Oxford University Press (227-228.

150 This was extensive evidence that the commission had gathered or considered, which amounted to 39719 pages of evidence. 
protests of this nature in the future. ${ }^{151}$ Other than that, the interests of justice were derailed as it 'assisted' perpetrators in circumventing criminal accountability.

It is discernible from the above reflection on the Marikana tragedy that justice was broken prior to the Marikana killings.

\section{Conclusion}

This article reflected on the cogitation of the fallacy of postapartheid jurisprudence, particularly on the continued perpetuation of social injustices as illustrated by the events preceding the Marikana Massacre, and after the tragic event. Through my examination of the actions of the Legal Aid board denying the marginalized persons the right to legal representation, and through the strict application of the requirements for the granting of legal representation, the issue of lack of access to courts and justice continues to perpetuate social injustices. This is all despite the so-called 'shift' from an objective and formal jurisprudence to a substantive, post-apartheid jurisprudence. It is should be clear that it is important to understand transformation as a structural problem. Transformation is divided into three phases; (i) society must be inclusive by providing resources to all those who have been previously excluded, (ii) everyone must participate in processes and power structures and (ii) there must be consolidation of democracy in all economic, political and social spheres in order to effective advocate and stimulate transformation. ${ }^{152}$ Consequently, when we apply the above standards of transformation it is evident that transformation in South Africa has gone astray. South Africa's project of transformation fails to consolidate democracy in all economic, political and social spheres.

Post-apartheid jurisprudence should fabricate propositions that are conducive for socio-economic consciousness, and that will facilitate reconstruction, recovery, unity and reparation in our society. The reflection on Marikana indicates the need for social and legal realisation and real practical implementation of fundamental constitutional principles. The Legal Aid Board failing to provide legal services to the victims of the Marikana tragedy amplifies the reason why post-apartheid jurisprudence is a 'fallacy'. Through the strict application of the requirements to obtain legal representation from Legal Aid on such a tragic event points towards a formalistic approach to law is still being practiced. The state's failure to facilitate social welfare and security, despite the Constitution's commitment to transformation, indicates the failure of the state to uplift the oppressed. Consequently, the state failed in its obligation to work

151 Farlam Commission (n 77 above).

152 Boloko (n 12 above) 42. 
towards substantive equality, and access to social security, in terms of section 27 of the Constitution. The least that the state could have done before, during and after this tragic event, would be to put in place the necessary support structures for the miners to improve their lives for a better living. Dishearteningly, the victims of the Marikana tragedy are yet to receive formal apology or financial compensation from the state. 